\title{
Tools for Ultrasonic Hot Embossing
}

Von der Fakultät für Maschinenwesen der Rheinisch-Westfälischen Technischen Hochschule Aachen zur Erlangung des akademischen Grades einer Doktorin der

Ingenieurwissenschaften genehmigte Dissertation

\author{
vorgelegt von
}

Sijie Liao

Berichter:

Universitätsprofessor Dr. rer. nat. Werner Karl Schomburg

Universitätsprofessor Dr.-Ing. Christian Hopmann

Tag der mündlichen Prüfung: 19. Oktober 2015

Diese Dissertation ist auf den Internetseiten der Universitätsbibliothek online verfügbar. 


\section{Acknowledgements}

Firstly, I would like to express my sincerely gratitude to my doctor study supervisor: Professor Werner Karl Schomburg. Under his patient, earnest guidance, I could finish my research work in KEmikro. His instructive advice and useful suggestion offered me great help in this thesis. Besides, I also learned a lot from him and his strong academic background.

Then, I would like to thank Mr. Thomas Janhsens for his support on technique work. Those discussions and co-operations at days and nights are never forgettable.

Thanks to Mrs.Inge Schleiden, whose warm-hearted concerns make me feel like home.

I am grateful to my very friend colleges: Johannes, Tim, Sebastian, Phillip, Alexander, Julia and Christopher etc., who accepted me like not only college but also friend.

Thanks to my family for their support on pursuing my research work.

Thanks to my close friends appeared in my life and those people who helped before.

Thanks to Bin for your 'help' when I wrote this dissertation. 


\section{Kurzfassung}

Ultraschallheißprägen ist eine aufkommende Technik, die die Formgebung von Thermoplasten in einigen Sekunden ermöglicht. Mit einer Sonotrode, welche mit einem Werkzeug bestückt ist und Ultraschallvibrationen einbringt, wird ein Polymerfolienstapel bis zur Teilschmelze erwärmt und währenddessen die Mikrostruktur des Werkszeugs eingeprägt. So wird die Mikrostruktur in wesentlich kürzerer Zeit als beim Spritzgußoder Heißprägenverfahren produziert.

Das Ziel dieser Arbeit war die Untersuchung unterschiedlicher Herstellungsprozesse für Heißprägewerkzeuge und deren Einflüsse auf geprägter Strukturen. In dieser Doktorarbeit wird zudem kurz diskutiert, wie sich die Energie auf dem Prozess verteilt. Wenn der Ultraschall erzeugt wird, wird die eingebrachte Energie hauptsächlich in die Sonotrode, die Polymerfolien, das Werkzeug und den Amboss übertragen und von diesem aufgenommen. An dieser Grenzfläche wird der Ultraschall reflektiert und trägt erneut zur Erzeugung lokaler Wärme bei. Die Analyse der Ultraschall-Energieverteilung basiert auf Messungen der Werkzeug- und der Mikrostrukturtemperatur in den Polymeren. Prägewerkzeuge aus Aluminium, Nickel, Stahl, Polykarbonat (PC) und Polyetheretherketon (PEEK) wurden herstellt und mit Polyethylen hoher Dichte (HDPE) abgeprägt. Abkühlgeschwindigkeiten unterschiedlicher Werkzeugmaterialien wurden verglichen, wohin gegen die Ultraschall-Energieverteilung $n$ den geprägten Polymerfolien und den Werkzeugen berechnet wurde.

Prägewerkzeuge mit großer akustischer Impedanz gegenüber dem geprägten Polymer reflektieren mehr Ultraschall, womit Polymer-Schmelze schneller erfolgt. Prägewerkzeuge mit großer Wärmeleitfähigkeit haben schnellere Abkühlgeschwindigkeiten nach dem Prägen zur Folge, während mit geringerer Wärmekapazität und Dichte eine höhere Werkzeugtemperatur erreicht wird. Eine Isolierung an der Grenzfläche zwischen dem Werkzeug und dem Amboss beeinflusst ebenfalls Werkzeugtemperatur und die Abkühlgeschwindigkeit. Folglich stellt Aluminium das geeigneteste Material für Sonotroden dar, während Nickel und Stahl geeigneter als Material für das Werkzeug sind. Werkzeuge aus PC und PEEK haben eine beschränkte Lebensdauer für das Ultraschallheißprägen und stellen keine geeigneten Alternativen.

Unterschiedliche Herstellungsverfahren wurden für die Ultraschallheißpräge-Werkzeuge gewählt. Diese waren das Fräsen, die Nickel-Galvanik, die Lithographie und das Silizium-Ätzen. Neue Kombinationen aus diesen Methoden wurden hierbei auch entwickelt, etwa um ein Werkzeug mit mehrstufigen Strukturen zu erzeugen. Bedienschritte, Prozessparameter, Herausforderungen, Vorsichtmaßnahmen, Vor- und Nachteile von diesen Methoden wurden diskutiert und verglichen. Darunter ist das Fräsen die aussichtsreichste Methode für die Herstellung von Werkzeugen, denn mit diesem Verfahren können dreidimensionale Strukturen mit einer Höhe von mehr als einigen 100 Mikrometern und einer Breite von unter 50 Mikrometern hergestellt werden. Außerdem ist die Nickel-Galvanik anwendbar, um Werkzeuge herzustellenderen Abmaße weniger als 50 Mikrometer betragensollen. Die Schablonen für die NickelGalvanik wurden mit Lithographie und Silizium-Ätzen vorbereitet. Amorphe MetallLegierungenwurden zudem ausprobiert, um das Werkzeug herzustellen. Ihre Eignung und der Grund ihres Versagens wurden zudem in dieser Arbeit diskutiert.

Einige Mikrosysteme wurden entwickelt und hergestellt. Dadurch wurde die Herstellung des Werkzeugs für dreidimensionale Mikrostrukturen durch das Ultraschallheißprägen demonstriert. Die Designideen, der Prozess der Herstellung und die Leistungsfähigkeit 
wurden vorgestellt. Eine Fresnel-Linse wurde hierbei zum ersten Mal durch das Ultraschalheißprägen hergestellt. Außerdem wurden Mikrodüsen, die für Gas- I Flüssigkeitsdispersion genutzt wurden, mit einem Durchmesser von $150 \mu \mathrm{m}$ und $250 \mu \mathrm{m}$, mittels des Ultraschallheißprägens und Schweißens hergestellt. Die Mikrodüsen konnten Belastungen von $29 \mathrm{MPa}$ und $2.5 \mathrm{MPa}$ bei $20^{\circ} \mathrm{C}$ bzw. $90{ }^{\circ} \mathrm{C}$ standhalten. Die Fähigkeit zur mehrphasigen Ausbreitung wurde auch demonstriert. Eine spiralförmige elektronische Spule für ein MID (Molded Interconnect Device), wurde auch per Ultraschallheißprägen hergestellt. Die Oberfläche der Spirale war nicht flach, sondern gebogen und die Kurve der Spirale war entlang einer dreidimensionalen Kurve dezentralisiert. Die berechneten und gemessenen Resonanzimpedanzen von dieser Spule, kombiniert mit einem Kondensator, sind 1,6 MHz beziehungsweise 1,65 MHz. Einige Polymeroberflächen wurden mit Werkzeugen geprägt, die mit Röntgenlithografie, Nickel-Galvanik und dem Fräsen von Aluminium mit unterschiedlich gestalteten Mikrostrukturen zur Erzeugung von hydrophoben Oberflächen hergestellt wurden. Das Benetzungsverhalten der geprägten Oberflächen wurde per Kontaktwinkelmessung untersucht. Die Oberfläche des Werkzeugs, welches mit dem LIGA-Verfahren (beinhaltet folgende Verfahrensschritte: Lithografie, Galvanik und Abformung) hergestellt wurde, erwies sich als wasserabweisender als die, die mit einem AluminiumWerkzeug geprägt wurde. Das Kontaktregime der geprägten Oberflächen wurde auch theoretisch für die beiden Werkzeugtypen analysiert. Die letzte Anwendung war die Herstellung eines Werkzeugs für das Ultraschallheißprägen von Nanostrukturen in PC-, Polymethylmethacrylat- (PMMA) und Polylactid- (PLA) Folien. Die Herausforderungen und Lösungsfindungen für das Ultraschallheißprägen und die Herstellung des Werkzeugs wurden dazu vorgestellt. Abschließend wurden die Nanostrukturen erfolgreich in das Thermoplast geprägt. 


\section{Abstract}

Ultrasonic hot embossing is an emerging technology enabling molding of thermoplastic polymers in seconds. A stack of polymer foils is heated by the friction between the foils and protruding microstructures on a tool when ultrasonic vibrations are generated by a sonotrode. The polymer is molten and adapts to the shape of the microstructures on the tool. Thus, a micro structure is generated in much shorter time than by injection molding or hot embossing.

The objective of this work was investigating how tools for ultrasonic hot embossing can be fabricated and what is the influence of the tool on the process. How the embossing energy is distributed in the whole process is briefly discussed in this thesis. When ultrasound is generated, the induced energy is mainly transferred to and absorbed in sonotrode, polymer stack, tool and anvil. At the interfaces, ultrasound is reflected and, this way, re-contributing to heat generation. Ultrasonic energy distribution analyses are based on temperature measurements in the embossing tools and dimension measurements on the embossed polymer micro structures. Embossing tools from aluminum, nickel, steel, polycarbonate (PC) and polyether ether ketone (PEEK) were produced and embossed with high density polyethylene (HDPE). The cooling rates of different tools are compared while the energy distributed into embossed polymer and embossing tool was roughly calculated. Embossing tools with larger acoustic impedance compared to the embossed polymer reflect more ultrasound back to the polymer for melting. Embossing tools with higher heat conduction result in a faster cooling rate after embossing while with less heat capacity and density a higher peak temperature is achieved. The isolation at the interface between embossing tool and anvil affects the tool temperature and its cooling rate. Consequently, aluminum is more suitable for the sonotrode while nickel and steel are suitable for the tool. Embossing tools from PC and PEEK have shown limited lifetimes for ultrasonic hot embossing and, therefore, are no appropriate alternative.

Various ways have been attempted to fabricate ultrasonic hot embossing tools. They are milling, nickel electroplating, lithography and silicon etching. New combinations of these ways were also developed to fabricate a tool with multi-level structures or enlarge the tool size. The operating steps, process parameters, challenges, precautions, advantages and disadvantages of these fabrication ways are discussed and compared. Among them, milling is the most promising way producing embossing tools allowing three-dimensional micro structures, up to more than several hundred micrometers in height and down to $50 \mu \mathrm{m}$ in width. Besides, nickel electroplating was applicable to produce the tools with structure dimensions of less than $50 \mu \mathrm{m}$. The templates for electroplating were prepared by lithography and silicon etching. Liquid metals were also prepared to be employed as embossing tool. Their performance and the reasons of failure are discussed.

Several micro devices were developed and fabricated demonstrating the fabrication of tools for ultrasonic hot embossing of three-dimensional micro structures. Design idea, production process and performance are introduced. A Fresnel lens was produced by ultrasonic hot embossing for the first time. Micro nozzles, 150 and $250 \mu \mathrm{m}$ in diameter, which were used for gas/liquid dispersion, were produced by ultrasonic hot embossing and welding. The nozzle could sustain pressures as high as $29 \mathrm{MPa}$ and $2.5 \mathrm{MPa}$ at $20^{\circ} \mathrm{C}$ and $90^{\circ} \mathrm{C}$, respectively. The multi-phase dispersing ability was also proven. An electronic spiral coil forming a molded interconnect device (MID) was fabricated by ultrasonic hot embossing. The surface of the coil was not flat but bowed and the coil line 
was distributed along a three-dimensional spiral curve. The calculated and measured resonance frequencies of this coil combined with a capacitor were $1.6 \mathrm{MHz}$ and $1.65 \mathrm{MHz}$, respectively. Several polymer surfaces were embossed with tools fabricated by $\mathrm{x}$-ray lithography and electroplating of nickel and milling of aluminum with different structures designs for hydrophobic surfaces. The wettability of the embossed surface was investigated by contact angle measurements. The polymer surface embossed from the x-ray lithography and electroplating of nickel tool turned out being more hydrophobic than the one embossed from the aluminum tool. The contact regimes of the embossed surface from the two embossing tools were also theoretically analyzed. The last application was the ultrasonic hot embossing of nanostructures, $600 \mathrm{~nm}$ in height, on PC and poly methyl methacrylate (PMMA) and poly (lactic acid) foils. The challenges and the solutions in ultrasonic hot embossing with this tool are introduced. Finally, the nanostructures were successfully embossed into these polymers. 


\section{Contents}

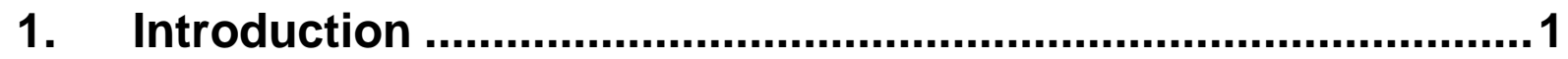

2. Development of ultrasonic hot embossing............................... 3

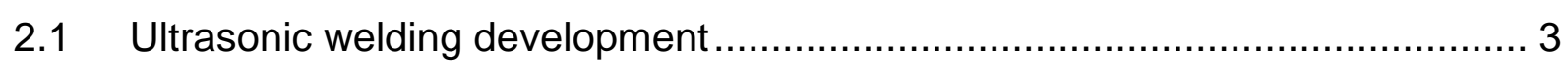

2.2 Ultrasonic hot embossing developments ................................................. 4

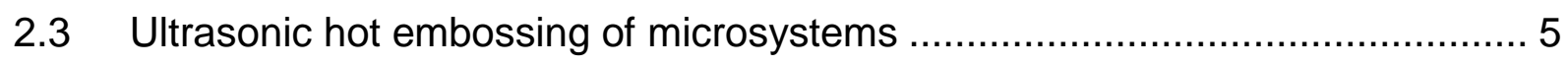

2.4 Limits and challenges for ultrasonic hot embossing ..................................... 8

3. Embossing tool evaluation during ultrasonic hot embossing $\mathbf{1 1}$

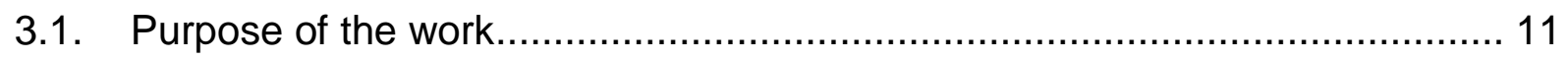

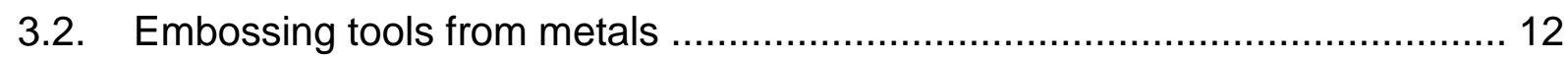

3.2.1 Embossing tool and embossed polymer preparation................................. 12

3.2.2 Temperature measurement ................................................................. 14

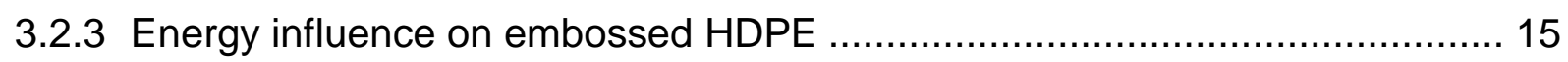

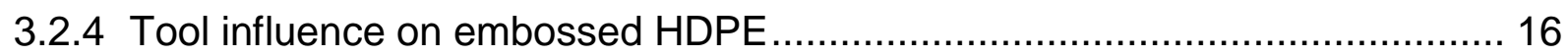

3.2.5 Anvil influence on embossed HDPE

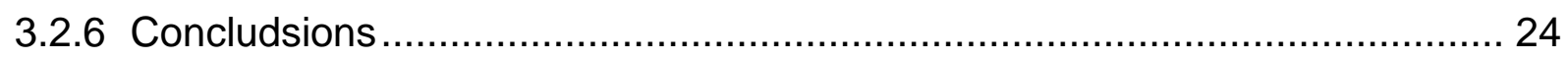

3.3. Embossing tools from aluminum and polymers …................................... 25

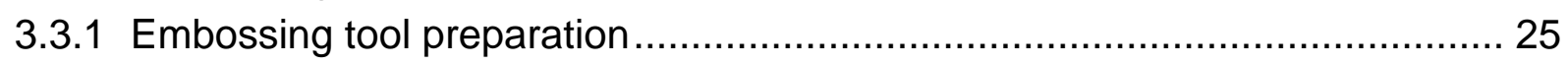

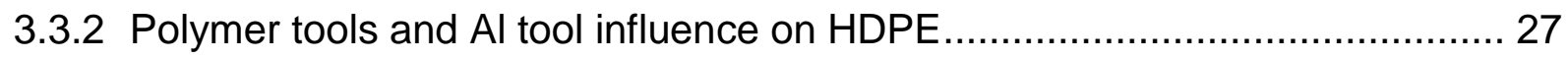

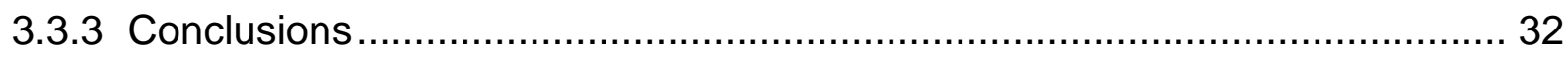

4. Tool fabrication for ultrasonic hot embossing .........................34

4.1 Ultrasonic hot embossing tool description ............................................... 34

4.2 Ways of tool fabrication for ultrasonic hot embossing ….............................. 35

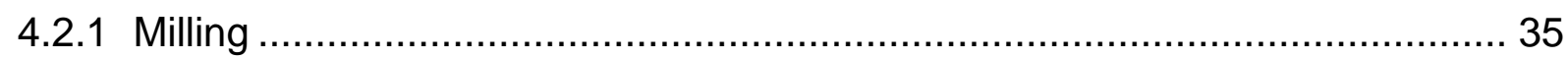

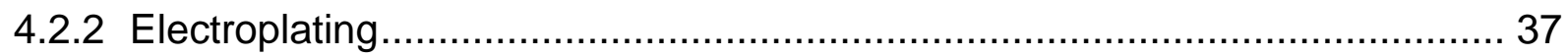

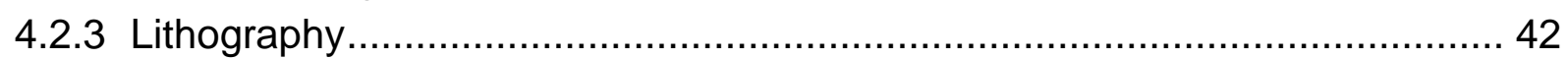

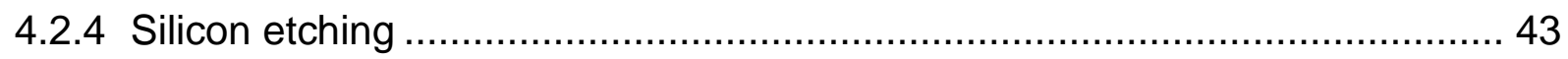

4.2.5 Photolithography, milling, and electroplating …...................................... 44

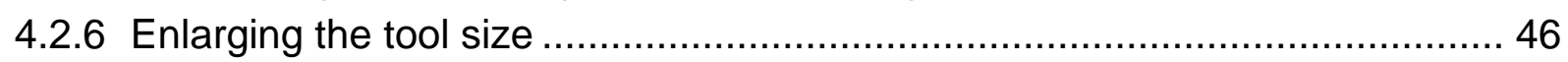

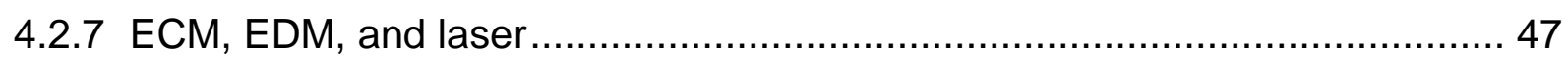

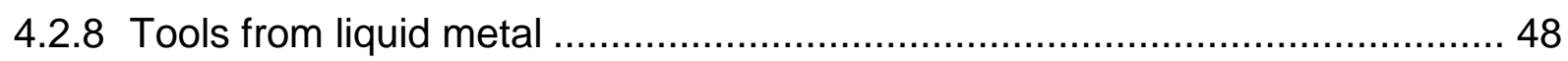

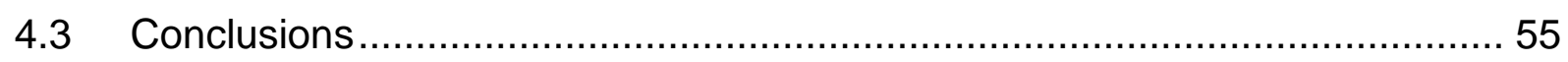

5. Tools for special applications .............................................56

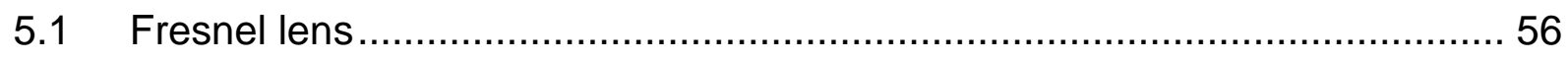

5.2 Micro nozzles for generating liquid/liquid and gas/liquid dispersions............. 57 


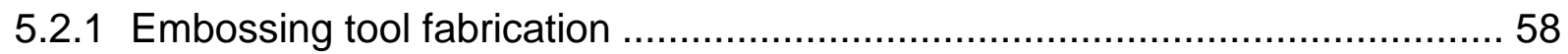

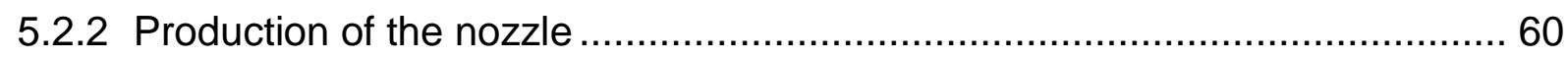

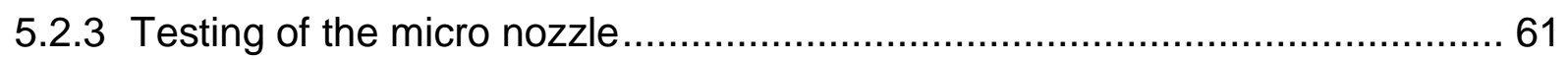

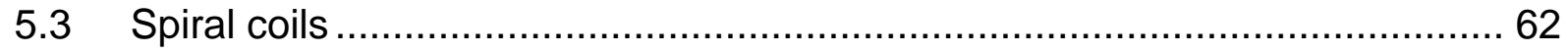

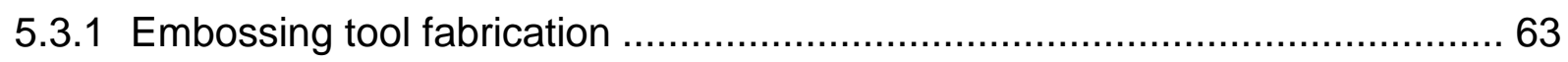

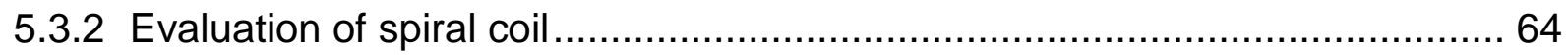

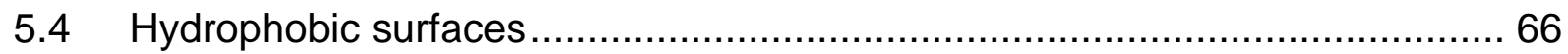

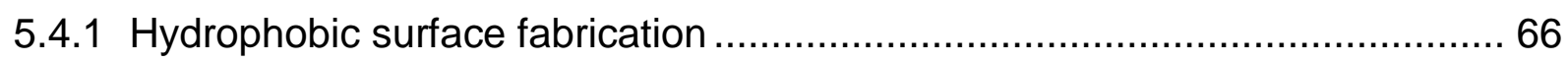

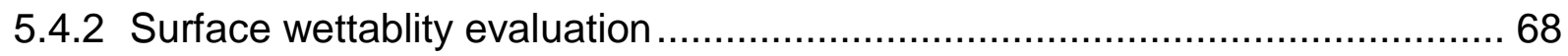

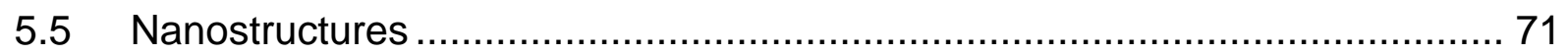

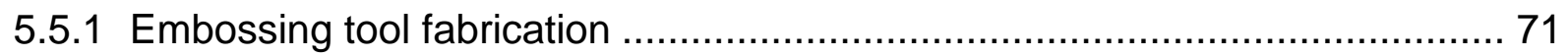

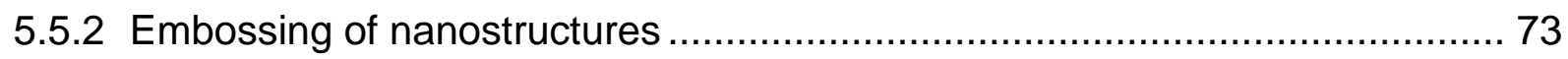

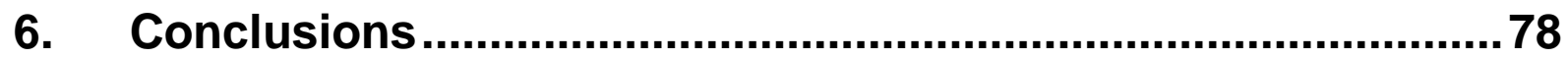

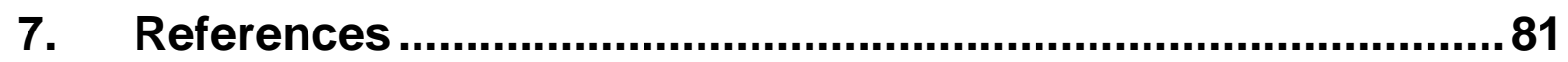




\section{Abbreviations}

The abbreviations in this thesis are listed in the following table:

\begin{tabular}{|c|c|}
\hline PMMA & Polymethylmethacrylate \\
\hline PVDF & Polyvinylidene fluoride \\
\hline PVC & Polyvinyl chloride \\
\hline PA 6 & Polyamide \\
\hline PC & Polycarbonate \\
\hline PEEK & Polyether ether ketone \\
\hline PS & Polystyrene \\
\hline HDPE & High density polyethylene \\
\hline PP & Polypropylene \\
\hline PET & Polyethylene terephthalate \\
\hline PLA & Poly (lactic acid) \\
\hline PPHM & PP with high Young's modulus \\
\hline SAN & styrene-acrylonitrile \\
\hline $\mathrm{Al}$ & Aluminum \\
\hline $\mathrm{Ni}$ & Nickel \\
\hline St235JR & Structural steel 235JR \\
\hline St1.2343 & Alloy tool steel 1.2343 \\
\hline $\mathrm{Ni}\left(\mathrm{SO}_{3} \mathrm{~N}_{2}\right)_{2}$ & Nickel sulfamate \\
\hline $\mathrm{NiCl}_{2} \cdot 6 \cdot \mathrm{H}_{2} \mathrm{O}$ & Nickel chloride \\
\hline DMF & Dimethylfomrmamide \\
\hline SDS & Sodium dodecyl sulfate \\
\hline EBL & Electron beam writing lithography \\
\hline FIB & Focused ion beam lithography \\
\hline$\mu \mathrm{ECM}$ & Micro electrochemical machining \\
\hline$\mu \mathrm{EDM}$ & Micro electro discharge machining \\
\hline
\end{tabular}




\begin{tabular}{|c|l|}
\hline CVL & Copper vapor laser \\
BOLDT & BOLDT Turbocoll 2000 repair adhesive \\
$\begin{array}{c}\text { Loctite steel } \\
\text { epoxy }\end{array}$ & Loctite EA 3472 steel metal-filled Epoxy \\
$\begin{array}{c}\text { Loctite } \\
\text { aluminum } \\
\text { epoxy }\end{array}$ & Loctite EA 3479 Al metal-filled Epoxy \\
Blue magic & Blue Magic Cargo thermosteel \\
Durabond & Durabond ${ }^{\text {TM }} 7032$ Stainless Putty \\
LIGA & $\begin{array}{l}\text { Shortname of Lithographie, Galvanik und Abformung in } \\
\text { German }\end{array}$ \\
\hline
\end{tabular}

\section{Notation and symbols}

The symbols from equations in this thesis are listed in the following table:

\begin{tabular}{|l|l|l|}
\hline Symbols & Definition & Unit \\
\hline $\mathrm{T}$ & Calculated temperature of embossing tool & ${ }^{\circ} \mathrm{C}$ \\
\hline $\mathrm{T}_{\mathrm{g}}$ & Glass transition temperature & ${ }^{\circ} \mathrm{C}$ \\
\hline $\mathrm{T}_{\mathrm{m}}$ & Melting temperature & ${ }^{\circ} \mathrm{C}$ \\
$\mathrm{A}_{0}$ & Measured peak temperature of embossing tool & ${ }^{\circ} \mathrm{C}$ \\
$\mathrm{T}_{0}$ & Measured environmental temperature of embossing tool & ${ }^{\circ} \mathrm{C}$ \\
$\tau$ & Time constant & $\mathrm{S}$ \\
$\tau_{1}$ & Time constant & $\mathrm{S}$ \\
$\tau_{2}$ & Time constant & $\mathrm{S}$ \\
$\mathrm{E}$ & Young's modulus/elastic modulus & $\mathrm{GPa}$ \\
$\mathrm{E}_{0}$ & Original energy input in the embossing process & $\mathrm{J}$ \\
$\mathrm{E}_{\mathrm{R}}$ & Reflected energy at metal and polymer interface & $\mathrm{J}$ \\
$\mathrm{E}_{\mathrm{p}}$ & Energy required for heating polymer & $\mathrm{J}$ \\
$\mathrm{E}_{\mathrm{T}}$ & Energy required for heating embossing tool & $\mathrm{J}$ \\
$\mathrm{E}_{\mathrm{Th}}$ & Energy transmitted through polymer and embossing tool \\
$\kappa$ & Thermal conductivity & $\mathrm{J}$ \\
$\mathrm{C}_{\mathrm{p}}$ & Specific heat capacity & $\mathrm{W} /(\mathrm{m} \cdot \mathrm{K})$ \\
$\mathrm{Z}$ & Acoustic impedance & $\mathrm{J} /(\mathrm{g} \mathrm{K})$ \\
$\mathrm{Z}_{\mathrm{HDPE}}$ & Acoustic impedance of HDPE & $10^{6} \cdot \mathrm{kg} /\left(\mathrm{s} \cdot \mathrm{m}^{2}\right)$ \\
$\mathrm{Z}_{\mathrm{M}}$ & Material acoustic impedance & $10^{6} \cdot \mathrm{kg} /\left(\mathrm{s} \cdot \mathrm{m}^{2}\right)$ \\
$\rho$ & Density & $10^{6} \cdot \mathrm{kg} /\left(\mathrm{s} \cdot \mathrm{m}^{2}\right)$ \\
$\mathrm{V}$ & Material volume & $\mathrm{g} / \mathrm{cm}^{3}$ \\
$\mathrm{R}^{2}$ & Reflection intensity between two different materials & $\mathrm{mm}{ }^{3}$ \\
$\mathrm{R}_{\mathrm{Al}-\mathrm{HDPE}}^{2}$ & Reflection intensity at the interface of Al sonotrode and & \\
\hline
\end{tabular}




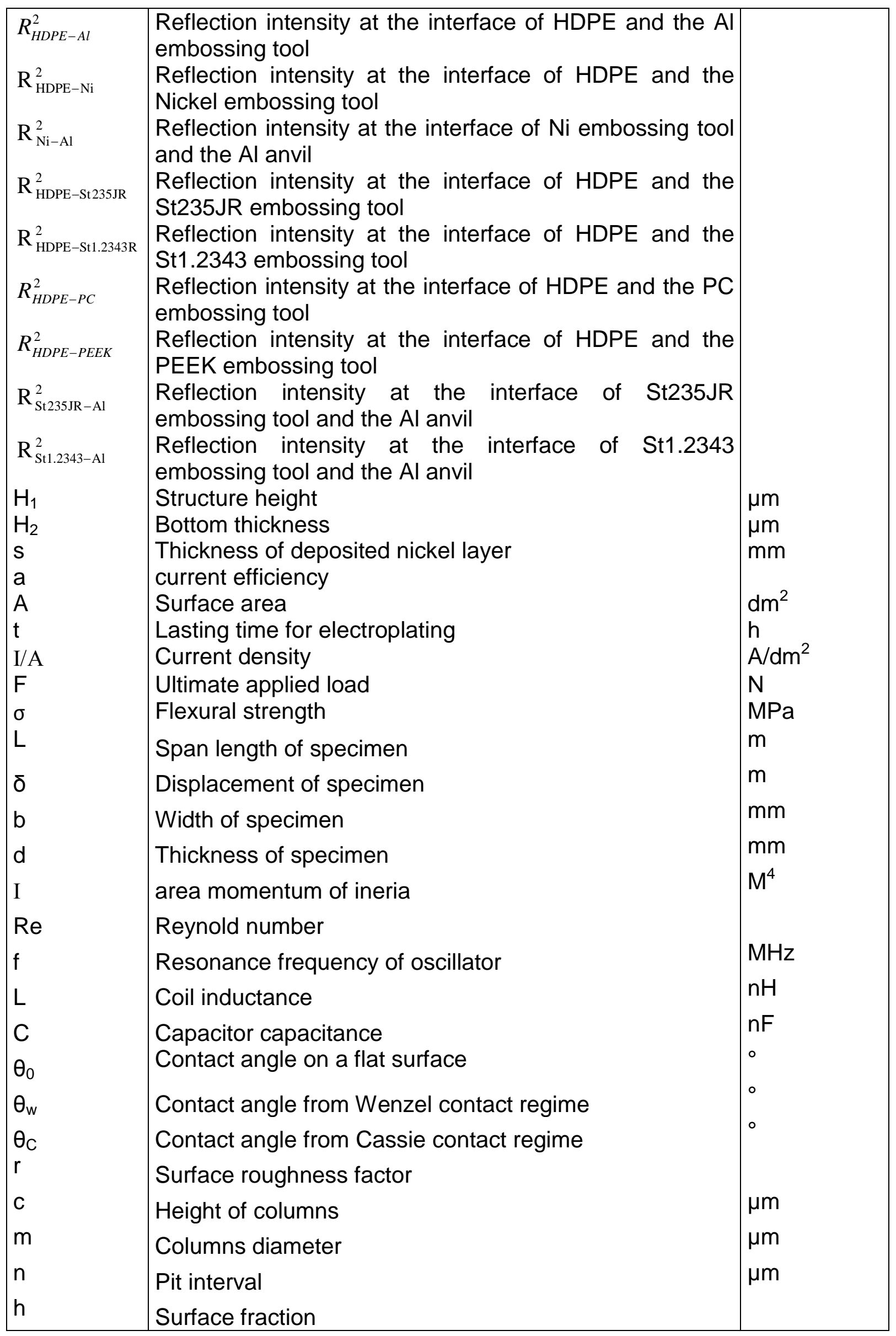




\section{Introduction}

In the past decades, versatile ways based on polymer replication have been developed for producing microsystems. The basic idea of replication by molding is to deform the polymer at a certain temperature to transfer a microstructure from an original mold (tool) to polymer. There are three main options for replication: injection molding, thermoforming, and hot embossing [1]. Besides these, reaction injection molding and injection compression molding were developed.

In between, injection molding is a process transferring thermoplastic granules into a heated barrel to melt and soft the polymer [2]. The material is pressed inside a mold at a holding pressure for a proper time. Later the mold temperature is raised over the glass transition temperature $\left(T_{g}\right)$ of the polymer to solidify the material and the molded parts are ejected. Typical examples produced by injection compression molding are compact disc CD and digital versatile disc (DVD) [3]. Advantages of injection molding are short cycle times [4], cost effective for mass production [4], and accurate shape replication in precise dimensions [5]. But the limits of this process include high initial investment cost of both molding equipment and master, strict mechanism requirement [6], especially the thermal resistance since the operating temperature of injection molding is higher than the one of hot embossing [7].

Thermoforming is realized by pressing thin plastic films onto a microstructure on the tool with compressed hot gas [8]. One application of thermoforming is producing a single use capillary electrophoresis (CE) chip [9]. This approach is low-cost and simple to manage and only the polymer film is heated up. However, micro structures with large aspect ratios (the ratio of the structure height to the smallest lateral dimensions) cannot be produced by thermoforming because the polymer cannot be heated too much to copy the structures or otherwise the polymer would become permeable when gas blows it onto the mold [10].

Hot embossing, which was first implemented to replicated hologram motion pictures of a television in USA in 1970 [11], is employed nowadays for many applications from large volume to tiny structures [12]. The basic principle of hot embossing is firstly heating the tool up to the $\mathrm{T}_{\mathrm{g}}$ of the polymer, then compressing the polymer in the mold, and keeping the pressing force a certain time. After the tool is cooled down to a certain temperature below $T_{g}$, the molded parts are separated from the embossing tool [12]. The cost of hot embossing is cheaper than for injection molding, because the expense for the tool is reduced, e.g., typical CD fabrication costs are about US $\$ 0.01 / \mathrm{cm}^{2}$ while hot embossed foils costs around US $\$ 0.001 / \mathrm{cm}^{2}$ [13]. The temperature of hot embossing tools is also less than the one of injection molding [7] and the residual stress in the polymer is less because the polymer flowing distance is less [14]. However, shortcoming of hot embossing is still noticeable: the embossing mold has to be robust to endure the cycles of heating and cooling, which also takes several minutes and the embossing microstructure should have a aspect ratio of more than 0.5 .

Even though injection molding and hot embossing possess many advantages in microsystem fabrication and the cycle time is in the order of a few minutes, investment and tooling costs are so high that these processes are employed only for research and large-scale production. In recent 15 years, it has been discovered that the heating and cooling speed of hot embossing is increased when ultrasonic vibrations are applied [15]. 
Embossing is possible and even faster, when heating is achieved only by ultrasound [16]. The new process was named ultrasonic hot embossing. The polymer is compressed between the sonotrode of an ultrasonic welding machine and a micro patterned tool; ultrasound is generating friction heat and, this way, softening the polymer. Similar as in hot embossing, the polymer adapts to the shape of the tool after switching off the ultrasonic vibrations and cooling down. The heating and cooling efficiency is very high compared to injection molding and hot embossing because only the polymer instead of the entire embossing tool is heated. Thus the advantages of ultrasonic hot embossing are cycle times of a few seconds; low cost [16] and high flexibility concerning new designs. The limits of ultrasonic hot embossing are caused by the temperature management of sonotrode and tool, the available force and ultrasonic power, the size of the sonotrode, and the properties of the tool. On the other hand, the minimum dimension realized by ultrasonic hot embossing is around $1 \mu \mathrm{m}$ [17] and is larger than the limit structures produced by hot embossing achieving $25 \mathrm{~nm}$ [18]. Micro structures and systems for a variety of applications have been produced successfully already by ultrasonic hot embossing $[16,19]$.

The purpose of this thesis was investigating what kinds of tools are suitable for ultrasonic hot embossing and what are the process limitations caused by the tool. Both tool's mechanical and thermal properties were considered.

Firstly, in Chapter 3, the performance of the embossing tool from three kinds of metals, aluminum, steel and nickel, and from two polymers, PC and PEEK, were compared by ultrasonic hot embossing of HDPE. The impact of ultrasound on the embossing result is discussed considering the propagation of heat and acoustic energy. The influence of tool properties on ultrasonic hot embossing was investigated by the dimensions of embossed structures and temperature measuring inside of embossing tools combined with some theoretical considerations. By analyzing the energy distribution in the whole hot embossing process, the mechanism of ultrasonic hot embossing is discussed.

In Chapter 4, the fabrication of tools for ultrasonic hot embossing from diverse materials and by different processes are described and compared. The performances of the tools generated that way were evaluated by the embossing results of polymers.

The fabrication of 3-dimensional structures with dimensions ranging from several $\mathrm{mm}$ down to hundreds nm produced by ultrasonic hot embossing are introduced in Chapter 5 . The design of micro structures, the process of fabrication and the results are demonstrated. Furthermore, the corresponding mechanical or electrical properties of embossed structures are tested and compared here as well. 


\section{Development of ultrasonic hot embossing}

\subsection{Ultrasonic welding development}

Ultrasound has many applications in industry. In 1974, it was firstly applied for molding acrylic and vinyl powders without external heat [20]. In later decades, ultrasound was employed welding thermoplastic structures, e.g., polyether ether ketone (PEEK) graphite composite and polypropylene (PP) parts separately [21, 22]. Not only micro parts from the same polymer but also the parts from different types of polymers can be welded. In [19], it has been investigated which kinds of polymers can be welded with each other. The combinations of several polymers which can be joined by ultrasonic welding has been listed in a table, in which styrene-acrylonitrile (SAN) and poly (lactic acid) (PLA) show excellent welding ability to various other polymers. In Table 2.1, there is shown a list of such polymers which have been used in this thesis.

Table 2.1: Thermoplastic polymers [23-31]

\begin{tabular}{llll}
\hline Polymer name & Abbreviation & $\begin{array}{l}\text { Glass transition } \\
\text { temperature }\left[{ }^{\circ} \mathrm{C}\right]\end{array}$ & $\begin{array}{l}\text { Melting tem- } \\
\text { perature }\left[{ }^{\circ} \mathrm{C}\right]\end{array}$ \\
$\begin{array}{l}\text { Polymethylmethacrylate } \\
\text { Polyvinylidene fluoride }\end{array}$ & PMMA & $104-105$ & 175 \\
Polyvinyl chloride & PVDF & -30 & 174 \\
Polyamide & PA 6 & 81 & 200 \\
Polycarbonate & PC & 150 & 220 \\
Polyether ether ketone & PEEK & 145 & $220-260$ \\
Polystyrene & PS & $90-100$ & 395 \\
High density polyethylene & HDPE & -110 & 289 \\
Polypropylene & PP & $0--10$ & $126-135$ \\
Polyethylene terephthalate & PET & 98 & $160-170$ \\
Poly (lactic acid) & PLA & 55 & $250-260$ \\
\hline
\end{tabular}

Beside this, aluminum alloy has been welded to titanium and copper alloy by ultrasonic vibrations with no intermetallic layer reaction [32, 33]. A thin metal wire, applied as electrical connections, was welded into polymer as well by ultrasonic vibrations [19]. Ultrasonic welding provides perfect bonding strength between polymer joints by melting energy directors. Take the welded mirco channel $(480 \mu \mathrm{m}$ in diameter) for example, the mean pressures which could be applied before leakage was observed were $2.9 \mathrm{MPa}$ and $2.5 \mathrm{MPa}$ at $20^{\circ} \mathrm{C}$ and $90^{\circ} \mathrm{C}$, respectively. Vibrating aptitude, force, and holding time of the welding process significantly contribute to the welding result and another key factor is the arrangement of energy directors. In industry the tube of toothpaste and car dashboards are examples of products joined by ultrasonic welding 
[19]. Sample flasks requiring hermetic seals and anesthesia filter are other applications of ultrasonic welding in medical fields [34]. Ultrasonic welding and also ultrasonic hot embossing can be applied to almost all thermoplastic polymers.

\subsection{Ultrasonic hot embossing developments}

Entering into the $21^{\text {st }}$ century, functional pattern surfaces produced by ultrasonic hot embossing appeared, as summarized in Table 2.2 and some photos of the patterns are shown in Figure 2.1. Different feature types with dimensions in the micro meter scale had been generated on many polymers and the embossing parameters are shown in Table 2.2. The surface morphology modification was achieved in just a few seconds. In addition, ultrasonic vibration has been combined with nanoimprint technology at room temperature to imprint PET sheets with channel length from $500 \mathrm{~nm}$ to $10 \mu \mathrm{m}$ and depths of $1 \mu \mathrm{m}$. The patterns were uniform and they were fabricated in one minute [35]. Superhydrophobic surfaces with micro channels (width: $30 \mu \mathrm{m}$, depth: $50 \mu \mathrm{m}$ ) were also produced by an ultrasonic imprinting system and a maximum contact angle of the embossed surface from PMMA of $152.2^{\circ}$ had been achieved [36].

Table 2.2: Surfaces patterned by ultrasonic hot embossing

\begin{tabular}{|c|c|c|c|c|}
\hline $\begin{array}{l}\text { Feature } \\
\text { type }\end{array}$ & Feature size & $\begin{array}{l}\text { Embosse } \\
\text { d material }\end{array}$ & $\begin{array}{l}\text { Best embossing } \\
\text { parameters }\end{array}$ & Reference \\
\hline Pyramids & $\begin{array}{l}\text { Base length: } 1 \mathrm{~mm} \times \\
1 \mathrm{~mm}\end{array}$ & $\begin{array}{l}\text { PMMA, } \\
\text { PVC, PE } \\
\text { and PP }\end{array}$ & $\begin{array}{l}\text { Embossing pressure: } \\
450 \mathrm{kPa} \text {, embossing } \\
\text { time: } 0.6 \mathrm{~s}\end{array}$ & [37] \\
\hline Pyramids & $\begin{array}{l}\text { Entrance length: } 100- \\
530 \mu \mathrm{m} \text {, depth: } \\
260 \mu \mathrm{m}\end{array}$ & $\begin{array}{l}\text { PMMA, } \\
\text { PC }\end{array}$ & $\begin{array}{l}\text { Embossing force: } \\
0.5 \mathrm{KN} \text {, embossing } \\
\text { time: } 60 \mathrm{~s}\end{array}$ & [15] \\
\hline $\begin{array}{l}\text { Square } \\
\text { pillar and } \\
\text { pore } \\
\text { arrays }\end{array}$ & $\begin{array}{l}\text { Length: } 70 \times 70 \mu \mathrm{m} \text {, } \\
\text { depth: } 50 \mu \mathrm{m}\end{array}$ & PMMA & $\begin{array}{l}\text { Vibrating amplitude: } \\
20 \mu \mathrm{m} \text {, embossing } \\
\text { time, } 2.5 \mathrm{~s} \text { (pore) and } \\
2 \mathrm{~s} \text { (pillar) }\end{array}$ & [38] \\
\hline $\begin{array}{l}V \text { shape } \\
\text { channel }\end{array}$ & $\begin{array}{l}\text { Angle: } 120^{\circ} \text {, channel } \\
\text { length: } 20 \mathrm{~mm}\end{array}$ & PMMA & $\begin{array}{l}\text { Embossing pressure: } \\
300 \mathrm{kPa} \text {, } \\
\text { vibrating time: } 1 \mathrm{~s}\end{array}$ & [39] \\
\hline $\begin{array}{l}\text { Hierarchic } \\
\text { al square } \\
\text { pillar } \\
\text { arrays }\end{array}$ & $\begin{array}{l}\text { Base square width: } \\
20 \times 20 \mu \mathrm{m} \text {, height: } \\
20 \mu \mathrm{m} \text {, top structure } \\
\text { width: } 1 \times 1 \mu \mathrm{m} \text {, height: } \\
600 \mathrm{~nm}\end{array}$ & PE & $\begin{array}{l}\text { Embossing force: } \\
690 \mathrm{~N} \text {, } \\
\text { embossing time: } 3 \mathrm{~s}\end{array}$ & [17] \\
\hline $\begin{array}{l}\text { Micro } \\
\text { square } \\
\text { well }\end{array}$ & $\begin{array}{l}\text { Edge length: } 300 \mu \mathrm{m} \text {, } \\
\text { height: } 150 \mu \mathrm{m}\end{array}$ & PS & & [40] \\
\hline
\end{tabular}



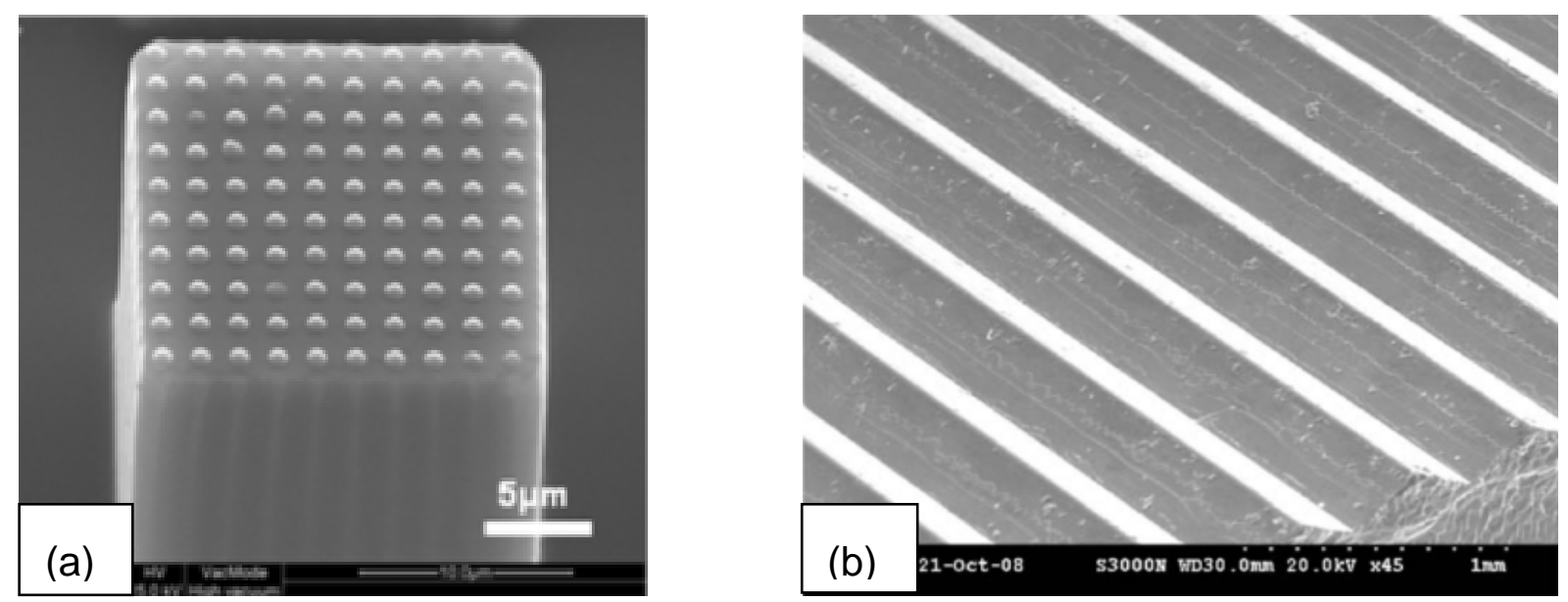

Figure 2.1: Micro patterned surface: (a) $1 \mu \mathrm{m}$ nanostructure on $20 \mu \mathrm{m}$ micro structures [17], (b) micro $V$ shape channels [39]. Reprinted with permission from IPO publishing and Elsevier.

\subsection{Ultrasonic hot embossing of microsystems}

At $\mathrm{KE} \mu$, ultrasonic hot embossing has been widely used. The schematic drawing of the ultrasonic hot embossing process on a tool with a patterned surface is demonstrated in Figure 2.2. The whole process is divided into the following steps:

1) Pre-embossing: The sonotrode of an ultrasonic welding machine is pressing polymer foils onto a tool with protruding micro structures on its surface.

2) Triggering: After the sonotrode contacts the polymer, the pressing force of the sonotrode increases until reaching a certain trigger force.

3) Embossing: Embossing starts with ultrasonic vibrations for a preset embossing time. Friction between the protruding micro structures and the polymer and between the different polymer layers generates heat softening the polymer. The softened polymer then adapts to the shape of the micro structures on the tool.

4) Holding: Ultrasonic vibrations stop but the sonotrode still keeps pressing the molded polymer with a certain force. The purpose of this is to make sure that the structures are fully solidified and molded.

5) Demolding: The sonotrode moves up and the molded part is ejected. The different polymer layers have been unified to a single piece where heat has been generated.

As shown in Figure 2.2, the whole process of ultrasonic hot embossing is completed typically in less than $2 \mathrm{~s}$. This is shorter than the cycle times of variotherm processes required for hot embossing and injection molding of micro structures, which last several minutes [4]. 


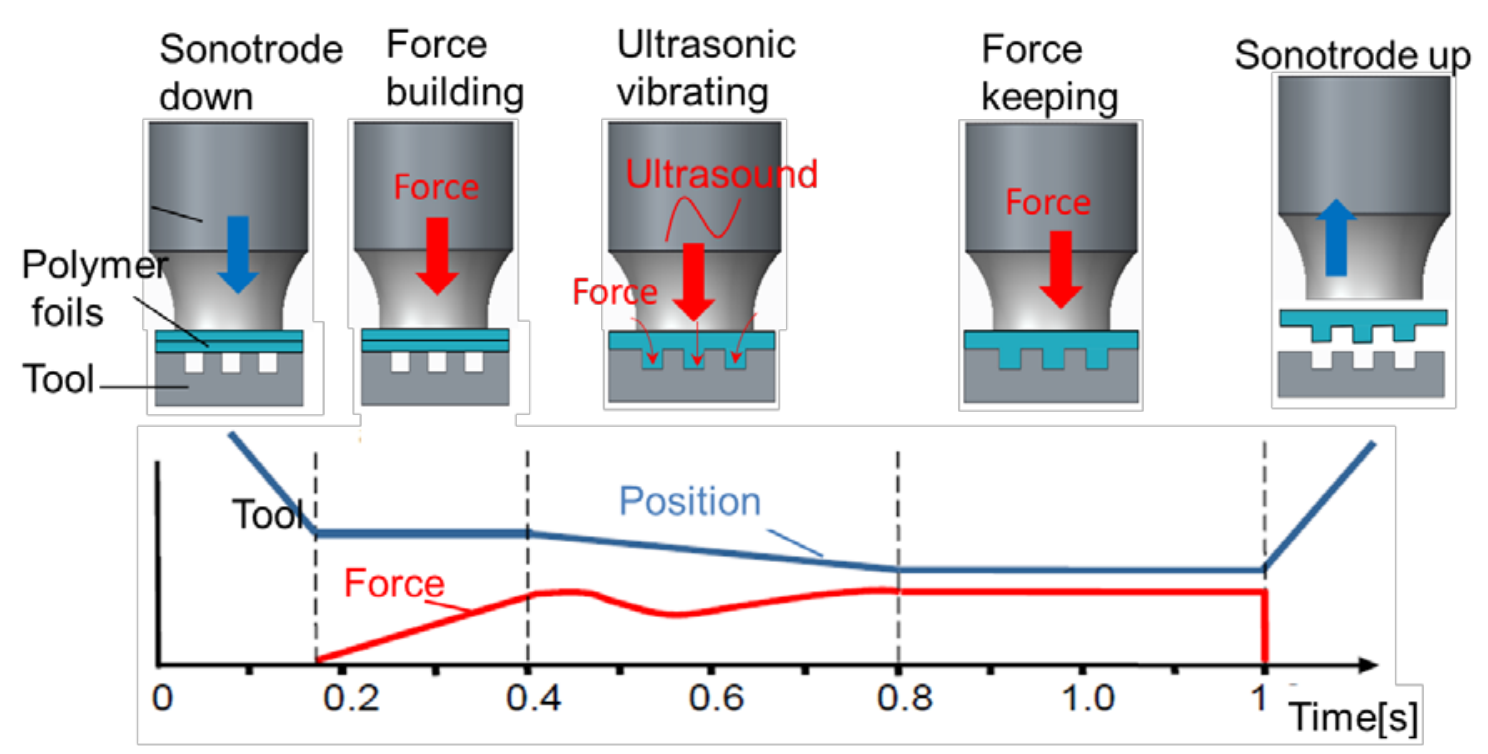

Figure 2.2: Ultrasonic hot embossing process.

Several microsystems, such as an anemometric flow sensor [41], micro fluidic systems [42], a micro pump [16] and micro valves [42, 43] have been produced by ultrasonic hot embossing in recent years. The anemometric flow sensor fabricated by ultrasonic hot embossing and welding was published in 2008 and is shown in Figure $2.3 \mathrm{a}$. A trapezoid channel with height, width and length of $500 \mu \mathrm{m}, 500 \mu \mathrm{m}$ and $1 \mathrm{~cm}$, respectively, and a taper angle of $60^{\circ}$ was embossed into PP foils in $300 \mathrm{~ms}$ and was enclosed with another PP film by ultrasonic welding in $180 \mathrm{~ms}$. A gold wire was fixed in the middle of the channel before welding the lid film. It caused friction heat in its surrounding during welding and was enclosed by polymer. The whole production of this flow sensor lasted only 1-2 s. The sensor was proven being suitable for the measurement of liquid flows.

Later a heat exchanger with three layers of micro channels from PVDF was produced. The micro channels $(400 \mu \mathrm{m}$ in depth and $600 \mu \mathrm{m}$ in width) were ultrasonically embossed into polymer layers and then three layers with micro channels were welded on top of each other (cf. Figure $2.3 \mathrm{~b}$ ) to realize a 3-dimensional fluidic channel connection. The inlet and outlets of the channels were welded at the same time to avoid additional fabrication steps. Energy directors along the channels were $150 \mu \mathrm{m}$ in width with a ball-shape on top. When fabricated with an embossing time and welding time of $290 \mathrm{~ms}$ and $100 \mathrm{~ms}$, respectively, the sealed channel sustained a pressure of $200 \mathrm{kPa}$.

The micro pump shown in Figure $2.3 \mathrm{c}$ was driven by a membrane $(14 \mathrm{~mm}$ in diameter) closing a micro chamber which had been ultrasonically embossed into PVC foils in $490 \mathrm{~ms}$. The membrane was welded in $350 \mathrm{~ms}$ with a protruding bar as the energy director to construct a sealed volume.

A micro valve with an electromagnetic drive was produced by ultrasonic hot embossing as well, with outer dimensions of $3.6 \mathrm{~mm}$ and $17 \mathrm{~mm}$ in height and diameter, respectively. The whole cycle time was approximately $5 \mathrm{~s}$, while the embossing time was less than $1 \mathrm{~s}$. The upper and lower housing of it were fabricated from PVDF. Two magnets and copper coils were assembled inside the housings, which were welded later by ultrasonic welding. By the same time, the electrical connections to the coils were also ultrasonically welded into the PVDF. The micro valve is bi-stable with 
a maximum inlet pressure of $125 \mathrm{kPa}$ and the switching electrical power was only $200 \mathrm{~mJ}$ at $15 \mathrm{~V}$. The whole valve is seen in Figure $2.3 \mathrm{~d}$.
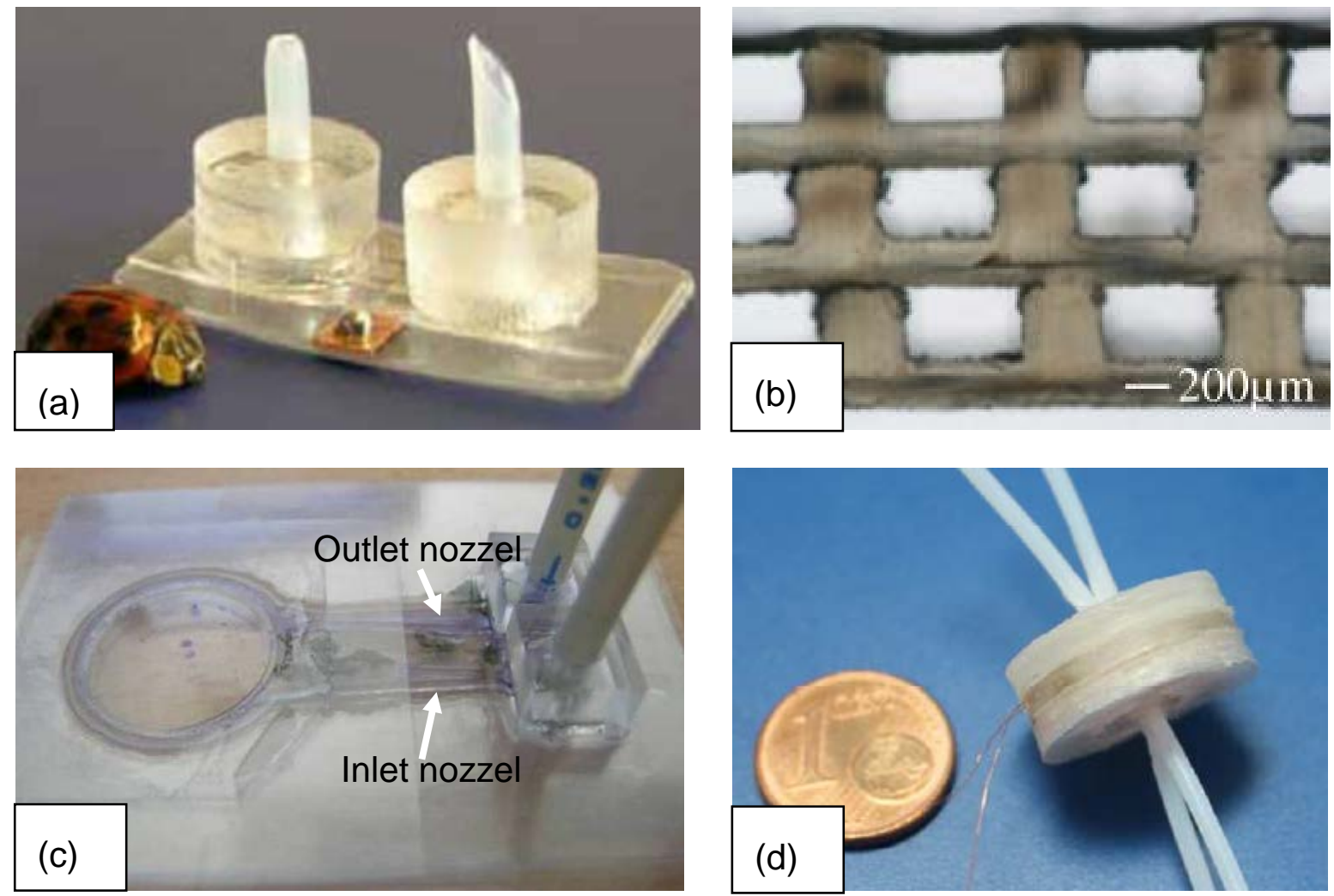

Figure 2.3: Microsystems produced by ultrasonic hot embossing: (a) anemometric flow sensor [41]; (b) cut through of a heat exchanger [42]; (c) micro pump [16]; (d) bistable micro valve driven by an electromagnetic field [43].

Other applications of ultrasonic hot embossing are patterning conductive polymer yarns [44] and electrical circuit boards [45], shown in Figure 2.4. The purpose of patterning a conductive filament is to fabricate sensors for ropes to detect overloading. The sensors consist of predetermined breaking points in polymer yarns ultrasonically hot embossed in $0.1 \mathrm{~s}$. The filaments were covered with a silver layer and a layer of polyurethane for insolation to the environment. When the rope is overloaded, the breaking point is torn before the rope is destroyed and this can be detected by measuring the electrical resistance of the whole polymer yarn.

The electrical circuit board fabricated by ultrasonic hot embossing was realized on a composited metal-polymer foil, where the polymer foils had been glued onto the metal layer, e.g., copper foils, $20 \mu \mathrm{m}$ in thickness. The metal layer was displaced into the insulating polymer by ultrasonic hot embossing to form different conductive levels and isolated layers. The pattern of the embossing tool is critical for the design of the electrical board as the arrangement of electronic elements should be decided before the tool is fabricated. Ultrasonic welding was following as shown in Figure 2.5. An anisotropic conductive foil was laid between embossed layers and electronic elements. The conductive foil is a thermoplastic polymer filled with randomly distributed conductive particles and is only conductive in the direction vertical to its surface but not in lateral direction. The anisotropic conductive foil was ultrasonically welded to the electronic elements on one side and to the embossed circuit board on the opposite side with a welding time of $0.3 \mathrm{~s}$. 

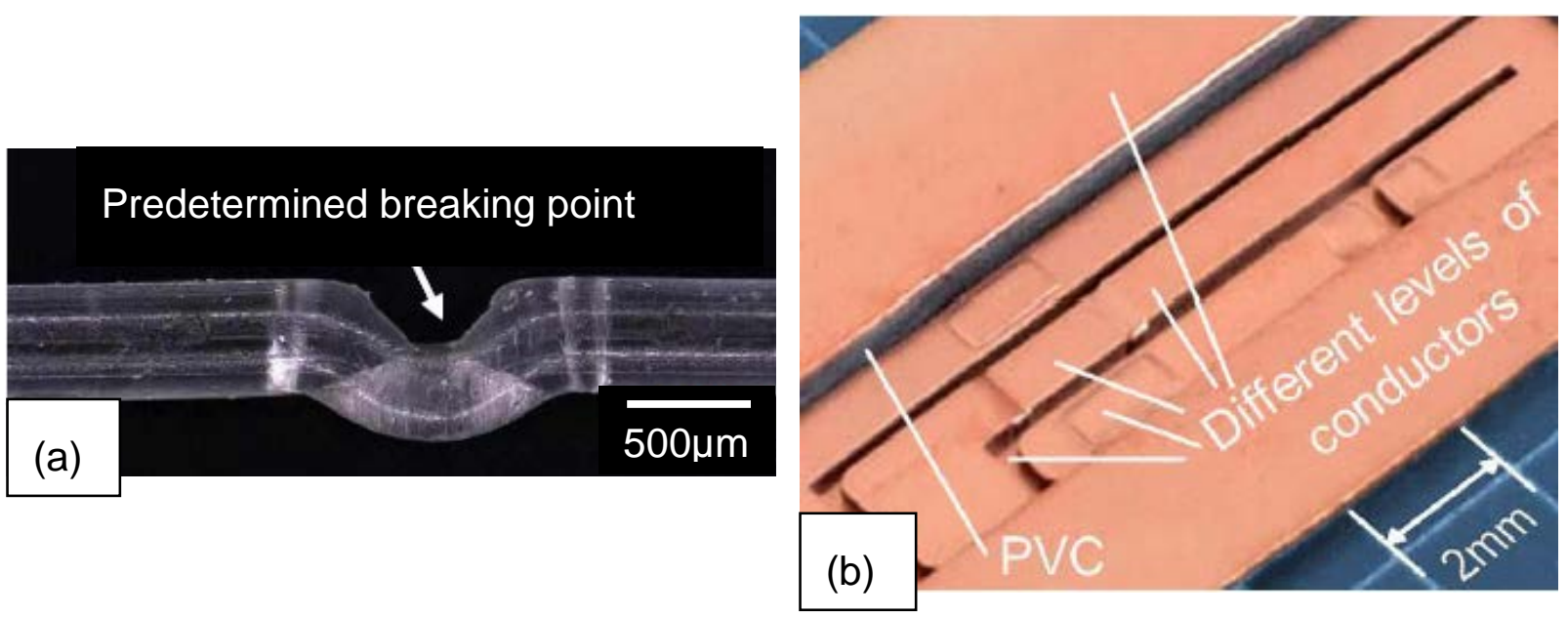

Figure 2.4: Applications of ultrasonic hot embossing: (a) Predetermined breaking point in a PA filament [44]; (b) electrical circuit board [45].

a)

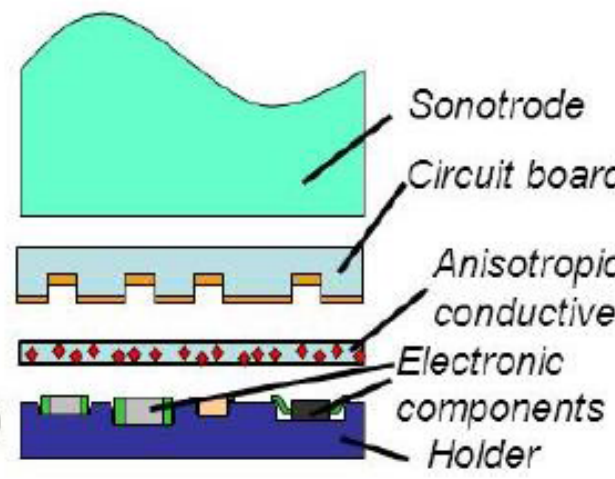

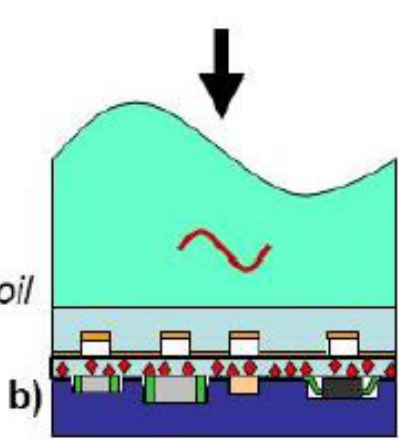
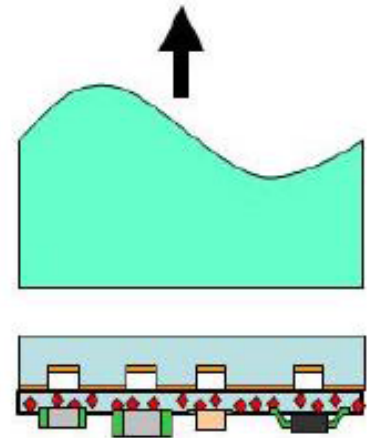

c)

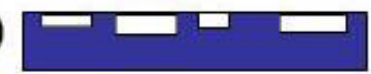

Figure 2.5: Ultrasonic welding of an electrical circuit board [45].

\subsection{Limits and challenges for ultrasonic hot embossing}

While ultrasonic hot embossing has been continually developed, there are still some challenges:

1. Temperature control: The temperature of sonotrode and tool significantly influence the embossing result. The temperature is a function of environment and ultrasound frequency [18]. As a consequence, the reproducibility of the process is limited.

2. Dimensions of embossed area: The area ultrasonically hot embossed in a single process step is limited by the dimensions of the sonotrode. At KE $\mu$, circular and rectangular sonotrodes are used. Their dimensions are $40 \mathrm{~mm}$ in diameter and 40 and $60 \mathrm{~mm}$ in width and length (cf. Figure 2.6), respectively. There are larger sonotrodes on the market; however, the larger the sonotrode's end face the smaller is the energy density available for heating the polymer.

3. Limited ultrasonic power: The output power of an ultrasonic welding machine can be too small for ultrasonic hot embossing of micro structures on a large area and for a polymer with high glass transition temperature. In this case, auxiliary heating of the embossing tool is required. It has been proven that the solidification of polymer is retarded when applying a heated tool facilitating filling of micro structures [19]. It is 
worth to mention that the extra heating temperature does not need to be as high as the one required for injection molding and hot embossing.

4. Minimum structure height: As far as what has been published, the achieved minimum dimension generated by ultrasonic hot embossing is $1 \mu \mathrm{m}$ [17].

5. Design limitations: Attention has to be paid to micro cavity filling in ultrasonic hot embossing. The cavity to be filled must be surrounded by neighboring protruding structures on the tool providing molten polymer which can flow into the cavity [16].

6. Tool: The design of micro structures generated by ultrasonic hot embossing and welding is also limited by the tool. The tool needs to show the desired shape of the micro structures and withstand the forces and temperatures occurring during fabrication. Besides this, the tool needs to reflect the ultrasound and to conduct the generated heat away from the polymer.

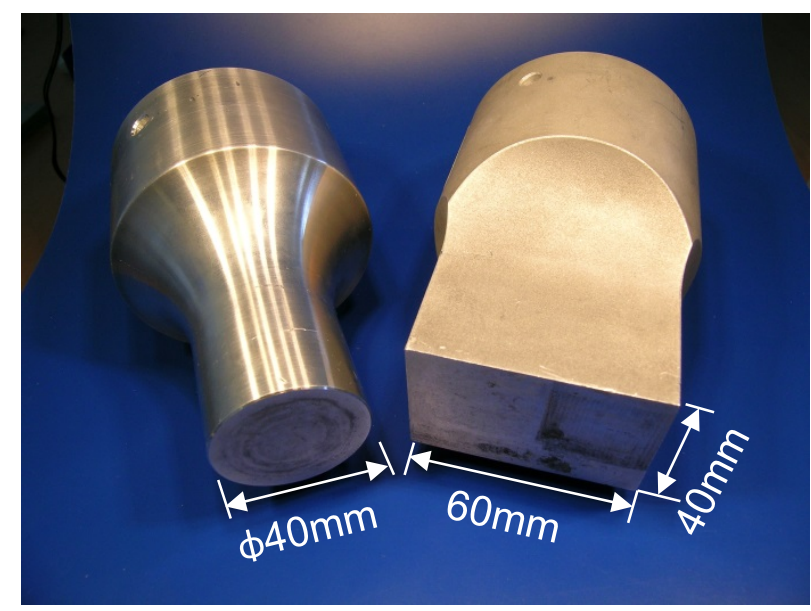

A lot of future developments for ultrasonic hot embossing are possible. Nano structures, e. g., waveguides and nano-fluidic systems for lab-on-

Figure 2.6: Two types of ultrasonic embosschip fabrication are supposed to be ing sonotrods employed at $K E \mu$.

designed. Another prospect could be more complex 3-dimensional structures produced by a sonotrode with structures. Figure 2.7 shows micro structures milled into the sonotrode end face. This is possible as long as the resonance frequency of the sonotrode is not altered too much. Such a sonotrode with micro channels down to $30 \mu \mathrm{m}$ in width had been used for ultrasonic nano imprinting into PMMA (cf. Figure 2.7 a) [36]. For producing predetermined breaking points in polymer yarns, a sonotrode with a single protruding bar (width: $500 \mu \mathrm{m}$ and height: $800 \mu \mathrm{m}$ ) was used [44] and is shown in Figure $2.7 \mathrm{~b}$.
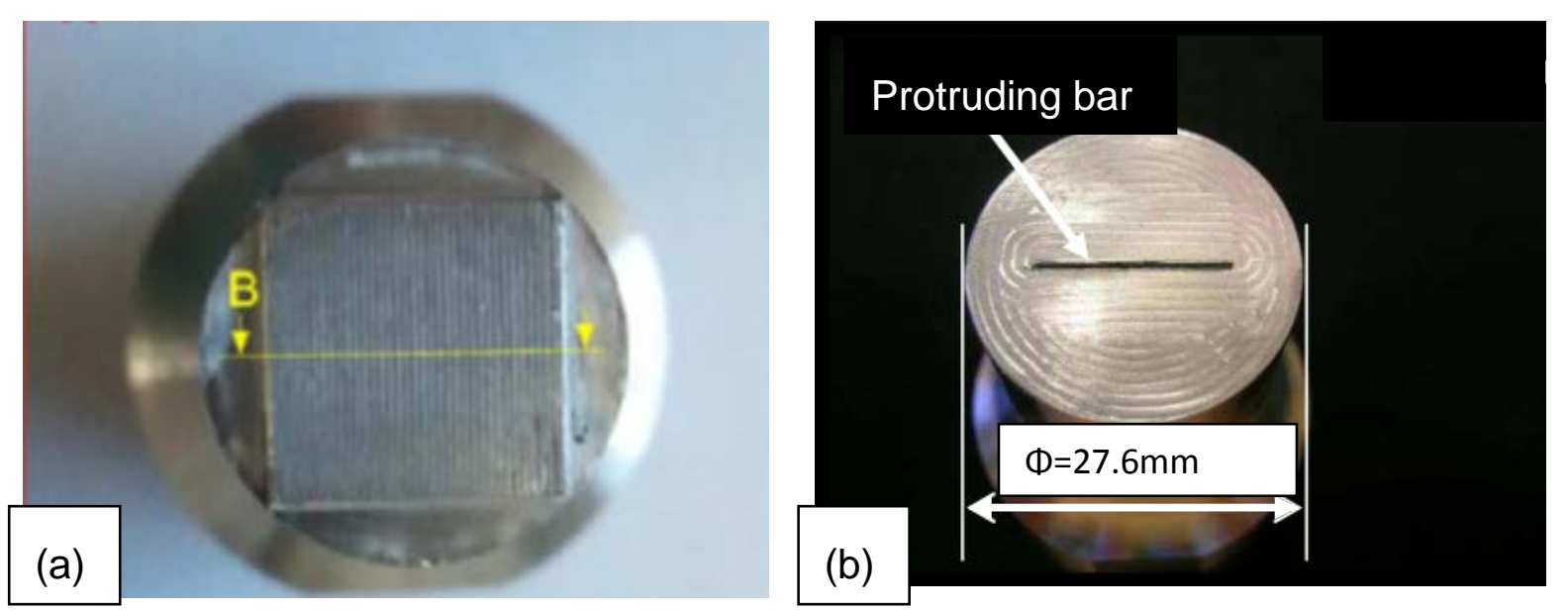

Figure 2.7: Ultrasonic sonotrode produced with structures: (a) micro channels [36], Repringted with permission from IPO publishing; (b) single bar [46] 
A lot of research has been done on injection molding and hot embossing, but the exploration of ultrasonic hot embossing is still at its beginning. There is no doubt that the ultrasound is assisting to melt the polymer and reducing the cycle time [15]. On the one hand, the heat generated from ultrasound stems from friction within polymer and between tool and polymer. When high frequency acoustic waves transfer through polymer foils, asperities on polymer surfaces are vibrated, accompanied with compressing, squeezing and slipping away with each other, leading to great friction and heat between polymer foils. This generated heat therefore increases the polymer temperature. When the temperature increases over the glass transition temperature $T_{g}$ of the polymer, melting happens. Therefore, only the molded area is heated up by ultrasonic hot embossing, the shrinkage of molded parts is less compared to injection molding and hot embossing. On the other hand, the longitudinal acoustic wave additionally spreads vertically to the pattern side of molding, thus helping the polymer flowing inside the mold pattern to improve the molding precision [15]. In basic ultrasonic hot embossing, heating of the embossing tool is not necessary anymore and, as a consequence, the process time is reduced.

When ultrasound propagates, on the one hand, not only the embossed polymer but also the sonotrode, the embossing tool and even the anvil are absorbing the acoustic wave during embossing. The absorbed energy is removed from the ultrasonic wave and transformed into heat [47]. It is attractive to identify the energy distribution during the whole process, for instance, how much of the energy has been converted from ultrasound into heat and how much heat is absorbed in each construction parts etc. On the other hand, at the interface of two media, sound waves are partly reflected backwards and the rest keeps traveling while some of them are lost. It is also curious and necessary to analyze how much of the wave's power is transferred, reflected and lost through the two media interfaces. All these discussions are presented in the following chapters. 


\section{Embossing tool evaluation during ultrasonic hot embossing}

Ultrasound used in hot embossing has a frequency higher than $10 \mathrm{kHz}: 20 \mathrm{kHz}$ and $35 \mathrm{kHz}$ are often used $[40,48]$. When ultrasound is propagating inside a material, it is absorbed and attenuated. Acoustic absorption is caused by the conversion of acoustic energy to heat while attenuation is due to spreading or dissipation of the acoustic energy in the material. Both processes lead to a reduction of the ultrasound wave amplitude.

In an experiment described in literature [47], an ultrasonic pulse at $10 \mathrm{MHz}$ was transmitted into a PP disk, $3 \mathrm{~mm}$ in thickness, by a transducer and the same transducer was employed recording the acoustic signals reflected back and forth at the surfaces of the plate. An oscilloscope image of the ultrasound is shown in Figure 3.1, where the interval between successive reflection implies the wave longitudinal velocity and the attenuation is seen from the ratio of the intensity of two successive reflections. The timing and the amplitude of the wave in Figure 3.1 are considered being due to sound speed and attenuation. This provides a hint how ultrasound propagates inside of the material, influencing the embossing result. The acoustic wave is reflected back and forth in the polymer and its amplitude is reduced both by absorption and attenuation. Absorption of the acoustic power in the polymer is desired because it contributes to heating and softening, but the energy lost by energy transmitted into the environment should be avoided as much as possible.

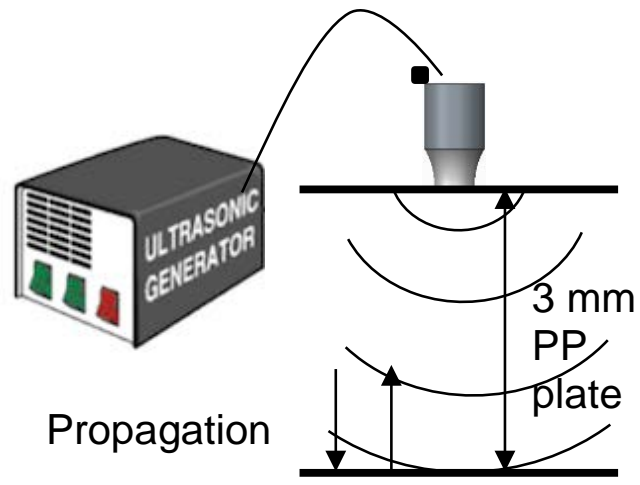

Reflection

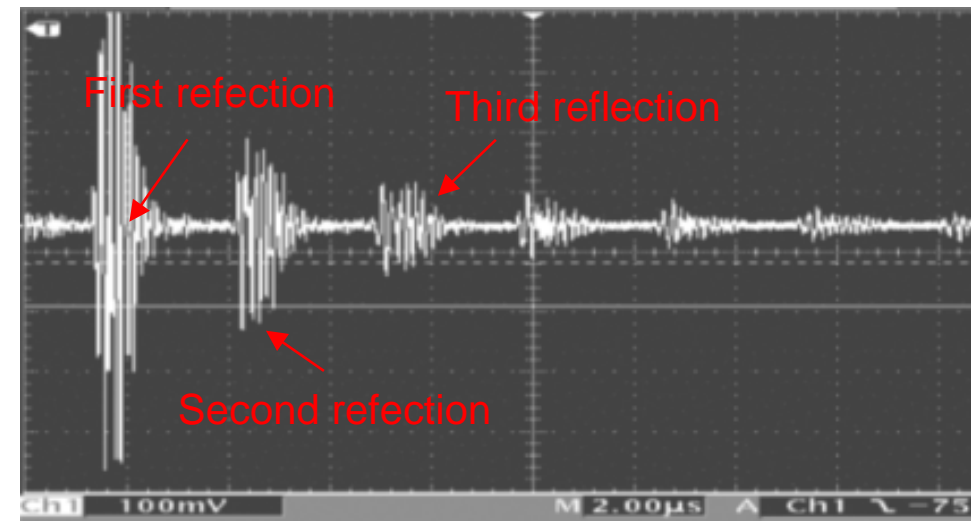

Figure 3.1: Ultrasound pulse-echo pattern obtain at $10 \mathrm{MHz}$ in a PP plate, horizontal scale is $2 \mu \mathrm{s} /$ division [47].

\subsection{Purpose of the work}

For ultrasonic hot embossing, ultrasonic vibrations are conducted into the polymer stack via the sonotrode and result in heat generated at the interfaces between the different layers (seen in Figure 3.2) by friction and inside of the layers by absorption. It is easy to recognize that not only the embossed material (polymers) but also the embossing tool and anvil are reached by ultrasound. A portion of the generated heat melts the polymer which adapts to the shape of micro structures on the surface of the tool while some other parts of the energy heat up the sonotrode and the embossing tool. After the ultrasound has been switched off, the heat is conducted away from the 
polymer through sonotrode, tool, and anvil. Meanwhile, the ultrasound scatters into the air as well.

At the interfaces, ultrasound is reflected, transmitted, and absorbed generating friction heat. Reflected ultrasound also contributes to the ultrasonic power available for $a b-$

sorption. Ultrasonic absorption, Young's modulus, friction coefficient, acoustical impedance, density, and viscosity are all a function of the temperature quickly rising during the process. Besides this, the geometry is changing while the polymer is adapting to the microstructures on the tool. Therefore, it is difficult calculating or at least estimating the influence of the properties of the involved parts such as polymer and tool.

In this situation, it has been attempted estimating the energy distribution and conduc-

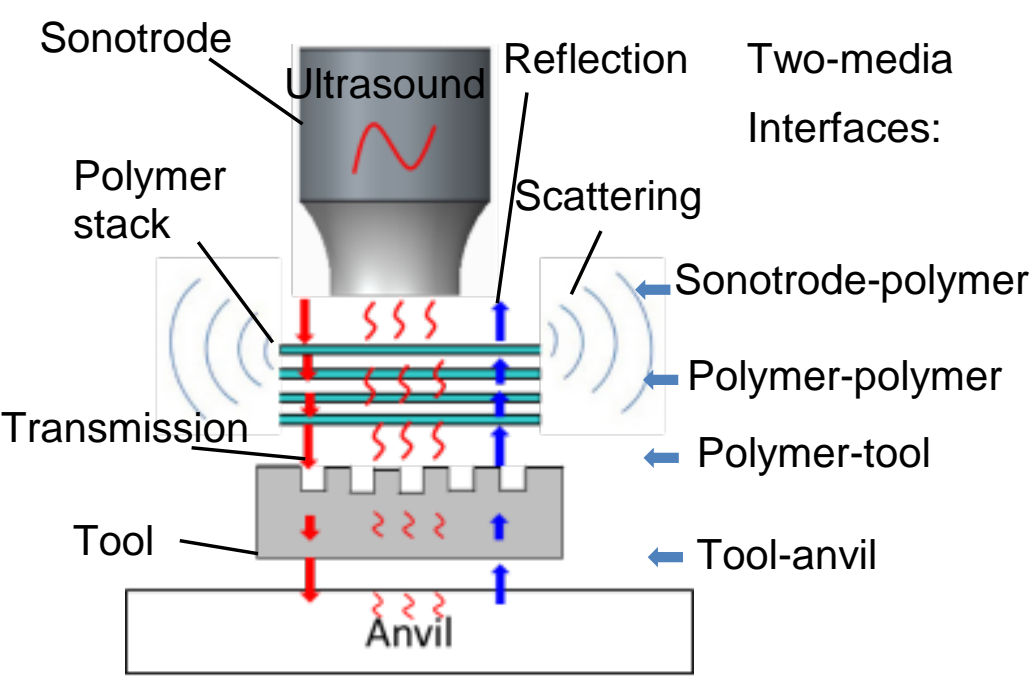

Figure 3.2: Propagation of the acoustic wave during ultrasonic hot embossing. tion during ultrasonic hot embossing. The investigations include:

1) measuring the temperature of the embossing tool to identify energy transmitting through polymer and tool,

2) measuring the dimensions of embossed structures,

3) calculating approximately the energy distribution during the embossing process.

All the ultrasonic hot embossing processes in this chapter were carried out by an ultrasonic welding machine: Herrmann Ultrasonics (HiQ DIALOG 1200), by which the embossing force, amplitude, energy and time etc. were set up and recorded automatically.

\subsection{Embossing tools from metals}

\subsubsection{Embossing tool and embossed polymer preparation}

The design of a heat exchanger published in [42] was employed as the embossing tool. The dimensions of the design are shown in Figure $3.3 \mathrm{a}$ and c. Tools were fabricated from four different metals: aluminum (Al), nickel, structural steel 235JR (St235JR), and alloy tool steel 1.2343 (St1.2343), as shown in Figure $3.3 \mathrm{~b}$, due to their common application in industry. Al, St235JR, and St1.2343 plates were milled by a Datron milling machine (M7 HP) with a processing time of 29 minutes for Al and 17 minutes for the steels. The time difference is due to cutting tool and selected parameters. The details of the milled Al tools are shown in Figure $3.3 \mathrm{~d}$. The nickel tool was produced by milling into aluminum and electroplating nickel since nickel is a very hard material to mill. The details of the fabrication process of the nickel tool are 
discussed in Chapter 4. Physical properties of these metals influencing ultrasonic hot embossing are listed in Table 3.1.

The embossed polymer was high density polyethylene (HDPE), $150 \mu \mathrm{m}$ in thickness, which is widely available and easy to emboss, since the melting temperature is 126 $135^{\circ} \mathrm{C}$. For embossing the structure in Figure 3.3, four layers of HDPE with a total thickness of $600 \mu \mathrm{m}$ were used. The physical properties of HDPE are also listed in Table 3.1. The embossing parameters of it on the four metal tools were the same enabling the comparison of the embossing results obtained with different tool materials. On the Herrmann ultrasonic welding machine, the embossing energy output was set at a certain value by computer control while the embossing time was adjusted automatically. Other related parameters were: embossing force at $250 \mathrm{~N}$, trigger force at $150 \mathrm{~N}$, amplitude at $16.3 \mu \mathrm{m}$, holding force at $150 \mathrm{~N}$ and holding time was $1.5 \mathrm{~s}$. The embossed structure on HDPE is shown in Figure 3.5.
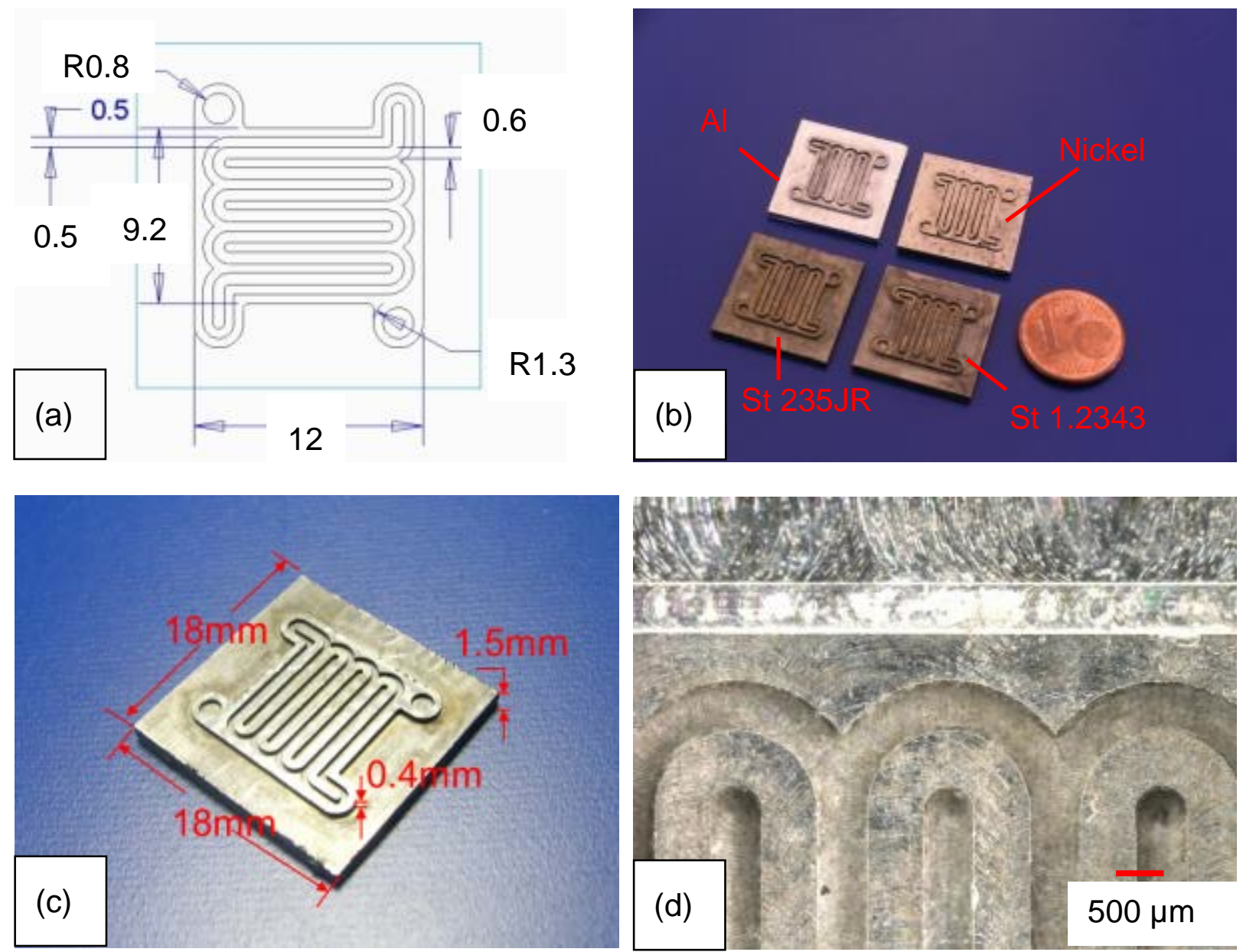

Figure 3.3: Pattern of the heat exchanger. (a) dimensions of detail structures (all measures are in $\mathrm{mm}$ ), (b) embossing tools from four metals; (c) width and thickness of structures; (d) details of the aluminum tool. 
Table 3.1: Physical properties of the materials involved in the embossing process.[23, 25, 49-54]

\begin{tabular}{l|l|l|l|l}
\hline & $\begin{array}{l}\text { Thermal con- } \\
\text { ductivity } \mathrm{K} \text { at } \\
25^{\circ} \mathrm{C}[\mathrm{W} /(\mathrm{m} \cdot \mathrm{K})]\end{array}$ & $\begin{array}{l}\text { Specific heat } \\
\text { capacity } \mathrm{C}_{\mathrm{p}} \text { at } \\
25^{\circ} \mathrm{C}[\mathrm{J} /(\mathrm{g} \mathrm{K})]\end{array}$ & $\begin{array}{l}\text { Acoustic impe- } \\
\text { dance } \mathrm{Z} \text { at } 25^{\circ} \mathrm{C} \\
{\left[10^{6} \cdot \mathrm{kg} /\left(\mathrm{s} \cdot \mathrm{m}^{2}\right)\right]}\end{array}$ & $\begin{array}{l}\text { Density } \rho \text { at } \\
25^{\circ} \mathrm{C}\left[\mathrm{g} / \mathrm{cm}^{3}\right]\end{array}$ \\
Aluminum & 205 & 0.9 & 17.33 & 2.7 \\
Nickel & 90.9 & 0.440 & 49.99 & 8.9 \\
Steel 235JR & 48.07 & 0.465 & 40.6 & 7.85 \\
Steel 1.2343 & 25 & 0.46 & 40.9 & 7.8 \\
HDPE & $0.38-0.51$ & $2.1-2.7$ & 2.33 & $0.94-0.97$ \\
\hline
\end{tabular}

\subsubsection{Temperature measurement}

To measure the temperature of the ultrasonic hot embossing tool, a thermocouple was employed. The thermocouple was embedded into thermoset glue and when ultrasound arrived at it, friction heat was generated between glue and thermocouple enhancing the temperature proportional to the intensity of the ultrasonic vibrations.

The experimental setup is shown in Figure 3.4 and the details of the ar-

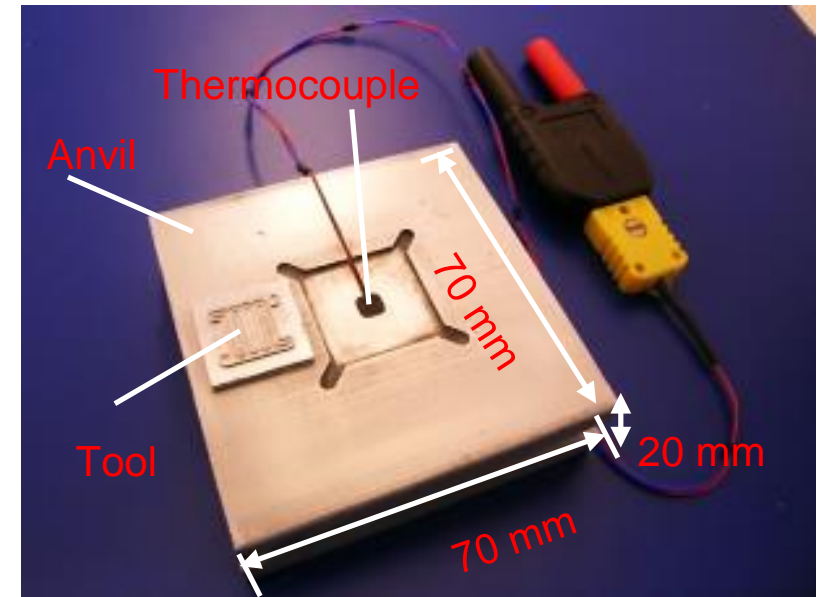

Figure 3. 4: Anvil, tool and thermocouple. rangement are shown in Figure 3.4. A $\kappa$-type thermocouple was glued into a recess (dimensions are $5 \times 5 \times 5 \mathrm{~mm}$ ) on the upper surface of the embossing anvil (dimensions are $70 \times 70 \times 20 \mathrm{~mm}$ ) under the embossing tool. Double-sided adhesive tape was employed fastening a tool onto an Al anvil. A hole (8 $\mathrm{mm}$ in diameter) had been cut out of the center of the double-sided adhesive tape and filled with thermo conductive paste (Wakefield). This way, a good thermal contact was achieved between thermocouple and tool. Both double-sided tape (Scotch) and thermoset glue (Petec) show low thermal conductivity. 


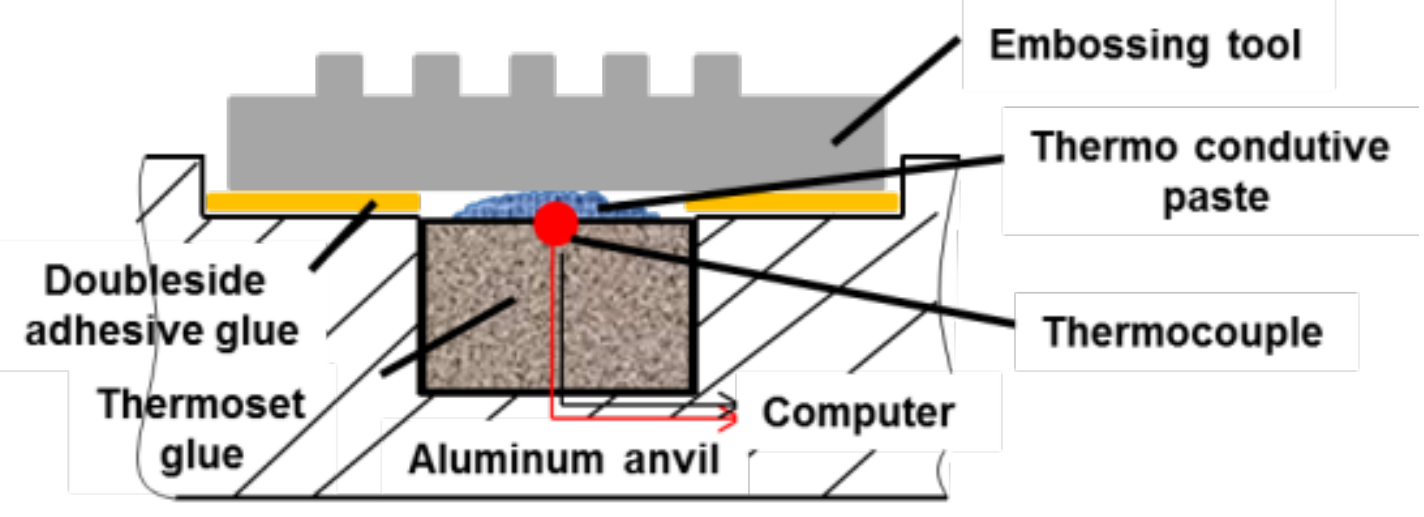

Figure 3.4: Arrangement of anvil, thermocouple, and tool.

Temperature measuring started $5 \mathrm{~s}$ before the embossing process and lasted $60 \mathrm{~s}$ to observe the cooling down process. The data were automatically recorded and displayed by Lab VIEW program.

\subsubsection{Energy influence on embossed HDPE}

The influence of the embossing energy on the embossed structures was investigated by measuring the geometry of micro structures embossed with the four tools mentioned above. The embossed HDPE (shown on the left of Figure 3.6) was cut through its middle to obtain the cross-section shown in the Figure 3.5 on the right. The structure height $\left(\mathrm{H}_{1}\right)$ and the bottom thickness $\left(\mathrm{H}_{2}\right)$ of embossed structures shown in Figure 3.7 are the average values from five specimens.

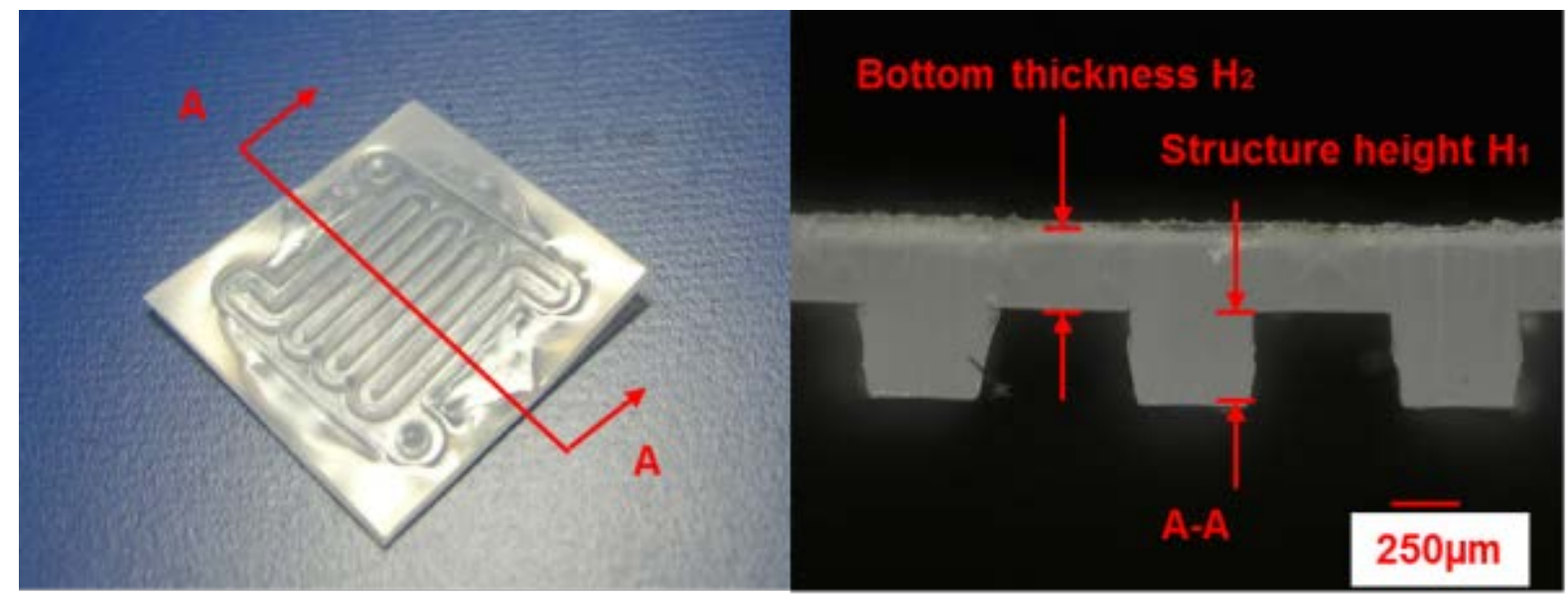

Figure 3.5: Embossed structure from HDPE and a cut through the structure (on the right).

The embossing energy was increased in $50 \mathrm{~J}$ steps from $300 \mathrm{~J}$ up to $800 \mathrm{~J}$. As shown in Figure 3.6, with increasing embossing energy $\mathrm{H}_{2}$ reduced noticeably while $\mathrm{H}_{1}$ is increasing only gradually to a limit until the melted polymer completely fills the inside of the structures on the embossing tool. This trend was the same in all cases. As more input energy was activated, the temperature of the polymer was raised up for more melting and promoting the polymer flow into the free voids on the embossing mold. The depth of the channel on the tool was about $400 \mu \mathrm{m}$. When $\mathrm{H}_{1}$ had reached 
this value, the corresponding embossing energy was assumed being the minimum limit. More energy is not necessary for embossing. Over embossing could reduce the bottom thickness down to zero, leading to failure when too much energy was used. By dimension measurements, the minimum ultrasonic hot embossing energies required in this heat exchanger were determined for the four tools Al, nickel, St235JR and St1.2343 as $600 \mathrm{~J}, 450 \mathrm{~J}, 300 \mathrm{~J}$ and $500 \mathrm{~J}$, respectively.


Figure 3.6: Dimension measurement of HDPE from four tools: (a) Al; (b) Nickel; (c) St 235JR; (d) St 1.2343.

\subsubsection{Tool influence on embossed HDPE}

The influence of tool materials on the embossed structures was investigated by measuring the geometry of micro structures employed by the four metal tools at the same embossing energy $(500 \mathrm{~J})$.

The depth of the micro structures on the four tools varied a bit due to the different fabrication processes. The fabrication parameters of ultrasonic hot embossing were optimized such that the entire cavities of the tool had been filled during the process. Complete filling of the tool structures was recognized by $\mathrm{H}_{1}$ arriving at around $400 \mu \mathrm{m}$. The height of the completely embossed micro structures was measured and taken as the maximum height that can be achieved with the certain tool. In Figure 3.7, this maximum height is compared with the height of the micro structures embossed with a constant energy of $500 \mathrm{~J}$. The percentage of HDPE filling of the tool 
was calculated and shown as well. It is noticeable that $\mathrm{H}_{1}$ obtained with the Al tool is smallest while the $\mathrm{H}_{2}$ is largest, showing that ultrasonic hot embossing with an aluminum tool requires more ultrasonic energy than with tools from other materials. On the contrary, $\mathrm{H}_{1}$ obtained with the St235JR tool is largest while $\mathrm{H}_{2}$ is smallest, indicating when ultrasonic hot embossing with the St235JR tool, the required embossing energy is minimum.
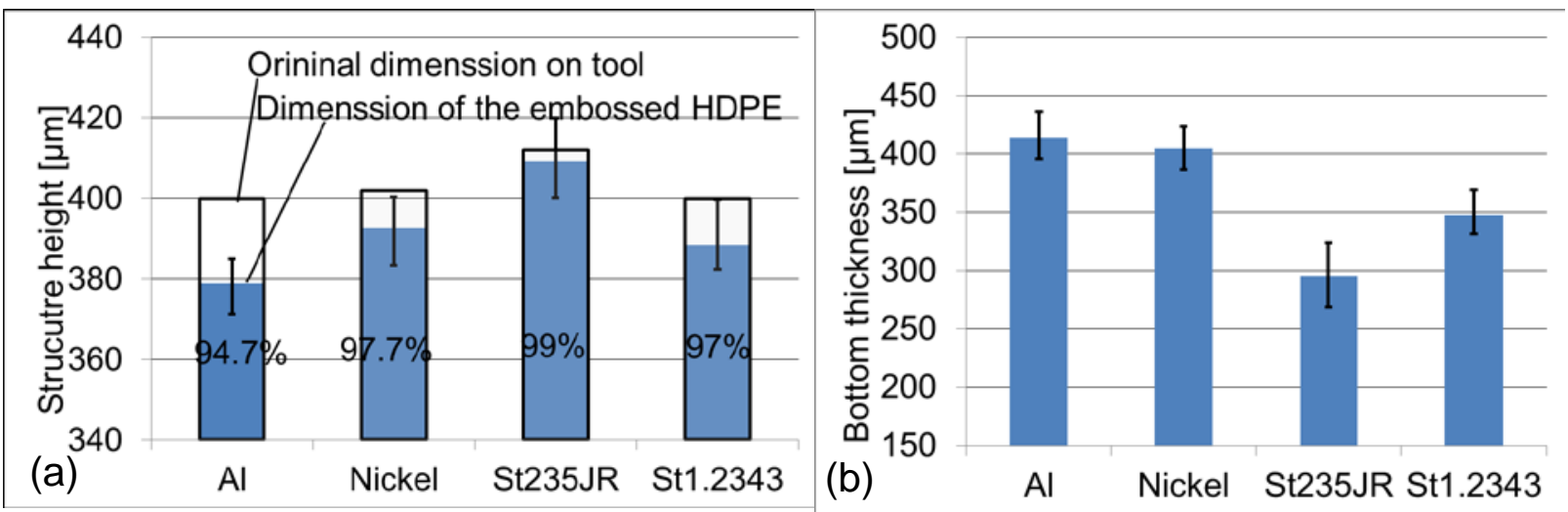

Figure 3.7: (a) Structure height $\mathrm{H}_{1}$ and (b) bottom thickness $\mathrm{H}_{2}$ of the embossed HDPE structures.

Figure 3.8 shows the temperature measurements of one embossing cycle for the tools from the four different materials. The time when the ultrasonic vibrations stopped with the nickel tool was also indicated. The maximum temperature was observed with the Al tool. In all cases the temperature of the thermocouple is rising to a maximum within $2 \mathrm{~s}$. The duration of the ultrasonic vibrations is shown in Table 3.2. It is less than the temperature rises of the thermocouple, which implies that the thermocouple is heated by the material in its near which had been heated by friction with the thermocouple and the energy generated at the interface of embossing tool and polymer continues to heat up the thermo couple after the embossing process ended.

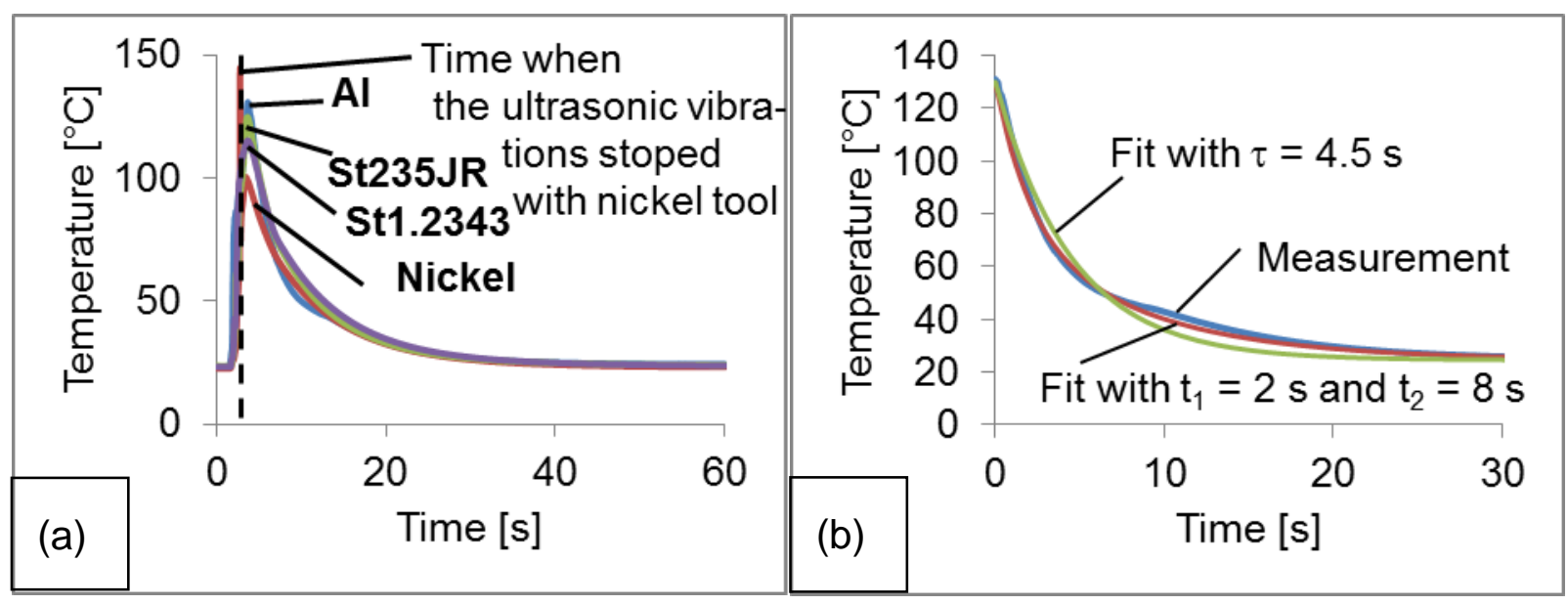

Figure 3.8: (a) Temperature measurement in one embossing cycle for different tool materials; (b) exponential functions fitted to the measurement with the aluminum tool. 
Table 3.2: Rising time of thermo couple and ultrasonic vibration time.

\begin{tabular}{lllll}
\hline Embossing tool & Al & Ni & St235JR & St1.2343 \\
Rising time of thermocouple [s] & 1.88 & 1.33 & 1.77 & 1.86 \\
Ultrasonic vibrating time $[\mathrm{s}]$ & 1.6 & 1.07 & 1.07 & 0.98 \\
Measured maximum temperature $\left[{ }^{\circ} \mathrm{C}\right]$ & 131 & 101 & 125 & 115 \\
\hline
\end{tabular}

The temperature fall after the maximum is steepest for the Al tool with the highest maximum. At a first glance, the temperature falling curve appears to be similar as an exponential function. Therefore, exponential functions according to Eq 3.1 have been fitted to the measured data.

$$
\mathrm{T}=\left(\mathrm{A}_{0}-\mathrm{T}_{0}\right) \mathrm{e}^{\frac{-\mathrm{t}}{\tau}}+\mathrm{T}_{0}
$$

In the above equation, $\mathrm{A}_{0}$ and $\mathrm{T}_{0}$ are the measured peak temperature and the environmental temperature measured a long time after cooling down, respectively. $\tau$ is the time constant of the observed cooling process and was determined from the best fit to the data curves. The fits showed that one exponential function is not suitable to fit the cooling process, especially when the aluminum tool had been employed (cf. Figure 3.8). As a consequence, it was assumed that two cooling processes with different time constants were involved and the fitting was tried with $\mathrm{Eq} 3.2$ :

$$
\mathrm{T}=\frac{1}{2}\left(\mathrm{~A}_{0}-\mathrm{T}_{0}\right)\left(\mathrm{e}^{\frac{-\mathrm{t}}{\tau_{1}}}+\mathrm{e}^{\frac{-\mathrm{t}}{\tau_{2}}}\right)+\mathrm{T}_{0}
$$

As shown in Figure $3.8 \mathrm{~b}$, much better fits to the measured temperature curves were obtained with Eq 3. 2. The time constants $\tau_{1}$ and $\tau_{2}$ obtained from the fits are listed in Table 3.3. The accuracy of the time constants was estimated to be $0.2 \mathrm{~s}$. The comparison of measured and calculated curves shows that the cooling process of the thermocouple is described significantly better by Eq 3.2 indicating that two time constants are involved rather than one. Cooling starts with a small time constant $\tau_{1}$ and then continues with a $\tau_{2}$ between 8 and $11 \mathrm{~s}$. This is interpreted as a quick dissipation of the heat generated in the thermocouple by ultrasonic vibrations into the embossing tool. After a few seconds the heat generated at the interface of tool and polymer is arriving in the near of the thermocouple. Thus the temperature difference driving the heat transfer is reducing and $\tau_{2}$ is larger. The time constants measured with an Al tool are shorter than those obtained with tools from nickel and steel. This may be attributed to the larger thermal conductivity of aluminum. However, the measurements with tools from nickel and steels do not support this interpretation, because nickel has better thermal conductivity than steel, but the cooling rates are more or less then same. 
Table 3.3: Time constants determined by a fit to the temperature measurements compared to the thermal conductivity of the employed tool.

\begin{tabular}{|c|c|c|c|}
\hline Tool material & $\begin{array}{ll}\mathrm{T} 1 & ( \pm 0.2) \\
{[\mathrm{s}]} & \end{array}$ & $\begin{array}{ll}\mathrm{T} 2 & ( \pm 0.2) \\
{[\mathrm{s}]} & \end{array}$ & Thermal conductivity at $25^{\circ} \mathrm{C}[\mathrm{W} /(\mathrm{m} \mathrm{K})]$ \\
\hline Al & 2 & 8 & 205 \\
\hline Nickel & 5 & 10 & 90.9 \\
\hline St235JR & 4 & 10.3 & $48[52]$ \\
\hline St1.2343 & 5 & 11 & 25 \\
\hline
\end{tabular}

From a different point of view, the larger ultrasonic energy required for ultrasonic hot embossing when the Al tool is employed, is believed to be partly due to less energy reflection and absorption at the interface of tool and polymer and not only due to the larger thermal conductivity of aluminum. This interpretation is supported by the larger maximum temperature measured at the thermocouple with the Al tool which would be due to more ultrasonic energy arriving at the thermocouple because of less reflection and absorption at the interface of polymer and tool. Less absorbed energy results in less embossed structure height achieved with the Al tool as seen in Figure 3.7. However, the low maximum temperature found with the nickel tool and the reduced structure heights compared to the steel tool St235JR are in contradiction to this interpretation: the temperature of the nickel tool is smallest but the embossed structure percentage are not the highest while the temperature of St 235JR is high, together with the maximum embossed structure percentage.

The polymer is heated up by the ultrasound until it is nearly molten and then adapts to the shape of the micro structures on the tool. Therefore, as a rough estimation, the energy absorbed by the polymer and the tool are calculated from the energy required to heat up both polymer and tool to the melting temperature $T_{m}$ of the polymer. The heated volume $\mathrm{V}$ is estimated as the structure height $\mathrm{H}_{1}$ times the outer dimensions of the area of the micro structures on the tool $\left(12 \times 12 \mathrm{~mm}^{2}\right)$. The energies required for heating polymer $\mathrm{E}_{\mathrm{P}}$ and Tool $\mathrm{E}_{\mathrm{T}}$ are calculated with $\mathrm{Eq} 3.3$ and shown in Table 3.4 together with the specific heat capacities $\mathrm{C}$ and the densities $\rho$.

$$
\mathrm{E}=\rho \mathrm{Vc}\left(\mathrm{T}_{\mathrm{m}}-\mathrm{T}_{0}\right)
$$

In Eq 3.3, heat capacity, density and volume are not constant as a function of temperature. For an approximate calculation, all properties (volume, heat capacity and density) of metals and the volume, heat capacity of HDPE, which are listed in Table 3.1 , are kept constant before and after embossing while polymer density varies according to its temperature.

At the melting point $\mathrm{T}_{\mathrm{m}}$, the density of HDPE $\left(\rho_{\mathrm{HDPE}}\right)$ is calculated by Eq 3.4 [55]:

$$
\rho=0.8647-6.313 \times 10^{-4} \times \mathrm{T}_{\mathrm{m}}+3.67 \times 10^{-7} \mathrm{~T}_{\mathrm{m}}^{2}-5.5 \times 10^{-10} \mathrm{~T}_{\mathrm{m}}^{3}
$$

Thus, $\rho_{\mathrm{HDPE}}=0.79 \mathrm{~g} / \mathrm{cm}^{3}$ at $\mathrm{T}_{\mathrm{m}}=130^{\circ} \mathrm{C}$. 
Table 3.4: Volume, heat capacity, density and energy required for heating up of the embossing tools and polymer to the melting temperature of HDPE.

\begin{tabular}{|c|c|c|c|c|c|}
\hline Material & $\begin{array}{l}\text { Volume } \\
\mathrm{V}\left[\mathrm{mm}^{3}\right]\end{array}$ & $\begin{array}{l}\text { Specific heat } \\
\text { capacity } \\
\text { c }[\mathrm{J} /(\mathrm{g} \mathrm{K})]\end{array}$ & $\begin{array}{l}\text { Density } \rho \text { at } \\
25^{\circ} \mathrm{C}[\mathrm{g} / \mathrm{cm} 3]\end{array}$ & $\begin{array}{l}\text { Temperature } \\
\text { rise } \\
\left(\mathrm{T}_{\mathrm{m}}-\mathrm{T}_{0}\right)\left[{ }^{\circ} \mathrm{C}\right]\end{array}$ & $\begin{array}{l}\text { Energy } \\
\text { E [J] }\end{array}$ \\
\hline Al & \multirow{5}{*}{58} & 0.9 & 2.7 & \multirow{5}{*}{110} & 15.5 \\
\hline $\mathrm{Ni}$ & & 0.44 & 8.9 & & 24.9 \\
\hline St235JR & & 0.46 & 7.8 & & 22.9 \\
\hline St1.2343 & & 0.46 & 7.8 & & 22.9 \\
\hline $\begin{array}{l}\text { Embossed } \\
\text { HDPE }\end{array}$ & & 2.4 & $0.94-0.97$ & & 12.1 \\
\hline
\end{tabular}

Obviously, the energy required for heating up the embossing tool is on the same order of magnitude as the one required for melting HDPE. The energy absorbed at the interface of tool and polymer is on the order of a few percent of the emitted ultrasonic energy (500 J). Thus, when a significant amount of the ultrasonic energy is reflected at that interface, it passes back to the polymer layers a second time with significant intensity and contributes more to polymer softening.

When ultrasound is transferred from sonotrode to anvil, the energy is lost at medium interfaces because of sound reflection and attenuation, (cf. Figure 3.1). Eq 3.5 is often used to calculate the reflection intensity between two different materials [47].

$$
R_{H D P E-M}^{2}=\left(\frac{Z_{H D P E}-Z_{M}}{Z_{H D P E}+Z_{M}}\right)^{2}
$$

where $\mathrm{R}_{\text {HDPE-M }}^{2}$ is the reflected intensity. $\mathrm{Z}$ is the acoustic impedance of the material and the index $\mathrm{M}$ refers to the different metals.

The ultrasonic energy reflected at HDPE and metal interface is calculated by the following equation Eq 3.6:

$\mathrm{E}_{\mathrm{R}}=\mathrm{E}_{0} \mathrm{R}_{\mathrm{HDPE}-\mathrm{M}}^{2}$

$E_{0}$ is the original energy input in the embossing process $\left(E_{0}=500 \mathrm{~J}\right)$

To simplify the estimation, only three interfaces are considered:

1) $\mathrm{R}_{\mathrm{Al}-\mathrm{HDPE}}^{2}$ : reflection intensity at the interface of Al sonotrode and polymer;

2) $R_{\text {HDPE-M }}^{2}$ : reflection intensity at the interface of HDPE to the embossing tool;

3) $\mathrm{R}_{\mathrm{M}-\mathrm{Al}}^{2}$ : reflecting intensity at the interface of embossing tool and Al anvil.

In the same way as the density, the acoustic impedance of HDPE $\left(Z_{\mathrm{HDPE}}\right)$ is a function of temperature. According to Eq 3.7 [47] the acoustic impedance was calculated from Young's modulus $\mathrm{E}$ and density $\rho$.

$Z=\sqrt{E \rho}$ 
Young's modulus of HDPE ( $\mathrm{E}_{\mathrm{HDPE}}$ ) reduces with increasing temperature due to the contracted molecules in chains [56]. This reduction induces the $\mathrm{Z}_{\mathrm{HDPE}}$ decrement as well. As far as it has been investigated in [57], at $90^{\circ} \mathrm{C} \mathrm{E}_{\mathrm{HDPE}}$ is reduced to $0.155 \mathrm{GPa}$ which is used here to replace $\mathrm{E}_{\mathrm{HDPE}}$ at $130^{\circ} \mathrm{C}$. Thus, from Eq 3.4 and $\mathrm{Eq}$. $7 \mathrm{Z}_{\mathrm{HDPE}}$ at $130^{\circ} \mathrm{C}$ is $0.349 \times 10^{6} \mathrm{~kg} /\left(\mathrm{s} \cdot \mathrm{m}^{2}\right)$.

The reflection intensity at the interfaces occurring in the experiments has been calculated as shown in Table 3.5.

The ultrasound is reflected at the interface of sonotrode and polymer to $92.2 \%$ and transmitted to $7.8 \%$. These $7.8 \%$ are reflected at the interface of polymer and tool to approximately $95 \%$. As a consequence, $7.8 \%$ of the ultrasound emitted from the sonotrode are reflected back at the interface of polymer and tool and then again at the interface of polymer and sonotrode. Thus, it is reflected back and forth through the polymer until it is absorbed at one of the interfaces (between polymer layers or between polymer and sonotrode or tool) or lost when transferred off the polymer into sonotrode or tool. As a result, nearly $7.8 \% \times 500 \mathrm{~J}=$ $39 \mathrm{~J}$ of the emitted ultrasound energy are available to generate friction between the polymer layers of the stack. The comparison with Table 3.4 shows that the available energy is enough for melting the polymer.

The larger the reflection at the surface of the tool, the more ultrasonic energy is available for polymer melting. Therefore, a tool from nickel appears being a bit better than a tool from aluminum as $R_{N i-H D P E}^{2}$ is largest in Table 3.5. Besides, the friction coefficient between the (molten) polymer and the tool material may also have a significant influence.

The ultrasonic energy transferred through the tool and arriving at the thermocouple is approximately calculated by $\mathrm{Eq} 3.8$ as the product of the energy transmitted through polymer and tool:

$$
\mathrm{E}_{\mathrm{Th}}=\left(1-\mathrm{R}_{\mathrm{Al}-\mathrm{HDPE}}^{2}\right)\left(1-\mathrm{R}_{\mathrm{HDPE}-\mathrm{Tool}}^{2}\right) \times 500 \mathrm{~J}
$$

The above equation does not take into account that ultrasonic energy is absorbed by friction at the various interfaces and inside of the materials, but, since in all experiments the same polymer and anvil have been employed, at least the trend of the calculated transferred Table 3.5: Reflection intensity at several interfaces

\begin{tabular}{l|l}
\hline Interfaces & $\begin{array}{l}\text { Reflection } \\
\text { intensity } \mathrm{R}^{2}\end{array}$ \\
\hline $\mathrm{R}_{\mathrm{Al}-\mathrm{HDPE}}^{2}$ & 0.922 \\
$\mathrm{R}_{\mathrm{HDPE}-\mathrm{Al}}^{2}$ & 0.922 \\
$\mathrm{R}_{\mathrm{HDPE}-\mathrm{Ni}}^{2}$ & 0.972 \\
$\mathrm{R}_{\mathrm{Ni}-\mathrm{Al}}^{2}$ & 0.235 \\
$\mathrm{R}_{\mathrm{HDPE}-\mathrm{St} 235 \mathrm{~J}}^{2}$ & 0.966 \\
$\mathrm{R}_{\mathrm{HDPE}-\mathrm{St} 1.2343 \mathrm{R}}^{2}$ & 0.966 \\
$\mathrm{R}_{\mathrm{St} 235 \mathrm{~J}-\mathrm{Al}}^{2}$ & 0.161 \\
$\mathrm{R}_{\mathrm{St} 1.2343-\mathrm{Al}}^{2}$ & 0.164 \\
\hline
\end{tabular}
similar as the one of the maximum temperatures measured with the thermocouple.

The expected trend is found in Table 3.6 although the different temperatures of the two steel tools are not reflected in the calculated energies. The Al tool had the highest temperature, indicating more energy arriving at the thermocouples and less energy being used for embossing, which is corresponding to the smaller structure height $\mathrm{H}_{1}$

The comparison with the structure heights is in contradiction to the interpretation for the steel tools of the experiment. The comparatively large structure height achieved with St235JR cannot be explained because the maximum temperature of $125^{\circ} \mathrm{C}$ 
measured at the thermocouple indicates that less energy is reflected at the tool than in the case of St1.2343 which corresponding to a smaller structure height $\mathrm{H}_{1}$.

Table 3.6: Comparison of calculated ultrasonic energy arriving at the thermocouple, measured maximum temperature, and structure heights.

\begin{tabular}{l|l|l|l}
\hline $\begin{array}{l}\text { Material of the } \\
\text { embossing tool }\end{array}$ & $\begin{array}{l}\text { Energy arriving at } \\
\text { the thermocouple }\end{array}$ & $\begin{array}{l}\text { Measured maximum } \\
\text { temperature }\end{array}$ & $\begin{array}{l}\text { Structure height } \\
\mathrm{H}_{1}\end{array}$ \\
\hline $\mathrm{Al}$ & $3.04 \mathrm{~J}$ & $131^{\circ} \mathrm{C}$ & $94.7 \%$ \\
$\mathrm{Ni}$ & $1.09 \mathrm{~J}$ & $101^{\circ} \mathrm{C}$ & $97.7 \%$ \\
$\mathrm{St235JR}$ & $1.33 \mathrm{~J}$ & $125^{\circ} \mathrm{C}$ & $99 \%$ \\
$\mathrm{St} 1.2343$ & $1.33 \mathrm{~J}$ & $115^{\circ} \mathrm{C}$ & $97 \%$ \\
\hline
\end{tabular}

\subsubsection{Anvil influence on embossed HDPE}

To investigate the anvil influence on ultrasonic hot embossing, $\mathrm{H} 1$ (cf. Figure 3.5) was also measured after ultrasonic hot embossing at an embossing energy of $500 \mathrm{~J}$. In this case, three anvils, $70 \mathrm{~mm}, 90 \mathrm{~mm}$, and $20 \mathrm{~mm}$ in width, length, and thickness, respectively, from Al, St235JR and PVC, respectively, (cf. Figure 3.9) were produced and tools from $\mathrm{Al}, \mathrm{Ni}$, or St235JR were glued with double-sided tape (Scotch) on top to accomplish ultrasonic hot embossing. But the temperature measurement on the anvil was not carried out. The structure heights $(\mathrm{H} 1)$ of embossed HDPE are shown in Figure 3.5. The filling percentage of HDPE and the theoretically reflection intensity of two interfaces $R_{\text {Tool-Anvil }}^{2}$ are calculat-

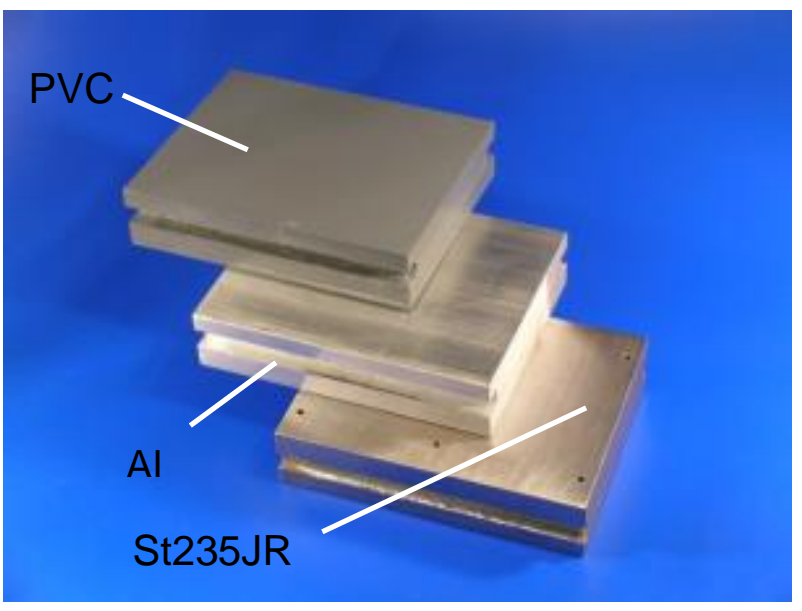

Figure 3.9: Anvils for ultrasonic hot embossing from three materials. ed by Eq 3.5 and listed in Table 3.7. 

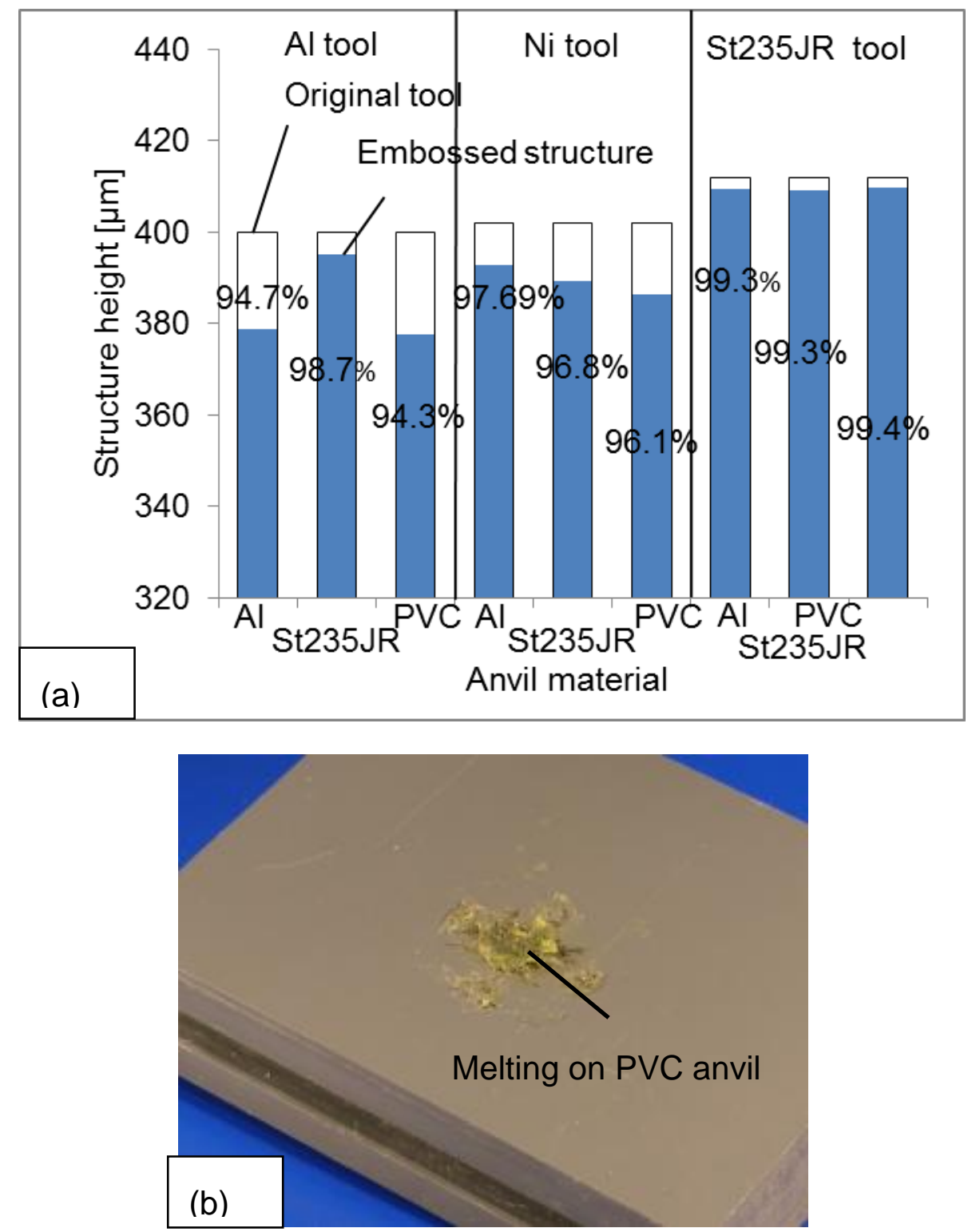

Figure 3.10: (a) Structure height $H_{1}$ measured from different embossing tools and anvils and (b) melting on the PVC anvil.

The analysis of the heights of the micro structures obtained by ultrasonic hot embossing with different tools illustrate that when the reflection intensity is larger, more embossing energy appears being reflected back to melt the polymer, resulting in a better degree of filling of the tool, and this phenomenon was confirmed for the Al tool (cf. Figure 3.7). However, this trend did not suit to the measurements with different anvils. When the Al tool and the St235JR tool were combined with the same anvil material, the filling degree of HDPE is not smaller at all, even though the reflecting intensity of them is theoretically zero. The acoustic impedance of PVC, $Z_{P V C}$ at $25^{\circ} \mathrm{C}$ is $3.27 \times 10^{6} \cdot \mathrm{kg} /\left(\mathrm{s} \cdot \mathrm{m}^{2}\right)$. Thus, the $R_{\text {Tool-PVC }}^{2}$ is larger compared to other interfaces (cf. Table 3.7). But the advantage of $R_{\text {Tool-PVC }}^{2}$ was not proven as the filling HDPE degree of the PVC anvil was not obviously higher compared to the Al and St235JR anvil. Besides, the double-side tape employed between the tool and the anvil may affect the ultrasound transmitting as well. Ultrasound could be reflected 
and trensmitted at the interface of tape and the anvil. This influence was ignored before and could be investigated later.

The PVC anvil was melted when too much embossing energy was used. Figure 3.10 b shows the melting spots on the PVC surface after several trying. Because of the inferior thermo conductivity of PVC, the gathering heat increased the temperature inside PVC over the glass transition temperature, which is only $81^{\circ} \mathrm{C}$ and the melting were induced.

Table 3.7: Filling degree and calculated reflection intensity for different tools and anvils.

\begin{tabular}{|c|c|c|c|c|c|c|c|c|c|}
\hline \multirow{2}{*}{$\frac{\text { Tool }}{\text { Anvil }}$} & \multicolumn{3}{|l|}{$\mathrm{Al}$} & \multicolumn{3}{|l|}{$\mathrm{Ni}$} & \multicolumn{3}{|c|}{ St235JR } \\
\hline & $\mathrm{Al}$ & $\begin{array}{l}\text { St235J } \\
R\end{array}$ & PVC & $\mathrm{Al}$ & $\begin{array}{l}\text { St235J } \\
R\end{array}$ & PVC & $\mathrm{Al}$ & $\begin{array}{l}\text { St235J } \\
R\end{array}$ & PVC \\
\hline $\begin{array}{l}\text { Filling } \\
{[\%]}\end{array}$ & 94.7 & 98.7 & 94.3 & 97.69 & 96.8 & 96 & 99.3 & 99.3 & 99.4 \\
\hline $\mathrm{R}_{\text {Tool-Anvil }}^{2}$ & 0 & 0.161 & 0.466 & 0.235 & 0.001 & 0.769 & 0.161 & 0 & 0.724 \\
\hline
\end{tabular}

It could had been that the anvil or the tool were uneven or tilted affecting the measurement results. Therefore, the arrangement direction of the anvil was also turned by $90^{\circ}$ as shown in Figure $3.11 \mathrm{a}$. The embossed structure heights $\mathrm{H}_{1}$ from both arrangements were measured and compared in Figure 3.11 and there is no big difference of embossed structure heights between the two anvil arrangements. Thus, the influence from anvil direction could be neglected. From Table 3.6, the energy arriving at the thermocouple, which is also the interface between embossing tool and anvil, are small. And it is supposed that the anvil has only a small effect on the embossing result.
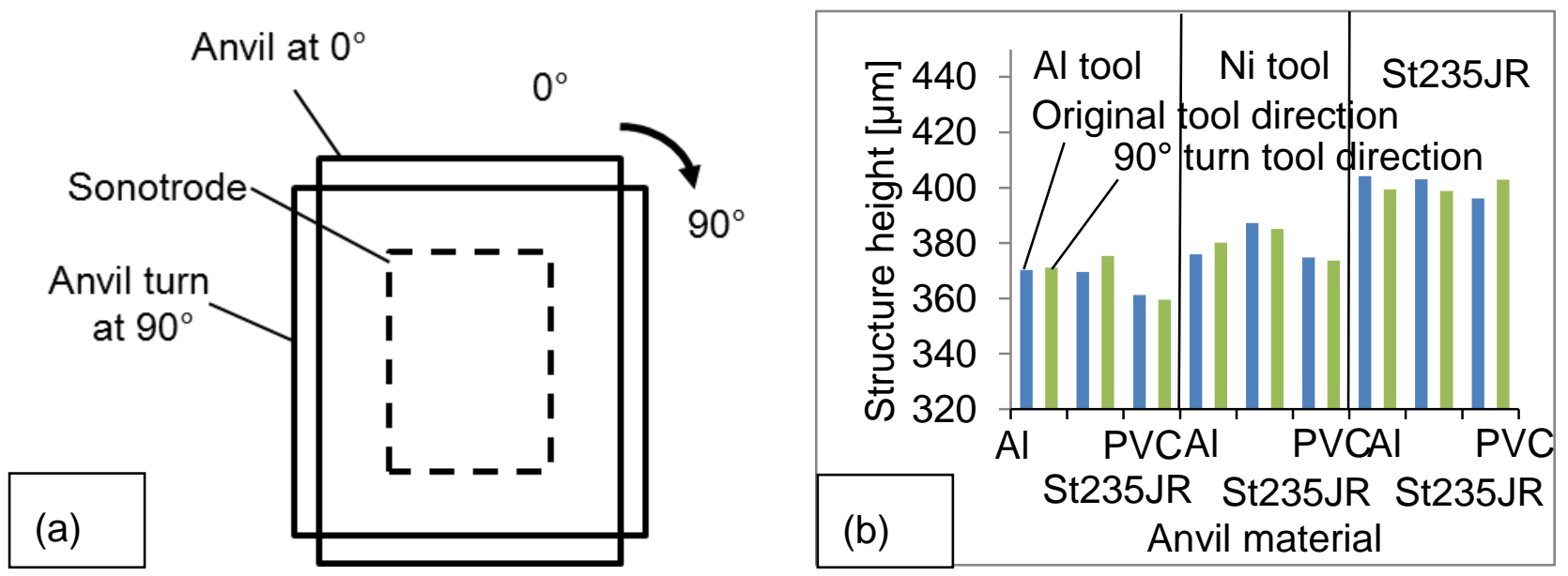

Figure 3.11: (a) Schematic drawing of two types anvil arrangements (b) embossed structure dimension comparison of two types anvil arrangements.

\subsubsection{Concludsions}

According to theoretical considerations, the ultrasound transferred into the polymer stack between sonotrode and tool is reflected back and forth until it is either absorbed 
at the interfaces of polymer and tool or sonotrode or the interfaces of the polymer layers, or it is transferred into tool or sonotrode. Therefore, the energy available for melting the polymer is maximized by small reflection of the ultrasound at the interface of sonotrode and polymer and large reflection at the interface of polymer and tool.

From this point of view, it appears being best employing a material with a large difference in acoustic impedance compared to the polymer such as nickel or steel for the tool and a material with small difference in acoustic impedance to polymer for the sonotrode such as Al. This interpretation is supported by the fact that more acoustic energy was measured transferred through a tool from aluminum than through a tool from nickel or steel. More specific, Al is suitable for being sonotrode while nickel and steel are more for embossing tool. The anvil's influence on embossing result is less than from the embossing tool.

In the light of best embossing results, $\mathrm{Al}$ is not as suitable as nickel or steel for the tool. On the other hand, the disadvantage due to employing Al for the tool can be compensated with enhanced ultrasonic energy and aluminum can be milled much easier than nickel or steel. However, it has been observed that other effects such as the friction coefficient between polymer and tool and the heat capacity of the tool also influence the embossing result as well, which is discussed by applying polymer materials as ultrasonic hot embossing tools.

\subsection{Embossing tools from aluminum and polymers}

Embossing tools not only from metal but also from polymers were also investigated. Heat capacity, thermal conductivity and melting temperature of the polymer are typical parameters which may influence the polymer's performance as an embossing tool. Besides, hardness, tensile strength, and toughness are expected to influence the embossing tool's quality as well. There are no concrete conclusions to define which property is the most important as the whole embossing process is combined with pressure-heating fields. Thus the elementary evaluations from Al and polymer tools for ultrasonic hot embossing were carried out here.

\subsubsection{Embossing tool preparation}

The positioning of the temperature sensor was different from the one described in Chapter 3.2.2. One end of the $\kappa$-type temperature sensor was inserted inside the tool instead of laying it under the tool, $0.5 \mathrm{~mm}$ away from the top of the surface while the other end was connected to a computer to record temperature changing. To improve the heat conductivity between thermo couple and embossing tool, thermal conductive paste (Wakefield) was coated around the inserted end of the thermocouples. As polymer and metal are in two completely different categories, it was interesting to observe their performance during ultrasonic hot embossing. Two different common polymers were selected: PEEK and PC according to their comparably higher melting temperature than other polymers. Holes arrays with diameter, height and interval of $1 \mathrm{~mm}, 0.35 \mathrm{~mm}$ and $2 \mathrm{~mm}$, respectively, were milled into the surfaces of the tools. The embossing tools from polymer and Al were $14 \mathrm{~mm}$ in diameter and $4 \mathrm{~mm}$ in thickness. From aluminum $10 \mathrm{~mm}$ thick tools were also produced, shown in Figure 3.12. In Figure $3.12 \mathrm{~b}$, there are some embossing tools with a recess milled into the backside, the function of which is mentioned later. All of the embossing tools were 
produced by a Datron milling machine (M7 HP) with a milling time of 2.5 min for PEEK and PC and 7 min for Al.

The embossed polymer was also HDPE, four layers with a total thickness of $600 \mu \mathrm{m}$. Some typical physical parameters of AI, PEEK, PC and HDPE are listed in Table 3.8.Table

The embossing parameters are shown in Table 3.9. Temperature measurements started at $2 \mathrm{~s}$ before embossing and lasted for $60 \mathrm{~s}$. The same Lab VIEW program was used as the one described in Chapter 3.2.2.
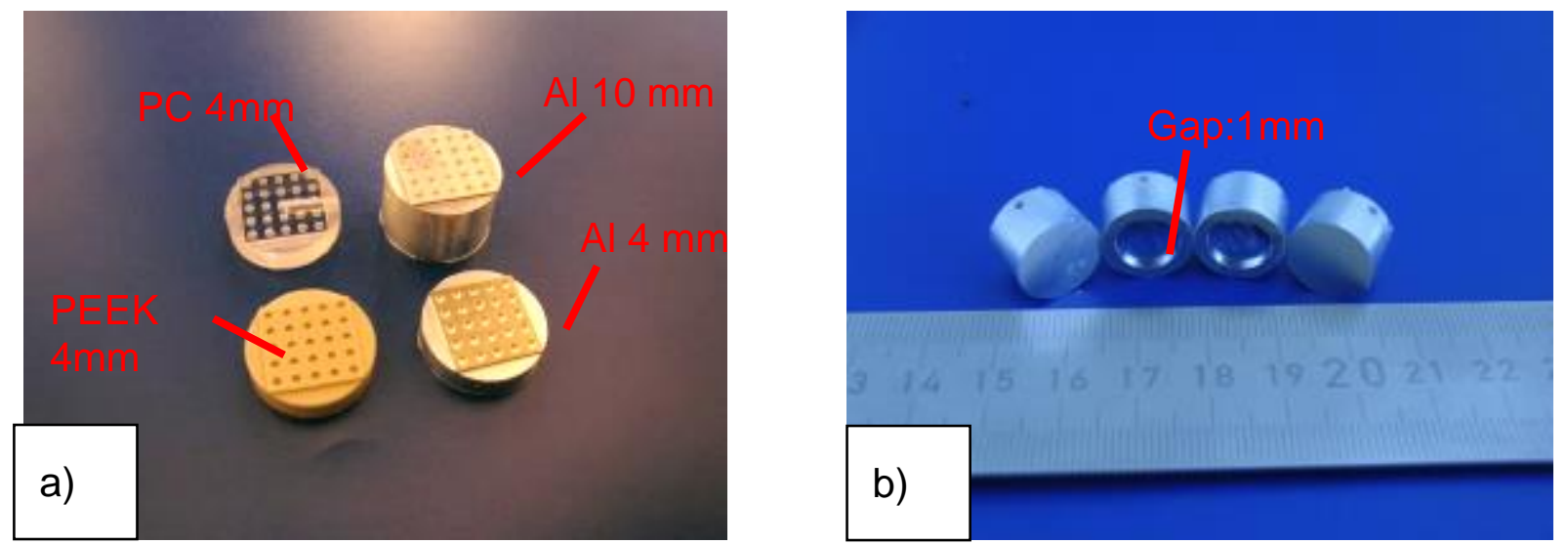

Figure 3.12: (a) Tools from PEEK, PC and Al; (b) recesses milled into the backsides of Al tools.

Table 3.8: Properties of aluminum, PEEK, PC, and HDPE [23, 58-62].

\begin{tabular}{l|l|l|l|l|l}
\hline Materials & $\begin{array}{l}\text { Thermal } \\
\text { conductivity } \\
\kappa \text { at } 25^{\circ} \mathrm{C} \\
{[\mathrm{W} /(\mathrm{m} \cdot \mathrm{K})]}\end{array}$ & $\begin{array}{l}\text { Specific heat } \\
\text { capacity c at } \\
25^{\circ} \mathrm{C} \\
{[\mathrm{J} /(\mathrm{g} \mathrm{K})]}\end{array}$ & $\begin{array}{l}\text { Melting } \\
\text { temperature } \\
\mathrm{T}\left[{ }^{\circ} \mathrm{C}\right]\end{array}$ & $\begin{array}{l}\text { Acoustic } \\
\text { impedance } \mathrm{Z} \\
\text { at } 250^{\circ} \mathrm{C} \\
{\left[10^{6} \cdot \mathrm{kg} /\left(\mathrm{s} \cdot \mathrm{m}^{2}\right)\right]}\end{array}$ & $\begin{array}{l}\text { Density } \rho \\
\text { at } 25^{\circ} \mathrm{C} \\
{\left[\mathrm{g} / \mathrm{cm}^{3}\right]}\end{array}$ \\
\hline Aluminum & 205 & 0.9 & 659 & 17.33 & 2.7 \\
PEEK & 0.25 & 1.15 & 334 & 3.29 & 1.32 \\
PC & 0.21 & 1.17 & 220 & 2.67 & 1.21 \\
HDPE & $0.38-0.51$ & $2.1-2.7$ & 130 & $2.33 / 0.349$ at & $0.94-0.97$ \\
\hline
\end{tabular}

Table 3.9: Embossing parameters of aluminum, PEEK, and PC tools.

\begin{tabular}{l|l|l}
\hline Embossing energy [J] & 100 & 300 \\
\hline Embossing tool & PEEK, PC, Al $(4 \mathrm{~mm})$ & $\mathrm{Al}(4 \mathrm{~mm}), \mathrm{Al}(10 \mathrm{~mm})$ \\
\hline Other parameters & $\begin{array}{l}\text { Embossing force: } 220 \mathrm{~N}, \text { vibration amplitude: } 16.3 \mu \mathrm{m}, \\
\text { cooling time: } 1000 \mathrm{~ms}\end{array}$ \\
\hline
\end{tabular}




\subsubsection{Polymer tools and Al tool influence on HDPE}

The embossed structures were pillar arrays. A profilometer (Bruker Dektak XT) and a microscope (Keyence) were used to measure the single pillar profiles shown in Figure 3.13. The differences of embossing results obtained with Al and polymer tools are noticeable. The pillar cross-sections of embossed HDPE from the Al tool fit better to the original embossing tool than the PEEK and the PC tool. There were some hollow parts in the middle of embossed pillars from PEEK and PC tool as shown in Figure 3.13).
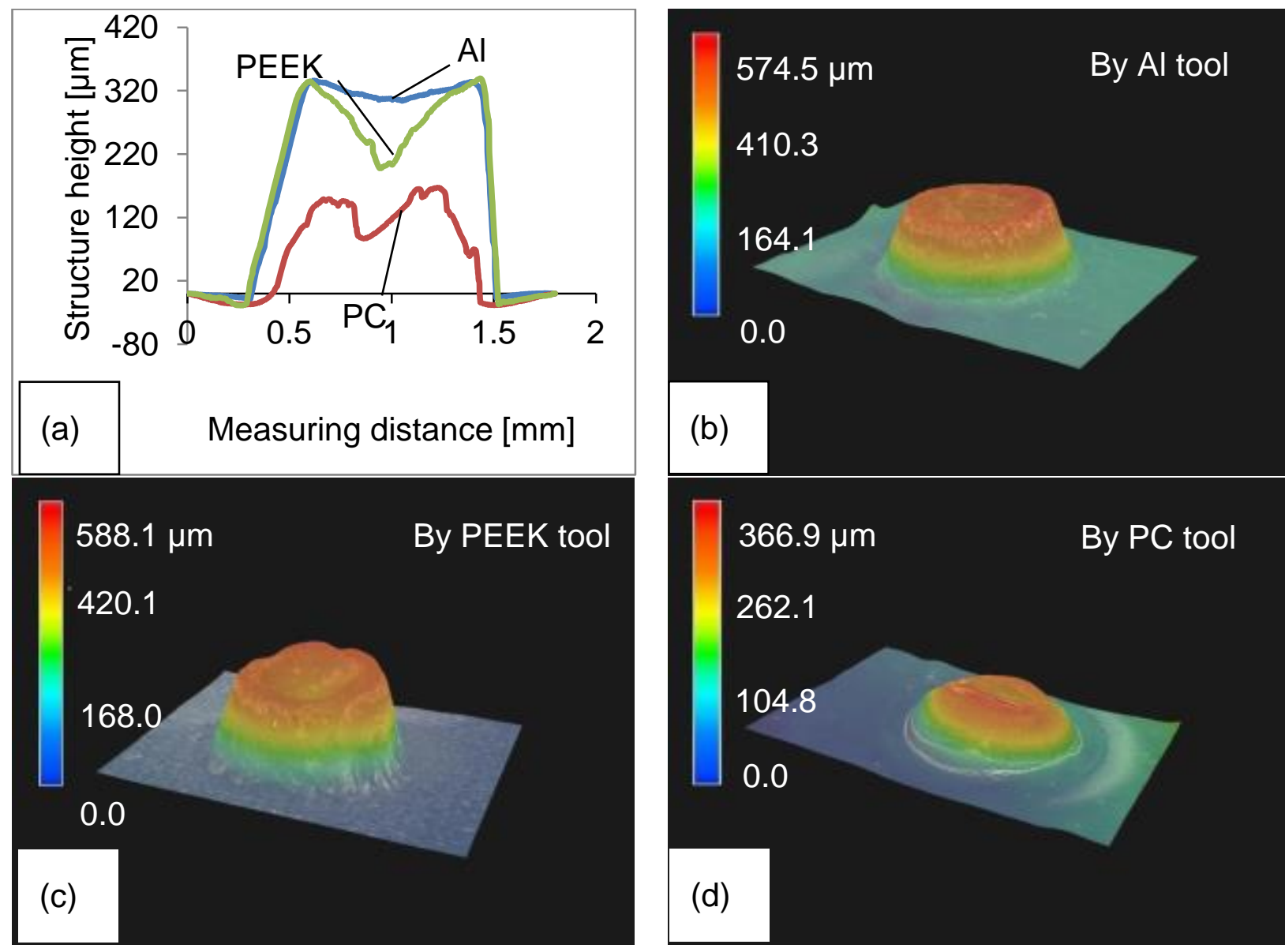

Figure 3.13: (a) profile measurement of HDPE embossed from PEEK, PC and Al tools; (b) pillar embossed from Al tool; (c) pillar embossed from PEEK tool; (d) pillar embossed from PC tool.

The temperature changes in one ultrasonic hot embossing cycle with an embossing energy of $100 \mathrm{~J}$ as a function of tool materials were recorded and are shown in Figure 3.14. The peak temperatures of the three tools are close while the cooling is slower for PEEK and PC tools.

The specific heat capacity c represents the material's ability of preserving heat and can be used to explain the tool's performance in ultrasonic hot embossing. An index $\mathrm{R}$ is defined by Eq.3. 9:

$\mathrm{R}=\mathrm{c} \times \rho$ 
c is the specific heat capacity and $\rho$ is the material density. Since the three tools have identical volume, $\mathrm{R}$ is proportional to the energy required for heating up the tool by $1^{\circ} \mathrm{C}$. When $\mathrm{R}$ is larger, more energy is required for heating up. Here $\mathrm{c}$ is considered to be constant while $\rho$ of the polymer is a function of temperature. At $60^{\circ} \mathrm{C}$, the density of PEEK would reduce to be 1.26 $\mathrm{g} / \mathrm{cm}^{3}$ [63] while the density of PC keeps constant at $1.21 \mathrm{~g} / \mathrm{cm}^{3}$ [64]. The calculation results of $\mathrm{R}$ for the three tools are listed in Table 3.10. It is found that $\mathrm{R}_{\mathrm{Al}}$ is larger than $\mathrm{R}_{\mathrm{PEEK}}$ and $\mathrm{R}_{\mathrm{PC}}$ indicating that more energy is need to heat up the Al tool. This fits to the temperature measurements in Figure 3.14 where at the same output energy, the temperature of the Al tool and PEEK tool is a bit lower than at the PC tool. But in contradiction, the temperature of the PEEK tool is even a bit lower than the one of the Al tool.

Table 3.10: $\mathrm{R}$ calculation of three materials.

\begin{tabular}{l|l|l|l}
\hline Material & Al & PEEK & PC \\
\cline { 1 - 1 } $\mathrm{R}=\mathrm{c} \times \rho\left[\mathrm{J} /\left(\mathrm{K} \times \mathrm{m}^{3}\right)\right]$ & 2.43 & 1.45 & 1.42 \\
\cline { 1 - 1 } Measured maximum temperature $\left[{ }^{\circ} \mathrm{C}\right]$ & 58.6 & 55.9 & 60.9 \\
\hline
\end{tabular}

The ultrasonic vibrating time and rising time of the thermocouple are listed in Table 3.11. Similar as in Table 3.2, the vibrating time is less than the temperature rising time of the thermocouple indicating that the heat generated by the ultrasound in the surrounding of the thermocouple kept warming up the thermo couple after the end of the embossing process. Especially the time difference for PEEK and PC tool were $0.33 \mathrm{~s}$ and $0.53 \mathrm{~s}$, respectively, which is longer than for the Al tool $(0.15 \mathrm{~s})$, maybe, due to the lower heat conduction of the polymer. Equation 3.2 was employed again to fit the temperature falling curve according to Figure 3.14 and the time constant $\tau_{1}$ and $\tau_{2}$ are listed in Table 3.12 with a calculation accuracy of $1 \mathrm{~s}$. The interpretation in Chapter 3.2.4 that $\tau_{2}$ is larger than $\tau_{1}$ also fits to explain the $\tau$ difference here. Obviously $\tau_{2}$ for polymer is larger than $\tau_{2}$ for metal as the polymer's inferior thermal conductivity. But this is no explanation when comparing with PEEK and PC. The temperature decreasing rate of PEEK is less than the one of PC but their thermal conductivities are nearly the same. 
Table 3.11: Rising time of thermal couple and the ultrasonic vibrating time.

\begin{tabular}{lccc}
\hline Embossing tool & PC & PEEK & Al \\
Rising time of thermocouple [s] & 0.81 & 0.61 & 1.65 \\
Ultrasonic vibrating time [s] & 0.28 & 0.28 & 1.5 \\
Time difference [s] & 0.53 & 0.33 & 0.15 \\
\hline
\end{tabular}

Table 3.12: Time constants determined by a fit to the temperature measurements compared to the thermal conductivity of the polymer and Alutool.

\begin{tabular}{cccc}
\hline Tool material & $\tau_{1}( \pm 1)[\mathrm{s}]$ & $\tau_{2}( \pm 1)[\mathrm{s}]$ & Thermal conductivity at $25^{\circ} \mathrm{C}[\mathrm{W} /(\mathrm{m} \mathrm{K})]$ \\
\hline Al & 8 & 18 & 205 \\
PC & 22 & 70 & 0.21 \\
PEEK & 48 & 45 & 0.25 \\
\hline
\end{tabular}

Material acoustic impedance appears to affect the tool performance. The reflecting intensity of the interfaces was again calculated employing Eq. 3.5 to identify the reflection intensity between HDPE and polymer tools. Similar as in Chapter 3.3.4, the reflection intensity at interfaces occurring in the experiments has been calculated and listed in Table 3.13.

The ultrasonic energy transferred into the tool and arriving at the thermocouple is approximately calculated by Eq 3.10 as the product of the energy transmitted through polymer and tool without consideration of energy consumption in the polymer layers and other energy loss at the interfaces:

$$
\mathrm{E}_{\mathrm{Th}}=\left(1-\mathrm{R}_{\mathrm{Al}-\mathrm{HDPE}}^{2}\right)\left(1-\mathrm{R}_{\mathrm{HDPE}-\mathrm{Tool}}^{2}\right) \times 100 \mathrm{~J}
$$

The calculated ultrasonic energy arriving at the thermo-

Table 3.13: Reflection intensity at several interfaces

\begin{tabular}{ll}
\hline Interfaces & $\begin{array}{l}\text { Reflection } \\
\text { intensity } \mathrm{R}^{2}\end{array}$ \\
\hline $\mathrm{R}_{\mathrm{Al} \text {-HDPE }}^{2}$ & 0.922 \\
$\mathrm{R}_{\mathrm{HDPE}-\mathrm{Al}}^{2}$ & 0.922 \\
$\mathrm{R}_{\mathrm{HDPE}-\mathrm{PC}}^{2}$ & 0.591 \\
$\mathrm{R}_{\mathrm{HDPE}-\mathrm{PEEK}}^{2}$ & $0.653(10)$
\end{tabular}
couple was calculated and listed in Table 3.14. The energy arriving at thermocouple of the $\mathrm{Al}$ tool is less than the one arriving at the PC and PEEK tool. Thus more energy has been reflected back to the interface of Al-HDPE and the tool temperature is reduced, which are similar as discussed in Chapter 3.2.4. 
Table 3.14: Comparison of calculated ultrasonic energy arriving at the thermocouple and measured maximum temperature.

\begin{tabular}{l|l|l}
\hline $\begin{array}{l}\text { Material of the } \\
\text { embossing tool }\end{array}$ & $\begin{array}{l}\text { Energy arriving at the } \\
\text { thermocouple }\end{array}$ & Measured maximum temperature \\
\hline $\mathrm{Al}$ & $0.06 \mathrm{~J}$ & $58.57^{\circ} \mathrm{C}$ \\
$\mathrm{PC}$ & $3.19 \mathrm{~J}$ & $60.89^{\circ} \mathrm{C}$ \\
PEEK & $2.7 \mathrm{~J}$ & $55.85^{\circ} \mathrm{C}$ \\
\hline
\end{tabular}

According to Table 3.14 and Figure 3.14, $\mathrm{R}_{\mathrm{HDPE}-\mathrm{Al}}^{2}$ is the largest (0.922), indicating more energy is reflected at the Al-HDPE interface helping to melt the HDPE and correspondingly the tool temperature is smallest. Oppositely, $\mathrm{R}_{\mathrm{HDPE}-\mathrm{PC}}^{2}$ is smallest (0.591), leading to more energy transferred into the PC tool. Thus, the tool temperature increases and less energy is contributing to melting. When the temperature is rising over the tool melting temperature, structures on the tool deform indicating that the polymer is damaged. However, this trend is not obvious in the PEEK-HDPE interface. The energy arriving at the thermo couple in the PEEK was larger than in Al, yet the peak temperature is less than for the Al tool and the embossed structure was also more damaged than from the Al tool.

In the embossing procedure, heat disperses into air or the embossing tool and anvil. On the one hand, the tool volume is proportional to its heat capacity. On the other hand, if the heat conducting path is blocked, the temperature of the embossing tool is supposed to rise up. To prove these effects, two designs were set up: type 1, changing the tool volume and type 2, hindering the heat conducting path. For type 1 , tools from Al with two different thicknesses $(4 \mathrm{~mm}$ and $10 \mathrm{~mm}$ ) were produced (cf. Figure $3.12 \mathrm{~b}$ ). In type 2 , because air and polystyrene (PS) have relatively low thermal conductivity: 0.025 and $0.16 \mathrm{~W} /(\mathrm{m} \cdot \mathrm{K})$ at $25^{\circ} \mathrm{C}$, they are supposed to affect the heat transferring from the Al tool to the anvil surface. Thereby, two nonconductive methods were designed: 1: an air gap, $10 \mathrm{~mm}$ and $1 \mathrm{~mm}$ in diameter and depth, respectively, had been milled into the bottom of a $10 \mathrm{~mm}$ high Al embossing tool, cf. Figure 3.12 b; 2: a rectangular PS foil with $40 \mathrm{~mm} \times 400 \mathrm{~mm}$ and $50 \mu \mathrm{m}$ thickness was isolating between embossing tool and anvil. For comparison of these tools the same HDPE foils were ultrasonically hot embossed at $300 \mathrm{~J}$ embossing energy.

The profile of a single embossed pillar from $4 \mathrm{~mm}$ and $10 \mathrm{~mm}$ high Al tools, $10 \mathrm{~mm}$ high tool with an air gap at the backside, and $10 \mathrm{~mm}$ high tool with a PS foil between tool and anvil were measured and are shown in Figure 3.15. The profiles of all pillars are more or less identical, showing that $300 \mathrm{~J}$ are enough for embossing these structures

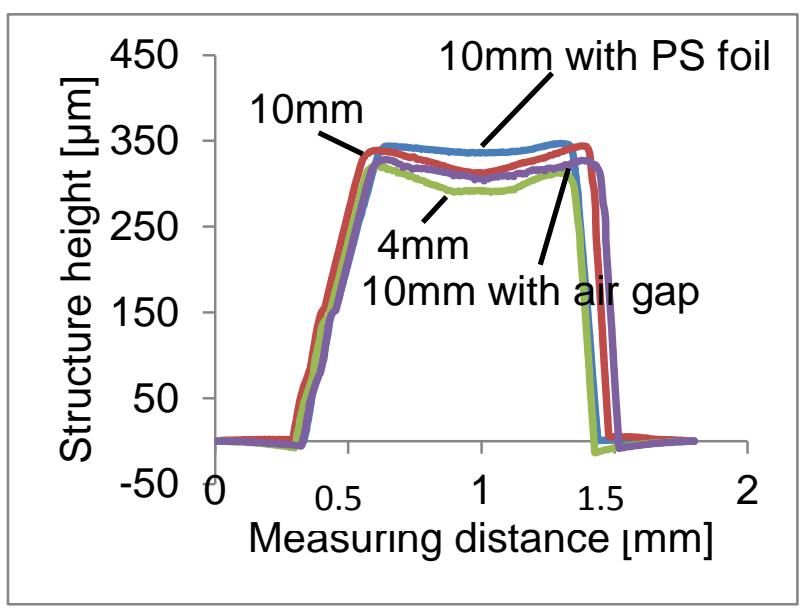

Figure 3.15: Profile measurement. 
on the above tools.

The results of the temperature measurements in the embossing tools, $4 \mathrm{~mm}$ and $10 \mathrm{~mm}$ in height, respectively, with and without gap is shown in Figure 3.16. Two results were obtained; 1 : the temperature of the $4 \mathrm{~mm}$ high Al tool had a higher peak temperature and it reduced faster than the one of the $10 \mathrm{~mm}$ high tool, cf. Figure 3.17 a. This is due to the difference in volume and, as a consequence, in heat capacity. 2: the temperature reducing rate of the $10 \mathrm{~mm}$ high $\mathrm{Al}$ tool is also smaller. By time constant calculation with equation $3.2, \tau_{1-4} \mathrm{~mm}$ and $\tau_{2-4 \mathrm{~mm}}$ are $9 \mathrm{~s}$ and $14 \mathrm{~s}$, respectively, while $\tau_{-10 \mathrm{~mm}}$ is $28 \mathrm{~s}$. The reason of the difference in cooling rates may be due to the longer way for heat dissipation to the anvil in the case of the $10 \mathrm{~mm}$ high tool.

However, the air gap at the back side of the tool has less influence on the temperature difference during embossing and cooling, cf. Figure $3.16 \mathrm{~b}$. The peak temperature of the Al tool with and without air gap are nearly the same and the cooling rate difference is small. Outside the air gap there is still a ring with contact to the anvil, which may be the reason why the air gap has only a small influence.
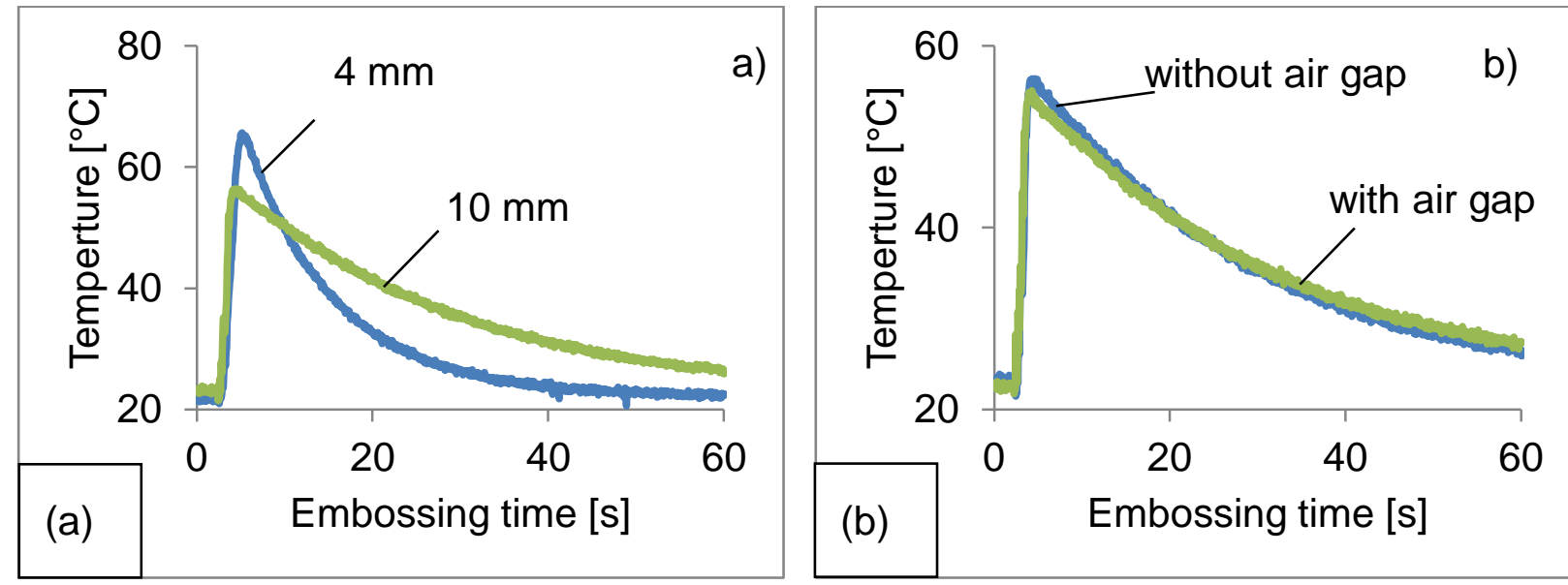

Figure 3.16: (a) Temperature measured in tools with different thicknesses; (b) temperature measured in tools with and without a gap on their backside.

The arrangement of the PS foils is shown in Figure 3.17 a and a comparison of tool temperature due to embossing with and without PS foil isolation is shown in Figure $3.17 \mathrm{~b}$. The temperature raising speed and peak values measured with and without PS foils are nearly the same, but the cooling rates difference is noticeable: the temperature in the Al tool with a PS foil was higher than without a PS foil. Time

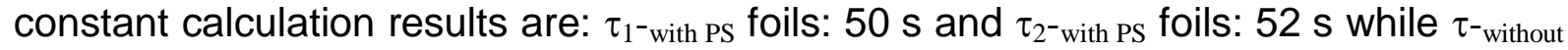
PS foils: $28 \mathrm{~s}$. It is confirmed that PS foils isolated heat from the embossing tool to the anvil, leading to the less heat dissipating rate. This difference also proves the poor heat conductivity of PS foils. 

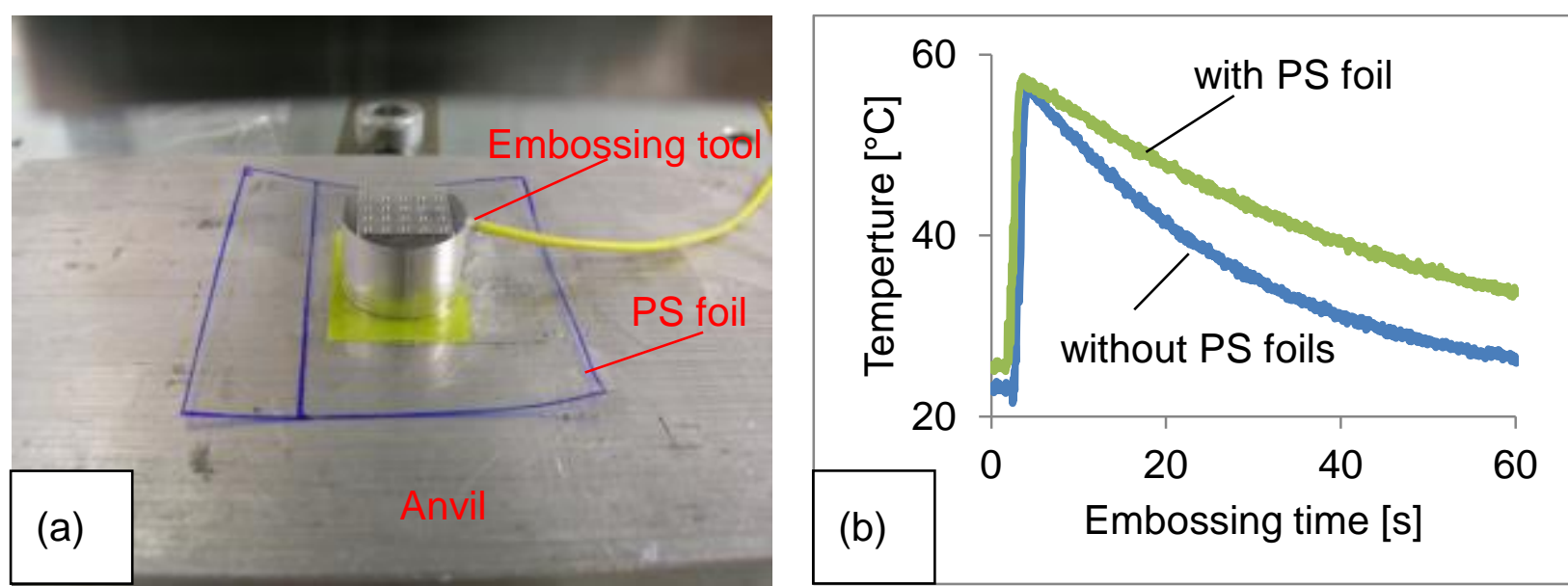

Figure 3.17: (a) PS foils arrangement under the embossing tool; (b) temperature comparison of tool with and without PS foils.

\subsubsection{Conclusions}

It is still under discussion which thermo parameter plays the key role in ultrasonic hot embossing. Perhaps it is better to conclude that these thermo properties of polymer tool would have composite influences on ultrasonic embossing result. The smaller $\mathrm{R}$ $=(c \times \rho)$ is, the higher temperature is achieved in the embossing tool. Larger heat conductivity leads to faster cooling after embossing of the tool. The larger the difference of acoustic impedance of embossing tool and embossing material are, the more energy is reflected back to the polymer and less tool temperature is measured at the interface to the tool. The thermo isolation between embossing tool and anvil blocks the heat loss of the embossing tool. This is beneficial for melting the polymer because the tool is heated up. But this is not the only factor influencing the embossing result. The volume of the embossing tool has less influence on the embossing result but affects the

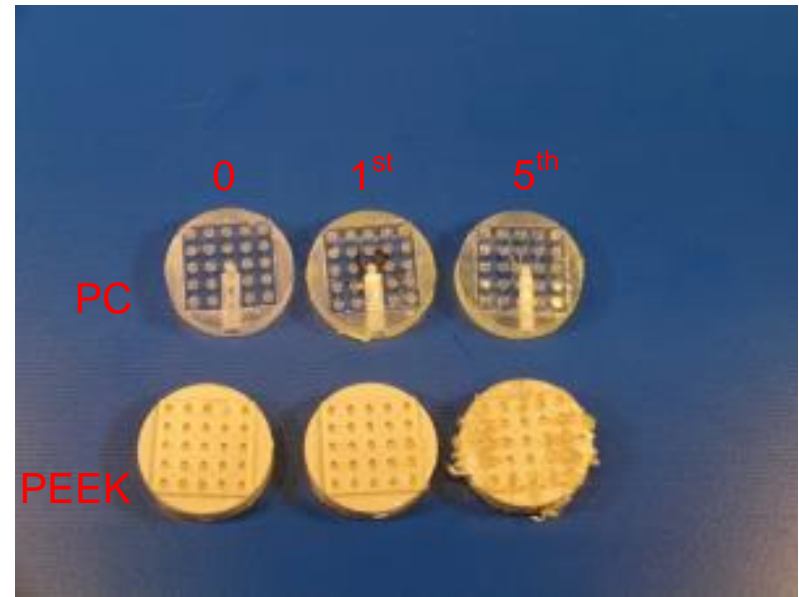

Figure 3.18: Embossing tool from PEEK and $P C$ before and after $1^{\text {st }}$ and $5^{\text {th }}$ embossing. tool's temperature and the cooling rate.

Worth to mention, polymers have comparably larger heat capacity and smaller heat conductivity than metals, thus in ultrasonic hot embossing, the tool temperature must be paid attention to not to exceed the tool melting temperature, or else the structures on it are melted too, leading to imprecision of embossed structures. The overheating may be one reason for failures in polymer tools e.g. the melting temperature of PC and PEEK are just $220^{\circ} \mathrm{C} \mathrm{PC}$ and $350^{\circ} \mathrm{C}$, which is much lower than that of metal. In fact, lifetimes of polymer tools are quite short, not above 5 times in our trying. Some structures deformation on polymer tools after one and five embossings are shown in Figure 3.18. When applying a metal tool, this temperature limit for normal ultrasonic hot embossing doesn't exist. 
Last but not the least, other reasons for failures of embossing tools may stem from the inferior tensile strength, hardness, inner stress and stiffness of polymer tools. In other aspects, polymer embossing tools still have other prospects, especially in nano imprinting for micro or nano structures replicating applications [65, 66]. Besides, they are relatively economical compared to metal. 


\section{Tool fabrication for ultrasonic hot embossing}

\subsection{Ultrasonic hot embossing tool description}

In ultrasonic hot embossing, vibrations are required for typically several hundred milliseconds up to several seconds as a function of the dimensions of the micro structures. The basic design rule of a tool for ultrasonic hot embossing is that the height of the protruding structures needs being large enough generating enough friction during ultrasonic vibrations. Therefore, some structures protruding typically more than $50 \mu \mathrm{m}$ are necessary in the near of all structures to be molded [16]. Comparatively large protruding structures in the near also allow filling of recesses and cavities in the tool. As a consequence, the design of the tool needs taking into account the generation of sufficiently much molten polymer.

Embossing quality depends on the one hand on the process parameters, e.g., embossing force and time; and on the other hand, the quality and the precision of the embossing tool. Cost of micro devices produced by ultrasonic hot embossing are due to mold fabrication and machine investment instead of polymers. Thus, how to reduce the expense of tool fabrication could be one consideration for optimizing the ultrasonic hot embossing process.

As a consequence of the process, tools for ultrasonic hot embossing should fulfill the following requirements:

1) Rigid enough to withstand the acting forces and temperatures;

2) Showing the inverse of the desired micro structures in the polymer and the protruding structures for producing friction;

3) Micro structures with dimensions between less than a micrometer and a few millimeters;

4) Patterned area not larger than the sonotrode;

5) Large heat conductivity and heat capacity.

Tools for ultrasonic hot embossing have similar requirements as tools for hot embossing [67], and, therefore, often many tools can be employed for both processes. Nevertheless, tool requirements for ultrasonic hot embossing are still a bit different from the ones of tools for hot embossing. Heat conductivity and capacity of the mold are not so important for hot embossing, because anyway the entire tool needs to be thermally cycled for that process. However, these two parameters investigated in Chapter 3 had confirmed their influence on tool performance in ultrasonic hot embossing. Besides this, unlike the tools for hot embossing or injection molding, the tool for ultrasonic hot embossing has no particular structures for ejector or anti-adhesion layers for demolding as the shrinkage of embossed polymer is less.

The techniques for tool fabrication include milling and drilling, laser ablation, x-ray lithography, electroplating, silicon etching, photolithography, and electro discharge machining. The fabrication process of these is discussed in this chapter in detail.

Tools from a lot of metals and metal alloys well comply with the requirements for ultrasonic hot embossing. Therefore, they are preferred materials for tool fabrication. The choice of the metal is influenced by the fabrication process employed for micro patterning. As far as being investigated, the options for ultrasonic hot embossing are less than for hot embossing and inject molding. For example, etched silicon wafers 
and soft materials (SU8 photoresist) have been applied as a mold in hot embossing $[68,69]$ but are less suitable for ultrasonic hot embossing.

\subsection{Ways of tool fabrication for ultrasonic hot embossing}

\subsubsection{Milling}

Milling and drilling with a CNC machine are comparatively cheap and a widely available processes for tool fabrication. At $\mathrm{KE} \mu$, the milling machines Kosy 3 A3 (Max Computer $\mathrm{GmbH}$, Germany) and Datron (M7 HP) are mainly used. Virtually every three-dimensional shape which can be embossed can be milled into the surface of a metal plate. Often plates from brass or aluminum (Al) are employed because they are a good compromise between the hardness desired for embossing and the comparatively soft metal suitable for milling. But the milling parameters, preparation and expenses of them are different. For a milling tool (vhf) with $2 \mathrm{~mm}$ head diameter, for example, $33 \mathrm{~mm} / \mathrm{s}$ and $12 \mathrm{~mm} / \mathrm{s}$ are applied as the feeding speed for St 235JR and Al, respectively. Besides, the coolant for milling Al and brass is basically ethanol while lubricant based coolant is required for steel.

A lowest surface roughness on the order of some $10 \mathrm{~nm}$ is achieved when a milling head from diamond is employed. Diamond milling heads also distinguish from hard metal heads by their long endurance allowing milling up to several $\mathrm{cm}^{2}$ with a single head if the sample does not contain any iron. This is an important advantage because adjusting a new milling head is typically entailed with alignment errors on the order of several micrometers resulting in a step of this size in the milled surface.

On the other hand, the smallest milling heads from diamond commercially available show a diameter of $100 \mu \mathrm{m}$, and thus, no narrower grooves can be milled into a sample and the minimum radius of concave corners cannot be smaller than the milling head. Milling heads from hard metal can be purchased with a diameter as small as $50 \mu \mathrm{m}$ but the achievable surface roughness of milled structures is on the order of $1 \mu \mathrm{m}$. Since demolding of micro structures fabricated by ultrasonic hot embossing is no problem compared to hot embossing and injection molding, from the fabrication point of view milling heads from hard metal are suitable. However, some applications such as optical components require surfaces with lower surface roughness.

Last but not least, the price for a milling head from hard metal, $100 \mu \mathrm{m}$ in diameter, from SPPW, is approximately $30 €$ while $500 €$ are asked for a head from diamond. For the tool with $2 \mathrm{~mm}$ head (SPPW), only $12 €$ need to be payed. Thus, micro milling of structures with dimensions of less than $100 \mu \mathrm{m}$ is both a challenge and expensive.

Besides metals and alloys, tools can be milled and drilled even from polymers with a high softening temperature, e.g., PEEK, which had been mentioned above. Manufacturing parameters need to be adapted to the properties of the polymer. By the Datron milling machine (M7 HP) a feeding speed of $110 \mathrm{~mm} / \mathrm{s}$ is used for polymers. As a consequence, the fabrication time for an $\mathrm{Al}$ and steel tool is longer than for a polymer tool. Typical milling times also depend on the complexity of the structures.

Several embossing tools for producing heat exchangers, nozzles, and cuvettes from Al produced by milling are shown in Figure 4.1. Milling times of these tools were 35 minutes, 200 minutes and 30 minutes respectively.

Holes, $280 \mu \mathrm{m}$ and $130 \mu \mathrm{m}$ in diameter and depth, respectively, had been milled into plates from aluminum, PEEK, and PC and later were transferred into HDPE by ultra- 
sonic hot embossing. Figure 4.2 shows the tools from aluminum and PEEK with the corresponding embossed structures. The ultrasonic embossing was carried out on an ultrasonic machine Dynamic 745 from Rinco Ultrasonics $\mathrm{GmbH}$, Switzerland. Suitable embossing time and force, vibration amplitude, and cooling time of the same design as a function of the tool material employed are listed in Table 4.1.

Compared with PEEK with drilled holes, the milling result of $\mathrm{Al}$ is better since no obvious burrs remained at the cutting edge after milling and no finishing is required. Burrs should be avoided by applying suitable milling parameters as they are detrimental to demolding. Thus, even PEEK is a suitable material for milling.

Among the possible materials for milling tools, Al is most applied because of its perfect cutting quality. However, wear and breakings are still possible to happen on an Al tool after several ultrasonic hot embossing. Steels have a larger tensile strength. However, the milling process of steel is more complicated than of $\mathrm{Al}$ and the steel tools may rust gradually in the air as well. Thus, the choice of the milling process must consider both the milling process and the material itself.

One limit of milling is the dimension, especially at less than $50 \mu \mathrm{m}$ scales, where further steps are required to verify the structures and the burr removing is a larger challenge [70]. In advance, structures with high aspect ratio are hard to mill as the large cutting stress may lead to structure deformation. By the development of micro machining, high precision micro milling can achieve a minimum channel width of $15 \mu \mathrm{m}$ in brass [70]. Another limit for milling is the material, which needs being suitable for milling. Hard metal like nickel or other hard alloys are quite a challenge for milling.
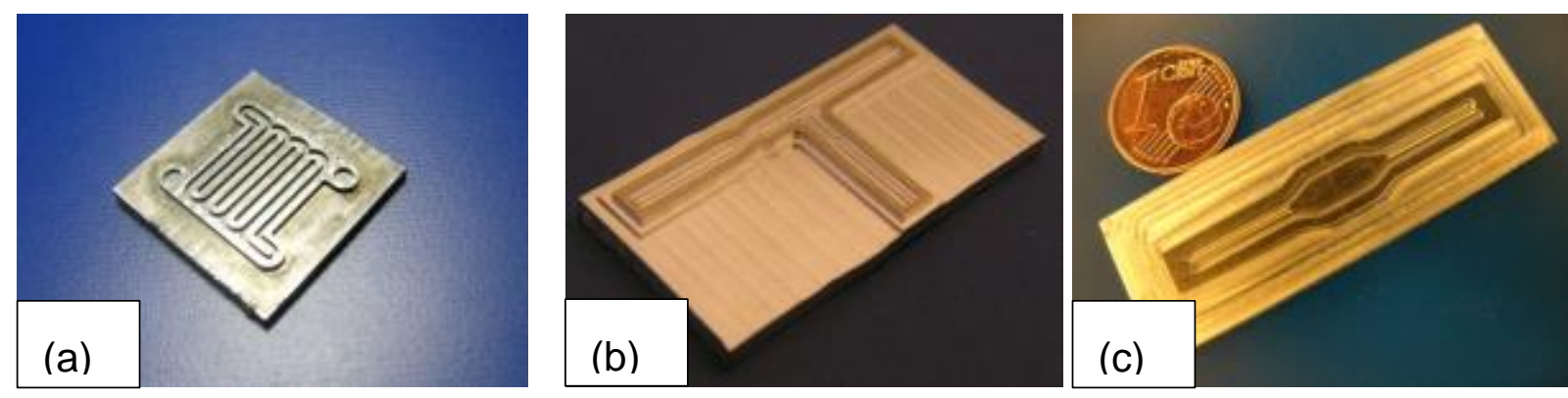

Figure 4.1: Ultrasonic hot embossing tools produced by milling of Al: (a) heat exchanger combined with channel and bars; (b) micro nozzle with inlet and outlet; (c) cuvette for examination of liquid samples. 

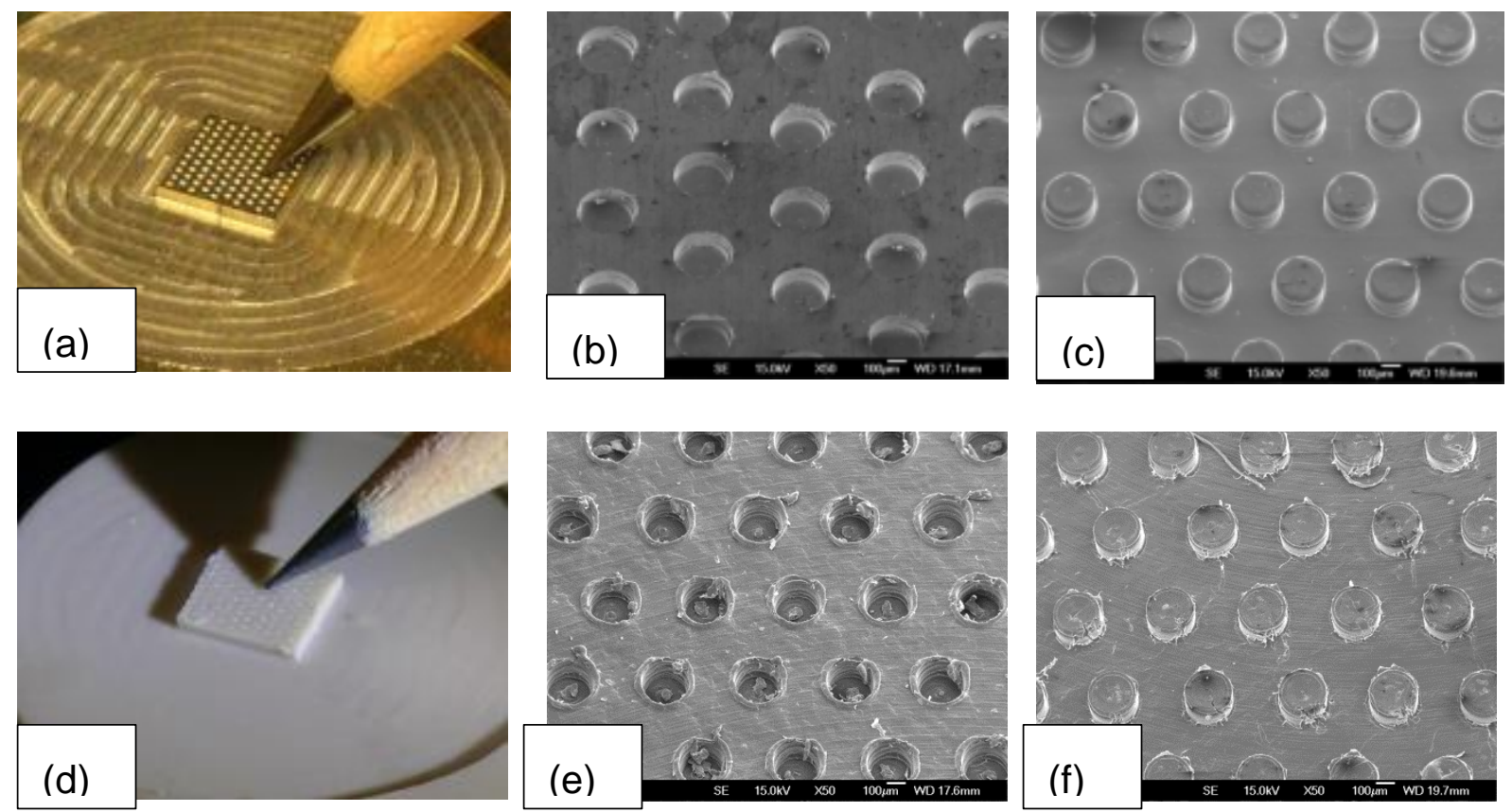

Figure 4.2: Tools drilled from aluminum $(a, b)$ and PEEK $(d, e)$ photographed with a camera $(a, d)$ and at an SEM $(b, e)$, and $(c, f)$ SEM of micro pillars embossed into HDPE with the corresponding tool. Dimensions: holes/pillar diameter: $280 \mu \mathrm{m}$, depth: $130 \mu \mathrm{m}$, interval: $500 \mu \mathrm{m}$.

Table 4.1: Embossing parameters of aluminum, PEEK, and PC tools. Embossing structure: holes with $280 \mu \mathrm{m}$ and $130 \mu \mathrm{m}$ in diameter and depth, respectively.

\begin{tabular}{llll}
\hline & Aluminum & PEEK & PC \\
Embossing time [ms] & 220 & $180-230$ & $220-240$ \\
Cooling time [ms] & 0 & 100 & 300 \\
Other parameters & Embossing force: $150 \mathrm{~N}$, vibration amplitude: $9 \mu \mathrm{m}$ \\
\hline
\end{tabular}

\subsubsection{Electroplating}

Electroplating allows converting the shape of a micro structure on a template from a brittle or soft material such as a resist not suitable for ultrasonic hot embossing into a metal tool. This enlarges substantially the possibilities of tool fabrication. Nickel (Ni) and its alloys are normally employed for electroplating [71-77] because of its excellent mechanical quality. Brinell hardness and ultimate tensile strength of Ni reach $109 \mathrm{HB}$ and $462 \mathrm{MPa}$ [23], respectively, which completely fulfill the tool requirement on rigidity. The lifetime of a nickel tool used for PC injection molding was tested to be over 10,000 times [2]. A typical electroplating bath is shown in Figure 4.3. A nickel plate with $99.99 \%$ purity and $30 \times 700 \times 0.5 \mathrm{~mm}^{3}$ outer dimensions (Conrad) were clamped as the anode to provide $\mathrm{Ni}^{2+}$ while the template was clamped to the cathode. 
If concave corners with radii smaller than the milling head are required on a tool, it is possible milling the inverse structure into a substrate and then electroplating the surface transferring the structures into a nickel tool. The pattern on the electroplated tool is mirrored and inversed compared to the template. I.e., holes become pillars and convex corners become concave ones. The surface of the template corresponds to the one of the embossed sample. Figure 4.4 shows the sharp concave corners milled by $300 \mu \mathrm{m}$ wide and $300 \mu \mathrm{m}$ deep cross grooves on the surface of an Al plate (a), the protruding crossing bars with sharp convex corners obtained after electroplating (b), and the embossed structures on HDPE (c). The Rinco ultrasonic welding machine was used for embossing and the parameters were: embossing force $200 \mathrm{~N}$ and embossing time $300 \mathrm{~ms}$. Since milling convex sharp corners in small dimensions often requires a further finishing step with a micro milling tool, which is challenging [70], transferring grooves with sharp concave corners into bars with sharp

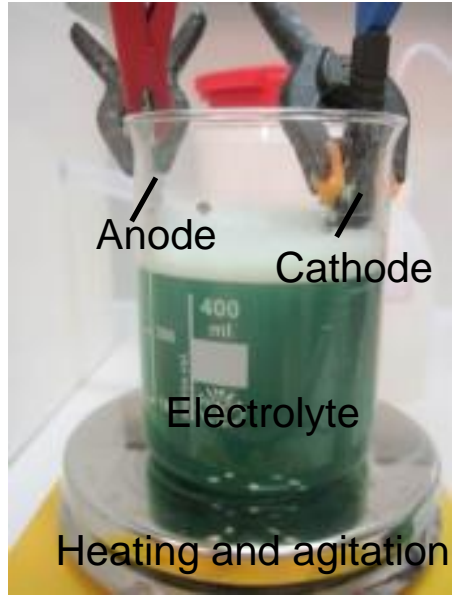

Figure 4.3: Electroplating bath. convex corners is an interesting alternative.
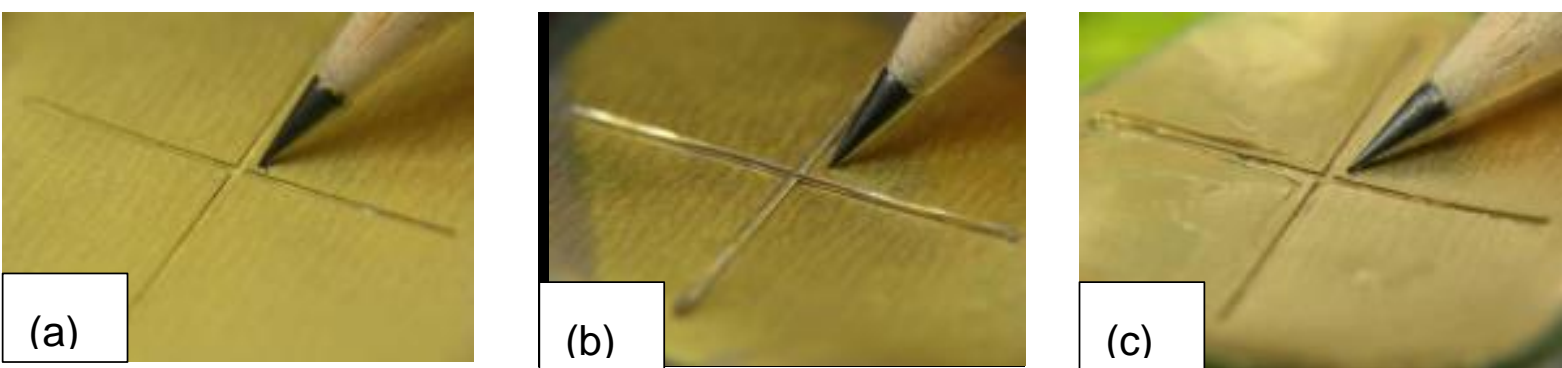

Figure 4.4 :Cross grooves milled into an aluminum substrate (a), nickel cross bar electroplated onto the grooves, and HDPE grooves ultrasonically hot embossed from the nickel bars (c). Dimensions of cross channels/bars: width: $300 \mu \mathrm{m}$, depth: $300 \mu \mathrm{m}$.

When carrying out nickel electroplating, the substrate has to be cleaned and free of grease. Besides, several issues must be paid attention to.

\section{The nickel electrolyte}

The ingredients of the electroplating solution employed and typical operating conditions are listed in Table 4.2. Chloride ions help to prevent anode polarization and increase anode dissolving efficiency. But the amount and purity of it needs to be strictly under limit $(0-10 \mathrm{~g} / \mathrm{L})$ as it raises the tensile stress in the deposited layer [78]. The function of boric acid is buffering the $\mathrm{pH}$ value, catalyst nickel deposition, suppress hydrogen evolution and so on [79]. At the cathode, not only $\mathrm{Ni}^{2+}$ ions but also the $\mathrm{H}^{+}$ion are co-reduced. Many hydrogen bubbles would stick to the surface of the sample, remaining as voids inside of the material, which deteriorate the nickel layer hardness and strength. To solve this problem, air or ultrasound agitation, or surface wetter addictive are often employed to get rid of air bubbles on the surface. Sodium dodecyl sulfate (SDS) is one kind of surface wetter speeding up the releasing of hydrogen bubbles from the deposited surface. Furthermore, the solubility of hydrogen in solution is improved by SDS [80]. Maintaining of electrolyte, such as replenishing boric acid; filtering the solution to get rid of impurities and anode dissolving slag, should be done after each production cycle. Preservation of nickel 
electrolyte should be paid attention to avoiding $\mathrm{Cu}^{2+}$ or $\mathrm{Fe}^{3+}$ ion contamination. Besides, the $\mathrm{pH}$ value should be kept under 4.5 otherwise $\mathrm{Ni}^{2+}$ may precipitate with hydroxide ions and reduce nickel layer depositing rate.

Table 4.2: Ingredients of nickel sulfamate solution, improved from [71] and operating conditions.

\begin{tabular}{ll}
\hline Bath ingredients & Concentration $[\mathrm{g} / \mathrm{L}]$ \\
Nickel sulfamate $\left(\mathrm{Ni}\left(\mathrm{SO}_{3} \mathrm{~N}_{2}\right)_{2}\right)$ & $300-450$ \\
Nickel chloride $\left(\mathrm{NiCl}_{2} \cdot 6 \mathrm{H}_{2} \mathrm{O}\right)$ & 5 \\
Boric acid & $30-45$ \\
Wetting agent (sodium dodecyl sulfate) & 0.02 \\
Current density & $\mathrm{Max} 32 \mathrm{~A} / \mathrm{dm}^{2}$ \\
Bath temperature & $25-60^{\circ} \mathrm{C}$ \\
pH & $4-4.5$ \\
\hline
\end{tabular}

\section{The current density}

The deposited quality of the layer greatly depends on the current density. At larger current density, the $\mathrm{Ni}^{2+}$ ions deposit with fast speed, resulting in larger inner stress inside the material. Large inner stress, either tensile or compressive, is detrimental to the mechanical properties and the morphology of $\mathrm{Ni}$ layers peeling it off from the substrate, brittle material, layer cracks or rough surface etc.. The reduction of inner stress in nickel has been proven to be associated with higher strength, hardness, and with finer grain size [81].

In Figure 4.5, several failures originating from large current density are shown. The growing nickel layers tend to bend towards the anode and to peel off the template during electroplating (cf. Figure $4.5 \mathrm{a}$ ), indicated large tensile inner stress generated in the nickel layer. The cracks in the nickel electroplated layer obtained at a current density of $10 \mathrm{~A} / \mathrm{dm}^{2}$ are shown in Figure $4.5 \mathrm{~b}$ and the micro surface morphology of it can be referred to in Figure $4.5 \mathrm{c}$, where large Ni particle accumulation with diameters of $200 \mu \mathrm{m}$ are noticeable. According to the electrical field analysis, the edge of the substrate is where the highest current density is concentrated. At high current density, the uneven distribution of the current field is more serious. So the burrs are easily produced at the edge of the substrate (cf. Figure $4.5 \mathrm{~d}$ ). These burrs influence the backside flatness of the tool and have to be polished away before the embossing tool can be employed.

Reducing the current density and employing the surface wetter solves the above mentioned problems. When current density is as small as $2 \mathrm{~A} / \mathrm{dm}^{2}$, this layer bending phenomenon is inhibited and the layer surface is smoother as seen in Figure 4.6 and a finer grain size was obtained. As a consequence, the electroplating time becomes more or less five times longer than applying a current density at $10 \mathrm{~A} / \mathrm{dm}^{2}$. 
In our common Ni electroplating, current density is controlled to be $2-5 \mathrm{~A} / \mathrm{dm}^{2}$ and the quality of the deposited nickel layer is satisfied. For fast electroplating with high concentration of nickel sulfamate, the current density could reach a maximum of $32 \mathrm{~A} / \mathrm{dm}^{2}$ [71]. Furthermore, the step increasing current density for electroplating is preferable, which means that at the beginning of the process, less current density (1$2 \mathrm{~A} / \mathrm{dm}^{2}$ ) is used to prevent the very thin layer from peeling off from the substrate due to inner stress. When a certained thickness has been achieved, i.e. the nickel layer is approximately more than $50 \mu \mathrm{m}$, which is stiff enough to sustain the inner stress bending, current density can be increased to $5 \mathrm{~A} / \mathrm{dm}^{2}$. This electroplating ways has also been applied in $[82,83]$ to successfully electroplate a cross bar ( $24 \mu \mathrm{m}$ in depth and $30 \mu \mathrm{m}$ in width) and various nanostructure patterns ( $2 \mu \mathrm{m}$ in height). For some ultra-small structures, e.g., less than $1 \mu \mathrm{m}$, the current density should be even less. For example, a nickel plate with holes arrays, $500 \mathrm{~nm}$ in diameter, was electroplated with a current density of $0.1 \mathrm{~A} / \mathrm{dm}^{2}$ [84] and $0.05 \mathrm{~A} / \mathrm{dm}^{2}$ was applied for producing a photon nanostructure $(50 \mathrm{~nm})$ in [85].
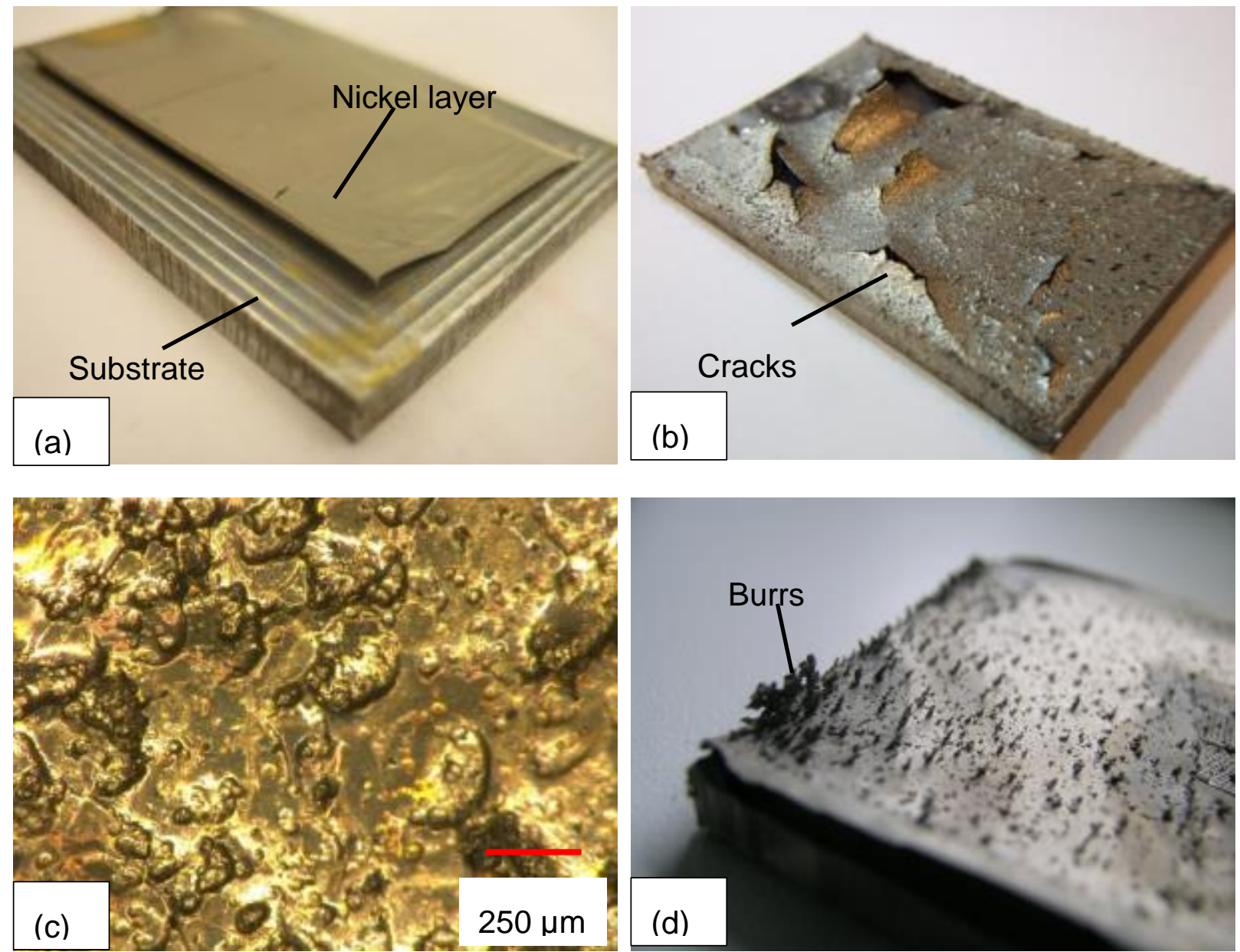

Figure 4.5: Some failures electroplating result due to large current density: (a) layer peeling off from substrate; (b) cracks on the layer; (c) morphology of the surface from layer in (b), taken by Keyence microscope; (d) burrs at the edge of the layer.

The thickness $\mathrm{s}$ in $\mathrm{mm}$, of a deposited Ni layer is estimated by the following formula:

$\mathrm{s}=\frac{12.294 \times \mathrm{a} \mathrm{I} \mathrm{t}}{\mathrm{A}}$ 
Where a is the current efficiency at the cathode, $95.5 \%$ is normally used, $\mathrm{t}$ is the time [h] of electroplating, A is the surface area to be electroplated, and I/A is the current density [86]. It is easy to figure out that the thickness of a layer is related to current density and time. Producing a $350 \mu \mathrm{m}$ thick nickel layer is obtained in approximately 15 hours at a current density of $2 \mathrm{~A} / \mathrm{dm}^{2}$.

When the backside of the nickel layer is uneven, typically a layer of a soft polymer, e.g., glue or a silicone layer is required between an electroplated tool and sonotrode or anvil avoiding breaking of the tool.

If the tool shall be mounted on the sonotrode, it should not be too thick (more than $350 \mu \mathrm{m}$ ), because otherwise the resonance frequency of the sonotrode would be altered too much and ultrasonic hot embossing is not possible any more. On the other hand, the tool may not be too thin, because it may break when pressed against the sample.

The nickel tool mentioned in chapter 3 (cf. Figure 3.3) was produced by nickel electroplating where the Al substrate was first milled with the reverse structure. The current density was set to $1 \mathrm{~A} / \mathrm{dm}^{2}$ at the beginning and raised up to $5 \mathrm{~A} / \mathrm{dm}^{2}$. Finally a bottom thickness of approximately $2 \mathrm{~mm}$ with $400 \mu \mathrm{m}$ high structures on the nickel tool were produced, the photos of a nickel tool from electroplating and a St235JR tool from milling are show in Figure 4.7. The dimensions of the structures from both nickel electroplating and milling were nearly the same, proving that the duplicating precision of nickel electroplating is satisfied.

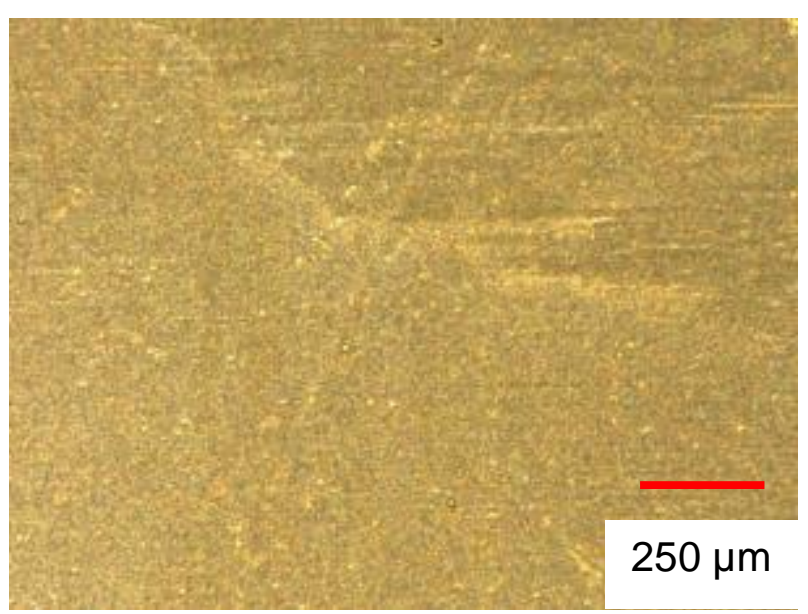

Figure 4.6: Surface morphology obtained at a current density of $2 \mathrm{~A} / \mathrm{dm}^{2}$.
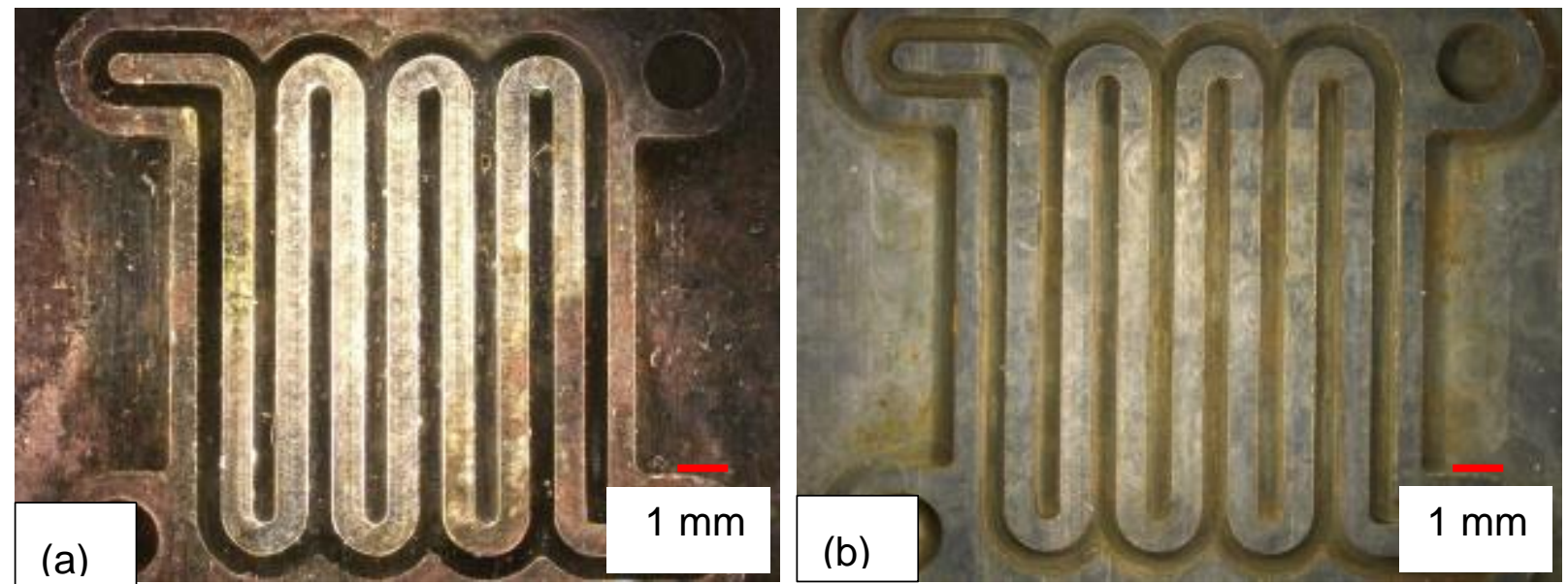

Figure 4.7 : Optical photos of a structure from tools: (a) electroplated from nickel and (b) milled into the steel St235JR. Photos have been taken by a Keyence microscope.

Last but not the least, not only a metal surface can be provided as a template for electroplating, polymer plates, e.g., PC and PEEK, are also suitable for milling and preparing as the temperate for electroplating. PMMA is not recommended as it swells 
in the aqueous solution of the electrolyte influencing the structure precision [87]. One more issue has to be considered is that polymer is not electrically conductive. Thus sputtering a metal layer (normally gold) onto the polymer surface is necessary. In addition, the surface energy difference between polymer and nickel is large, thus the deposited layer tends to peel off the substrate more easily. Normally, a titanium layer is acquired before gold sputtering to increase the sticking force between nickel layer and polymer surface. Small current density at the beginning is recommended to reduce inner stress of the deposited layer. The main limits of nickel electroplating are: a production time of more than 10 hours and the sensitivity of the process to the chemical composition of the electrolyte which changes by evaporation of ingredients during the process. Besides this, nickel electroplating is a good way for tool fabrication.

\subsubsection{Lithography}

Besides milling, templates for electroplating can also be fabricated from resists by lithography. By photolithography the aspect ratio typically is on the order of 1 when tools for ultrasonic hot embossing shall be fabricated. With x-ray lithography the aspect ratio is not limited by tool fabrication but by the deepest groove in the tool which can be filled with molten polymer. The achievable lateral dimensions can be as small as several micro meters or even nano meters, and the roughness of sidewalls is on the order of $10 \mathrm{~nm}$ [72, 88-92]. Because of the high running expense of X-ray synchrotrons, UV light is preferred for lithography when no high aspect ratio is required. In this work, hole arrays $(50 \mu \mathrm{m}$ in diameter and $80 \mu \mathrm{m}$ in pit interval) were produced on a silicon wafer by UV lithography. The schematic drawing of whole process of lithography and nickel electroplating are schematically shown in Fig. 4.8. The basic lithography process was composed of:

1) Cleaning the substrate with acetone to wash away pollutants.

2) Spin coating negative photoresist (AZ125XT, MicroChemicals) onto the wafer. Since AZ 125XT is a severe viscous negative photoresist, for $50 \mu \mathrm{m}$ thick photoresist, the spin coating was carried out in two spinning steps: 1) $2200 \mathrm{rpm}$ for $1.4 \mathrm{~s}$ and 2) $1900 \mathrm{rpm}$ for $8 \mathrm{~s}$. After spin coating, the photoresist bead concentrated at the edge of the wafer was removed because otherwise there would be a gap inhibiting the close contact between the mask and the photoresist during UV exposure, leading to dimension deviations of exposed structures. Dimethylformmamide (DMF) was employed to remove the bead at a spinning speed of $500 \mathrm{rpm}$.

3) Preheating samples to remove the solvent inside photoresist. The soft baking was carried out at $140^{\circ} \mathrm{C}$ for 8 minutes.

4) Exposure of the wafer with $365 \mathrm{~nm}$ UV light for 2 minutes $30 \mathrm{~s}$ (see Fig. $4.8 \mathrm{a}$ ).

5) Developing with the solvent AZ326MIF developer (MicroChemicals) for $80 \mathrm{~s}$ (see Fig. 4.8 b).

6) Clean the developed wafer with de-ionized water.

No post baking process was required. After lithography, $12 \mathrm{~nm}$ gold were sputtered onto the photoresist to achieve electric conductivity. After nickel electroplating, the silicon wafer was dissolved by heated $\mathrm{KOH}$ solution while the photoresist was removed by the remover ( $A Z 100$ MicroChemicals) to obtain the nickel embossing tool.

The optical photos of the photoresist pattern with micro holes on a silicon wafer, the SEM of the pillar arrays of the nickel tool and the embossed structures on HDPE are 
shown in Figure 4.9. The Branson 2000IW+ ultrasonic welding machine was used for embossing into HDPE with this tool. The embossing parameters are: embossing force at $150 \mathrm{~N}$, embossing time at $0.6 \mathrm{~s}$ and $24 \mu \mathrm{m}$ amplitude.

As far as known, nickel electroplating is not limiting the structure dimensions. Thus, a template with nano-structures generated by X-ray lithography, electron beam writing lithography (EBL) or focused ion beam lithography (FBL) can be used for nickel electroplating as well.

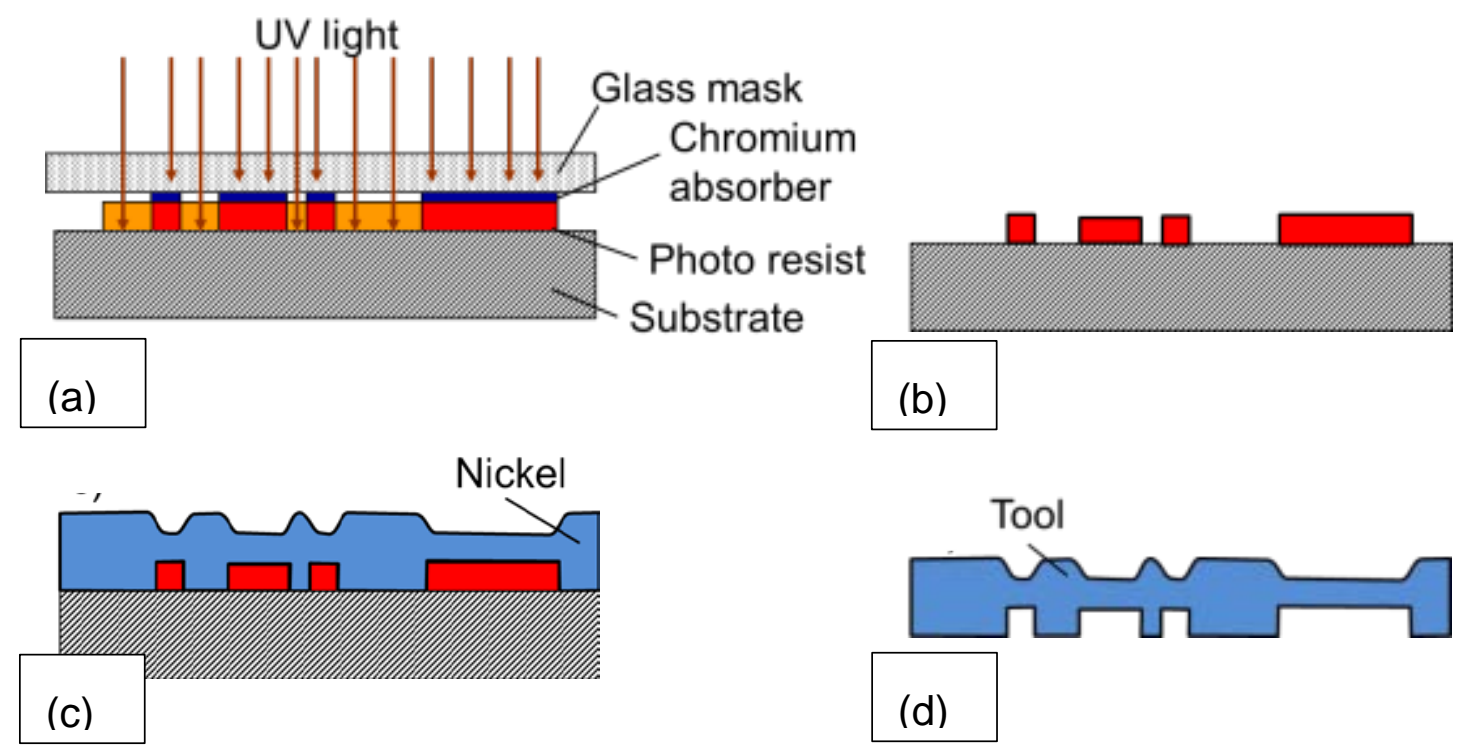

Figure 4.8 : Tool fabrication by photolithography and electroplating: (a) Exposure of the resist to UV light; (b) developing of the exposed part of the resist; (c) nickel electroplating; (d) dissolving or mechanical removing of substrate and resist.
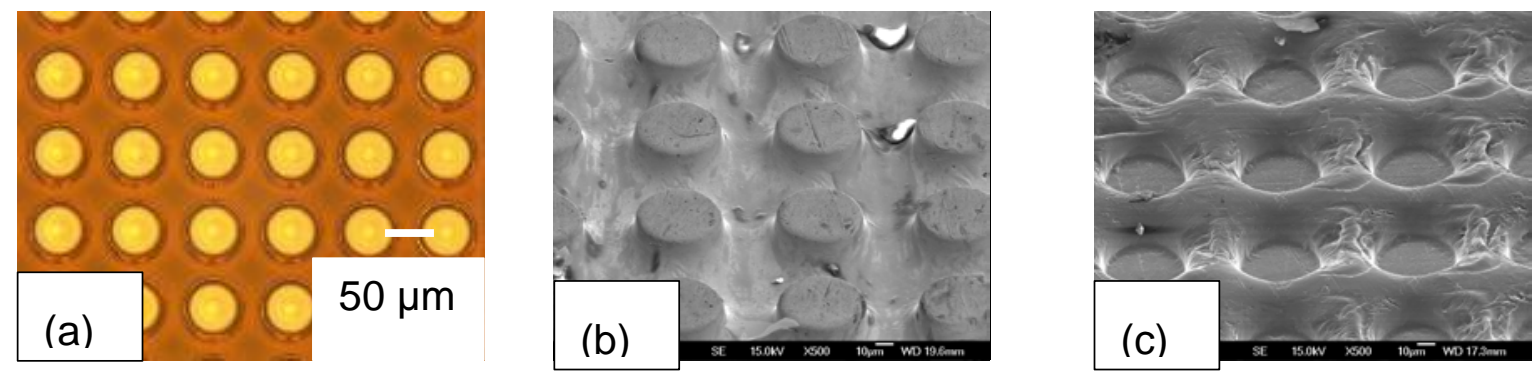

Figure 4.9: Photos of (a) hole arrays of photoresist on silicon wafer, (b) SEM of the structure on the nickel tool and (c) embossed hole arrays on HDPE. Diameter: $50 \mu \mathrm{m}$, depth: $50 \mu \mathrm{m}$, interval: $80 \mu \mathrm{m}$.

\subsubsection{Silicon etching}

Silicon wafers patterned by anisotropic wet etching or reactive ion etching may also be used as embossing tool for hot embossing and injection molding [68, 93]. However, the main drawback of silicon tools is the short lifetime due to its brittleness and tensile stress sensibility [68]. Thus, electroplating the structures on the silicon wafer is a suitable way to obtain sufficient hardness and tensile strength for tools. Figure 4.10 shows a microchip design with $25 \mu \mathrm{m}$ deep structures fabricated by reactive ion etching (RIE) on a silicon wafer. The SEM photos of detail structures are in- 
cluded as well. Later the surface was sputtered with $12 \mathrm{~nm}$ titanium and $12 \mathrm{~nm}$ gold for electroplating. After electroplating, the silicon wafer was dissolved by heated $\mathrm{KOH}$ solution to obtain the nickel tool, which was used for ultrasonic hot embossing onto HDPE. The embossing process was realized by the Branson welding machine while the embossing parameters were embossing force: $944 \mathrm{~N}$, embossing time: $0.7 \mathrm{~s}$ and amplitude: $32 \mu \mathrm{m}$. As mentioned above, one design rule for ultrasonic hot embossing tools is the protruding structures (normally more than $50 \mu \mathrm{m}$ ) to provide molten polymer for filling cavities on the tool. The $25 \mu \mathrm{m}$ heigh structures here were a challenge to be embossed because the protruding of the structures was very small. Some improvements were introduced to solve this problem as mentioned in the next chapter. No deviation from the microstructures on the wafer was found on the ultrasonic hot embossed HDPE.
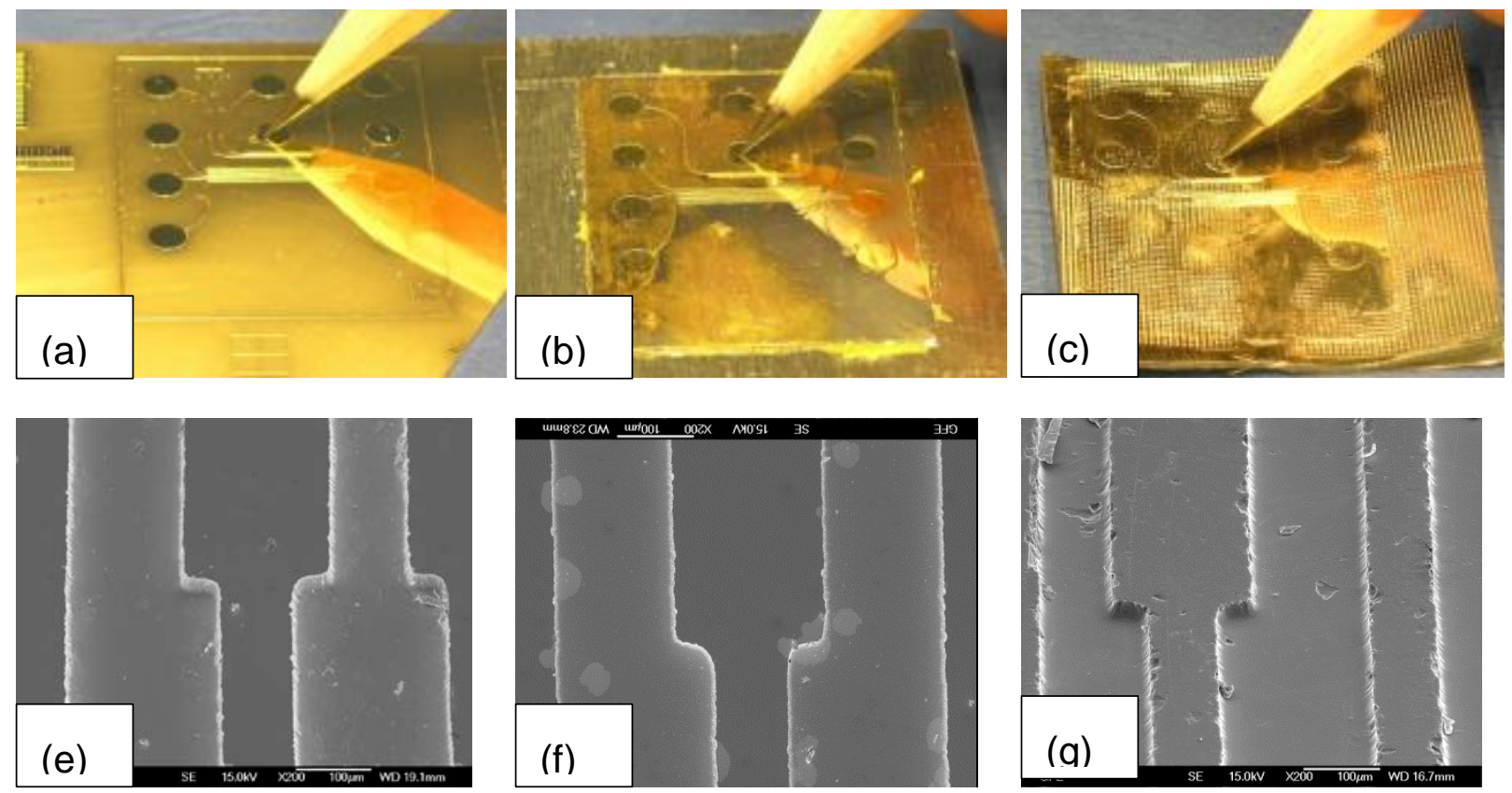

Figure 4.10: (a) microchip design structures on a silicon wafer; (b): structures on the nickel tool copied from the silicon wafer; (c) nearly the same structures ultrasonically hot embossed into HDPE foils; (e-g) are SEM photos of detail structures corresponding to (a-c).

\subsubsection{Photolithography, milling, and electroplating}

It is difficult producing micro structures on several levels by photolithography but comparatively small dimensions are possible to be achieved with this process. On the other hand, several levels are easily realized by micro milling but the size of the micro structures is limited by the diameter of the milling head. Therefore, a combination of both processes was tried and appeared to be advantageous when micro structures smaller than $50 \mu \mathrm{m}$ need to be generated on a tool together with more than one level.

For photolithography, a flat substrate is required ensuring that the resist is coated smoothly in the focal plane which is in close contact to the mask. On the other hand, the substrate needs to be suitable for milling if it shall be employed in combination with photolithography. Silicon and glass wafers show the desirable flat surface required for photolithography but cannot be milled. Metal plates normally are not delivered with the flatness needed for photolithography. Therefore, polymer plates from PEEK and PC, were employed. Certainly the substrate material needs to withstand the tem- 
peratures occurring in the fabrication process and to keep a flat and smooth surface, especially at the baking temperature of the photoresist.

To test combining milling and photolithography for tool fabrication, the negative photoresist AZ125XT with a soft baking temperature of $140^{\circ} \mathrm{C}$ was employed on a PC plate. First micro holes, $150 \mu \mathrm{m}$ and $40 \mu \mathrm{m}$ in diameter and depth, respectively, were fabricated at a relative distance to each other of $250 \mu \mathrm{m}$ by photolithography in the photoresist (cf. Figure $4.11 \mathrm{a}$ ). Then the surface of the substrate was $200 \mu \mathrm{m}$ deep milled down around groups of four such holes leaving islands, $1.4 \mathrm{~mm}$ in diameter, with four holes (cf. Figure 4.11 b). The distance between the islands was $400 \mu \mathrm{m}$.

Approximately $12 \mathrm{~nm}$ titanium followed by $12 \mathrm{~nm}$ gold were sputtered onto the template providing enough conductivity for electroplating. Then nickel was electroplated generating the tool (cf. Figure $4.11 \mathrm{c}$ ). Finally the tool was employed for embossing into HDPE foils (cf. Figure $4.11 \mathrm{~d}$ ). The embossing process was carried out by the Rinco ultrasonic welding machine with the embossing force $200 \mathrm{~N}$ and embossing time $300 \mathrm{~ms}$. The photos of whole PC template fabiricated by lithography and milling, electroplated nickel tool and the embossed HDPE foils are shown in Figure 4.12.

One challenge of this process was alignment of the milling island around the groups of micro holes. Besides this, the structures from photoresist are fragile and can easily be destroyed by the milling head. In Figure 4.11, the micro holes are not in the exact center of the island. The center of four-hole arrays is $250 \mu \mathrm{m}$ deviated from the center of the island due to the imprecise alignment of cutting. This problem could be improved by more precise position control during lithography and milling.

The combination of milling and lithography reduces the limit of lithography in producing 3-dimensional structures, which normally require multiple lithography process steps. 

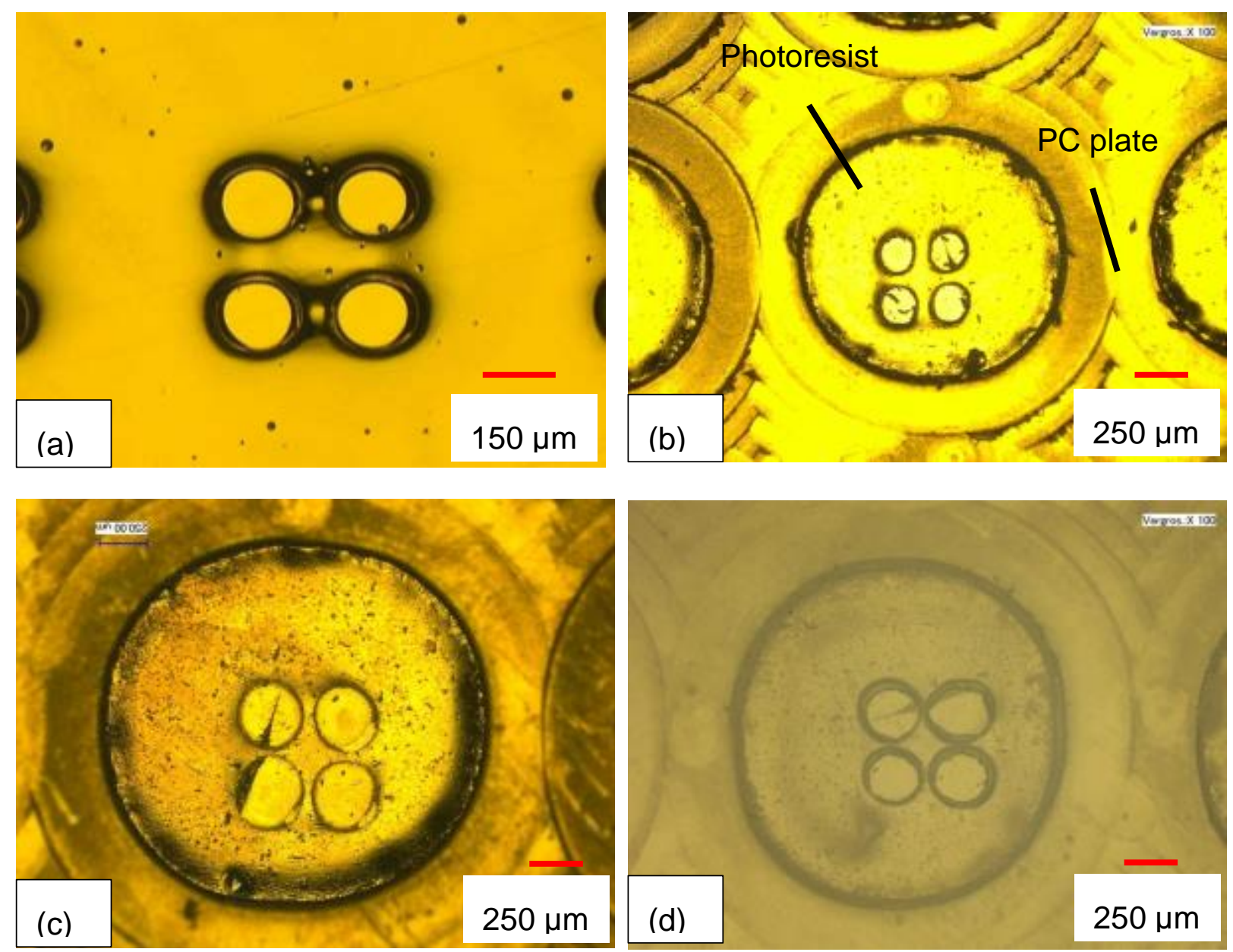

Figure 4.11 : Optical photos taken by a Keyence Microscope of: (a) micro holes fabricated by lithography on a PC plate; (b) milling an island surrounding the micro holes; (c) structures generated by nickel electroplating the template shown in (b); (d) structure embossed from the tool shown in (c).

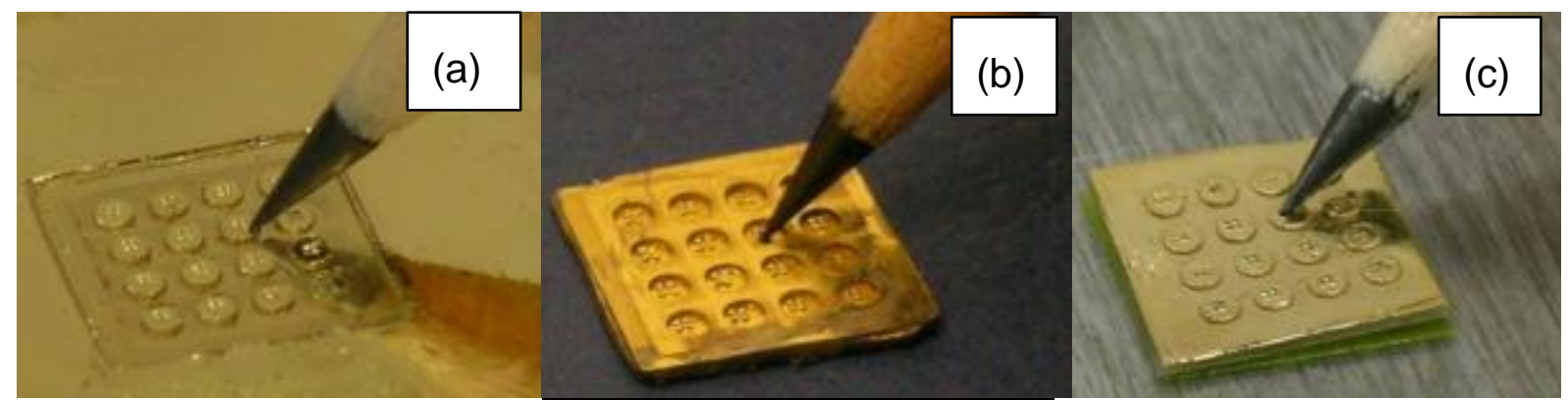

Figure 4.12: (a) PC template fabricated by lithography and milling; (b), electroplated nickel tool; (c), and HDPE foils embossed from the nickel tool.

\subsubsection{Enlarging the tool size}

Several fabrication processes such as micro milling are suitable generating micro structures smaller than $200 \mu \mathrm{m}$, but it is difficult and expensive patterning areas of more than a few $\mathrm{cm}^{2}$. If repeated micro structures are required on a sample with large area, it is possible patterning a polymer template by repeated ultrasonic hot emboss- 
ing of one or more smaller tools and then electroplating the template producing a large tool for ultrasonic hot embossing.

To demonstrate how the tool area can be enlarged this way, 100 holes, $250 \mu \mathrm{m}$ and $125 \mu \mathrm{m}$ in diameter and depth, respectively, had been milled into a PC plate $3 \mathrm{~mm} \times$ $3 \mathrm{~mm}$ in length and width, and $4 \mathrm{~mm}$ in thickness (cf. Figure 4.13). This template was electroplated with nickel and employed for repeated ultrasonic hot embossing into another PC plate which again was electroplated generating a nickel tool for ultrasonic hot embossing on larger areas. Figure 4.14 shows a nickel tool with an area of $5 \mathrm{~mm}$ $\times 5 \mathrm{~mm}$ employed to produce larger nickel tools with areas of up to $40 \mathrm{~mm} \times 56 \mathrm{~mm}$, the pillar arrays on top of the tool are seen in Figure $4.14 \mathrm{~b}$. The alignment of repeated embossings relative to each other turned out being difficult. An accuracy of approximately $500 \mu \mathrm{m}$ was achieved by manual alignment.

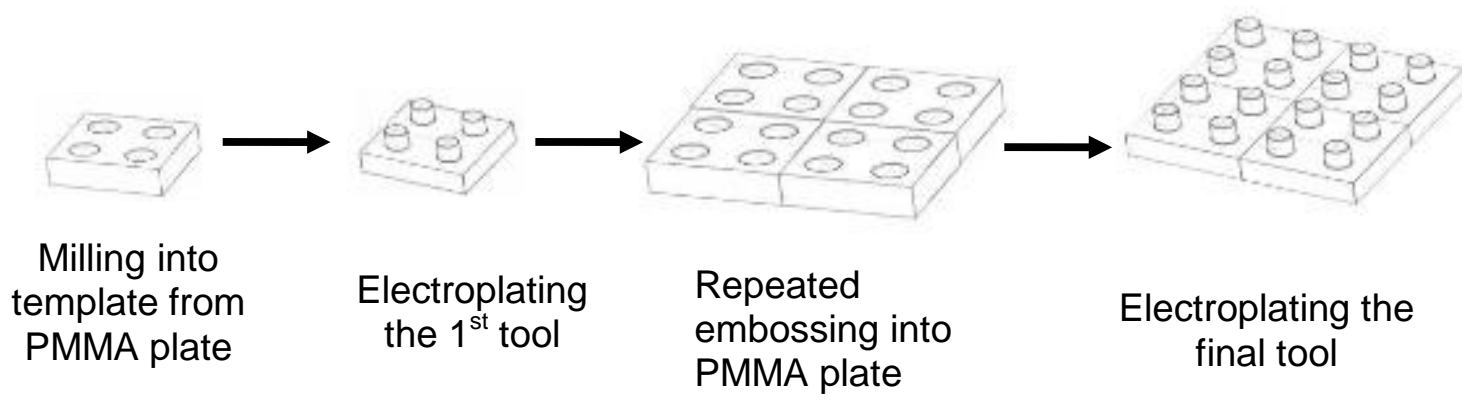

Figure 4.13: Enlarging the embossing tool by repeated ultrasonic hot embossing and electroplating.
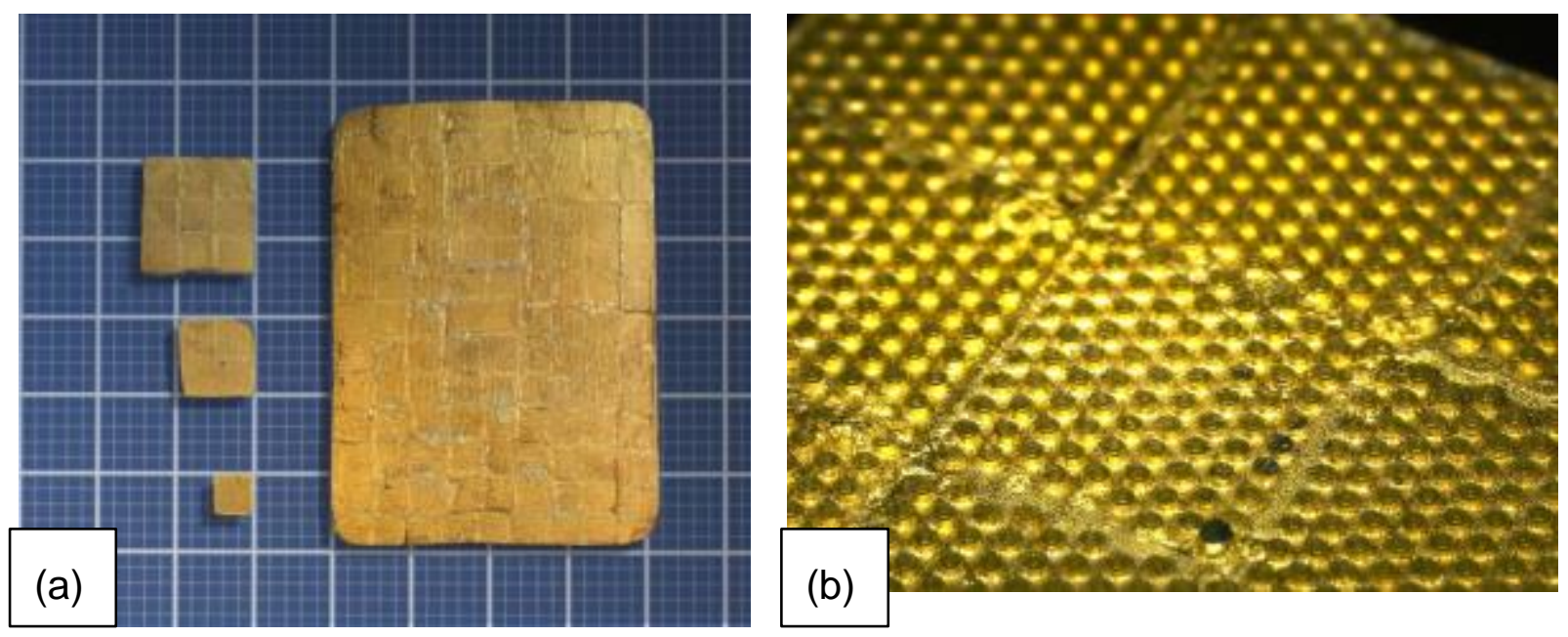

Figure 4.14: (a) Enlargement of the embossing tool: the area of the original tool is $5 \mathrm{~mm} \times 5 \mathrm{~mm}$ and the largest one is nearly $40 \mathrm{~mm} \times 56 \mathrm{~mm}$; (b) pillar arrays on the surface of the embossing tool.

\subsubsection{ECM, EDM, and laser}

Tools for hot embossing have been manufactured from brass and stainless steel by micro electrochemical machining $(\mu \mathrm{ECM})$ and micro electro discharge machining 
( $\mu$ EDM) $[94,95]$. To the knowledge of the author these tools were not employed for ultrasonic hot embossing, but it is obvious that they are suitable because hot embossing has similar requirements on the tools as ultrasonic hot embossing. The advantage of these tool fabrication processes is, that tools from comparatively hard metals can be generated promising to withstand thousands or even more embossing steps without degradation. Micromachining with a laser is also expected to be suitable for tool fabrication for ultrasonic hot embossing. Holes as small as $52 \mu \mathrm{m}$ in diameter were drilled by a helical drilling strategy with a copper vapor laser (CVL) [96]. The limits of these three methods are complex fabrication procedure, high cost and high roughness. Only electrical conductive metals are suitable for $\mu \mathrm{ECM}$ and $\mu E D M$. Besides, the roughness of a surface generated by a laser on carbon steel may be ten times rougher than of an electroformed nickel surface [97], which may affect the micro structure dimension and the demolding process.

\subsubsection{Tools from liquid metal}

It also has been tried fabricating tools for ultrasonic hot embossing from so-called liquid metals. These are mixtures of metal particles with an adhesive. On the market there are mainly two types of liquid metals differing in mixing and solidification. Epoxy liquid metal is realized by firstly mixing two components manually: resin with catalytic or co-reactants and then waiting for the curing reaction between the components. The fine metal particles are previously added to the resin, which can be any compound containing one or more $\alpha$ - or 1, 2-epoxy groups. With curative additive, the mixing is converted to thermoform 3-dimensional network structures, which are reliable to obtain various properties, such as chemical resistance, mechanical properties etc. [98]. Besides the epoxy metal liquids, one component adhesives are of interest as well. The 'one component' often refers to fine metal particles (diameter in the order of $100 \mu \mathrm{m}$ ) from stainless steel, $\mathrm{Al}, \mathrm{Ni}$, etc., which has been mixed with hardener (i.e., ceramic colloid) already and sealed inside of a container. Before curing, the adhesive must be stirred at ambient temperature. Then either at ambient or an elevated temperature, the hardening proceeds and the metal particles are finally glued together and become a stiff material. This type of liquid metal can sustain temperatures as high as $1000^{\circ} \mathrm{C}$, thus it is usually applied to repair devices working at high temperature. Due to the particular performance of liquid metal in industry, they were attempted here to fabricate the tools for ultrasonic hot embossing and they were tested whether they can fulfill the requirements of a tool for ultrasonic hot embossing.

Several available products on the market from different companies were selected, shown in Figure 4.15. The basic information of these products from their datasheet is listed in Table 4.3. The preparations of liquid metals are different. For Loctite and BOLDT liquid metal, the epoxy resins have to be additionally mixed with metal particles manually. But the Blue magic and Durabond liquid metals could directly be mixed as the ceramic colloid had been added already. 
Table 4.3: Basic information of selected liquid metals.

\begin{tabular}{|c|c|c|c|c|c|c|}
\hline $\begin{array}{l}\text { Product } \\
\text { name }\end{array}$ & $\begin{array}{l}\text { Abbreviation } \\
\text { name in text }\end{array}$ & $\begin{array}{c}\text { Heat } \\
\text { resistance } \\
\mathrm{T}\left[{ }^{\circ} \mathrm{C}\right]\end{array}$ & $\begin{array}{l}2 \text { component } \\
\text { epoxy/adhesive }\end{array}$ & Appearance & $\begin{array}{l}\text { Preparing } \\
\text { time [h] } \\
\text { at } 20^{\circ} \mathrm{C}\end{array}$ & $\begin{array}{l}\text { Price } \\
€ / g\end{array}$ \\
\hline $\begin{array}{c}\text { BOLDT } \\
\text { Turbocoll } \\
2000 \\
\text { repair } \\
\text { adhesive } \\
\end{array}$ & BOLDT & $-40-300$ & $\begin{array}{c}2 \text { component } \\
\text { epoxy }\end{array}$ & putty & 1.5 & 0.142 \\
\hline $\begin{array}{c}\text { Loctite EA } \\
3472 \text { steel } \\
\text { metal-filled } \\
\text { Epoxy }\end{array}$ & $\begin{array}{c}\text { Loctite steel } \\
\text { epoxy }\end{array}$ & $-20-120$ & $\begin{array}{c}2 \text { component } \\
\text { epoxy }\end{array}$ & Gray liquid & 12 & 0.123 \\
\hline $\begin{array}{l}\text { Loctite EA } \\
3479 \\
\text { aluminum } \\
\text { metal-filled } \\
\text { Epoxy }\end{array}$ & $\begin{array}{l}\text { Loctite } \\
\text { aluminum } \\
\text { epoxy }\end{array}$ & $-20-190$ & $\begin{array}{c}2 \text { component } \\
\text { epoxy }\end{array}$ & Gray putty & 12 & 0.132 \\
\hline $\begin{array}{l}\text { Blue Magic } \\
\text { Cargo } \\
\text { thermosteel }\end{array}$ & Blue magic & 1316 & Adhesive & Paste, putty & $\begin{array}{l}\text { Minimum } \\
24\end{array}$ & 0.117 \\
\hline $\begin{array}{c}\text { Durabond }^{\mathrm{TM}} \\
7032 \\
\text { Stainless } \\
\text { Putty }\end{array}$ & Durabond & 1050 & Adhesive & Paste, putty & $\begin{array}{c}1^{\text {st }} 24 \\
2^{\text {nd }} 66^{\circ} \mathrm{C} \\
4 \mathrm{~h}\end{array}$ & 0.417 \\
\hline
\end{tabular}

Similar as electroplating, liquid metals require a mold to duplicate the reverse structures. The original mold for liquid metal casting can be fabricated in many ways, e.g., milling or lithography. Here two different designs were selected: 1) heat changer tool and 2) hole arrays ( $1 \mathrm{~mm}$ in diameter, $500 \mu \mathrm{m}$ in depth and $2 \mathrm{~mm}$ in interval) on the substrate. The process of how to prepare the liquid metals was: firstly, a silicone rubber (Clorex) was employed to duplicate the pattern from the original Al tools. As silicon rubber can be deformed freely without breaking and replicates the original structure precisely, it is suitable to transfer the pattern from a metal substrate to liquid metal and the soft rubber is easy for demolding. The replicas of silicon rubber from two structures are shown in Figure 4.16.

Secondly, the mixed liquid metals were cast onto the solidified silicon rubber form and cured. Finally the liquid metal tools were demolded and ready for ultrasonic hot embossing. 


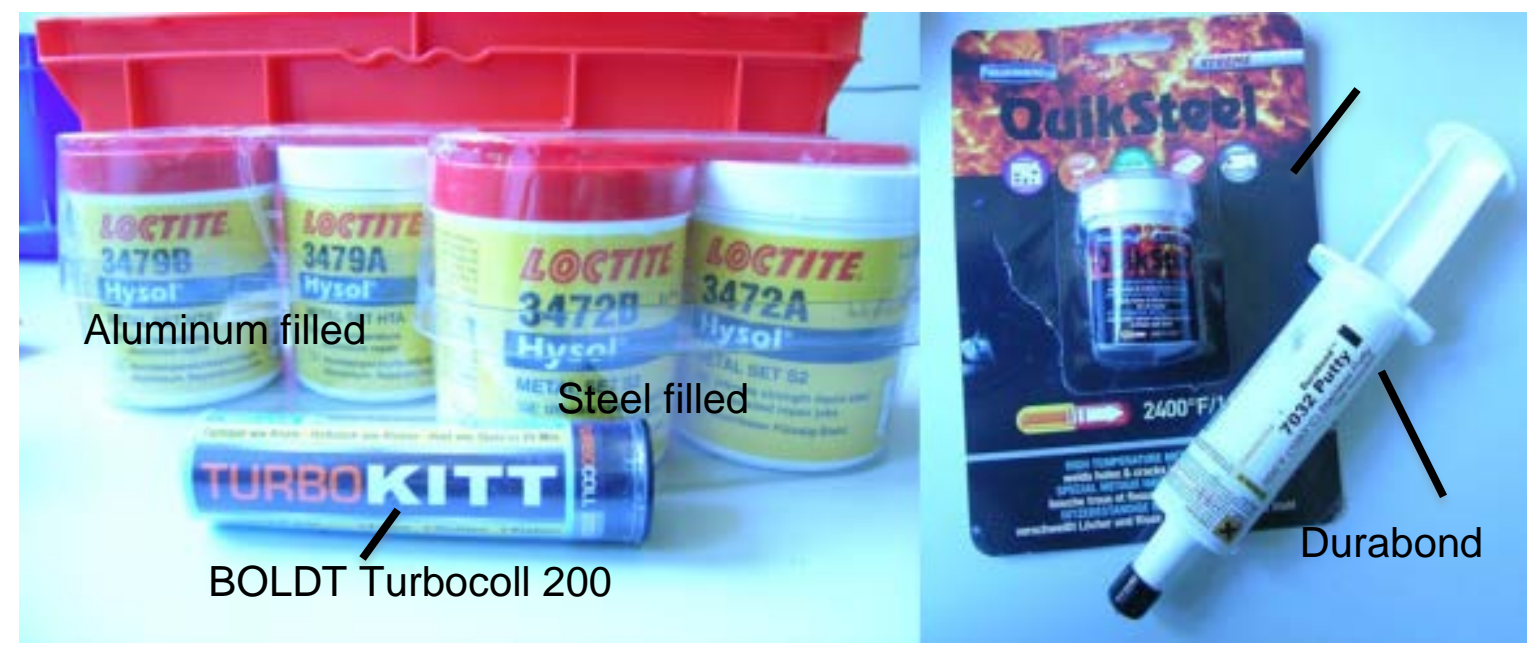

Figure 4.15: Several products of liquid metals.

Figure 4.17 shows the two types of replicated structures from different liquid metals and Figure 4.18 is the surface morphology of each liquid metal taken by the Keyence microscope. The structures obtained from Loctite liquid metals are more fluidic and easily filled into the cavities of the template while the copy quality from liquid metal of Durabond, BOLDT and Blue magic were inferior as these three liquid metals were putty clay with high viscosity, which required external force to compress during casting and curing. In between, the liquid metal form Durabond even failed to produce the embossing tool with hole arrays since the structures collapsed during demoldng from the silicon rubber mold. In Figure 4.18, the variation of surface morphology is noticeable. Surfaces prepared by Loctite and BOLDT are condenser and smoother than the ones from Blue magic and Durabond without visible particles.
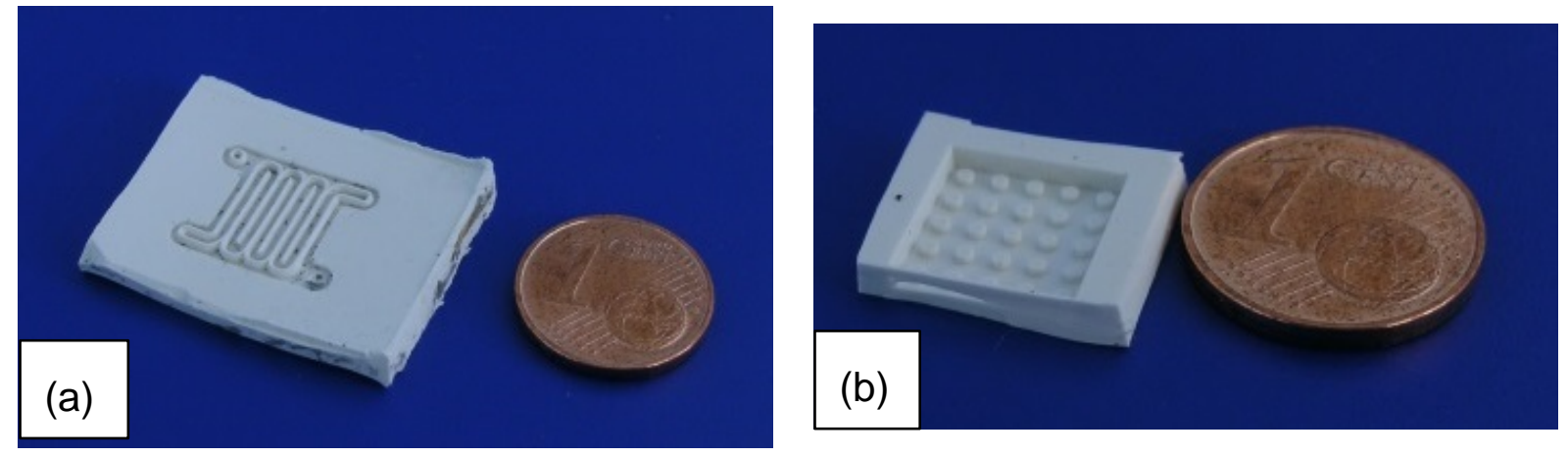

Figure 4.16: Silicone rubber replica from (a) heat exchanger tool; (b) holes arrays.

It is clear that the surfaces of the liquid metals from Blue Magic and Durabond are rough and porous with many visible voids existing inside the material. Especially in Blue Magic liquid metal, particles sizes as large as about $100 \mu \mathrm{m}$ in diameter are shown and glued out of order. While on the surface of Durabond particles and voids size are reduced, but the roughness is still obviously larger than on the liquid metals form Loctite and BOLDT. 

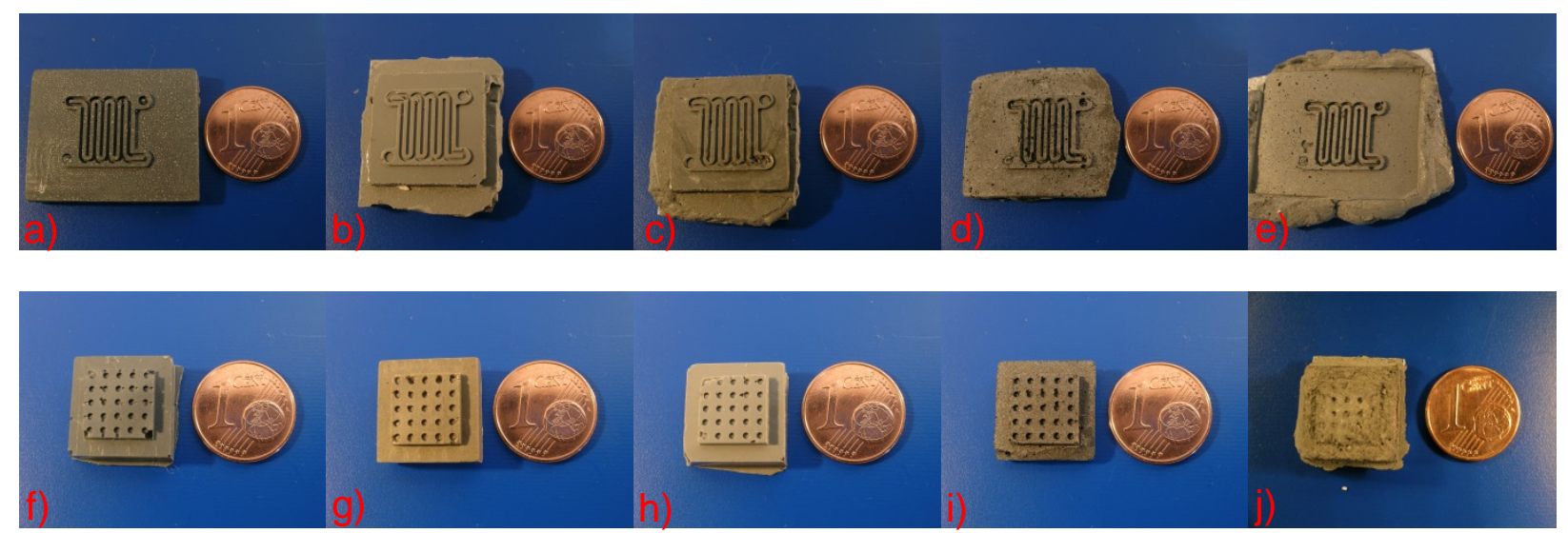

Figure 4.17: Structures of (a-e) heat exchanger and (f-j) holes arrays on fluidic metals replicated from silicone rubber. (a, f) Loctite aluminum epoxy; $(b, g)$ Lotite steel epoxy; (c, h) BOLDT; (d, i) Blue Magic; $(e, j)$ Durabond.
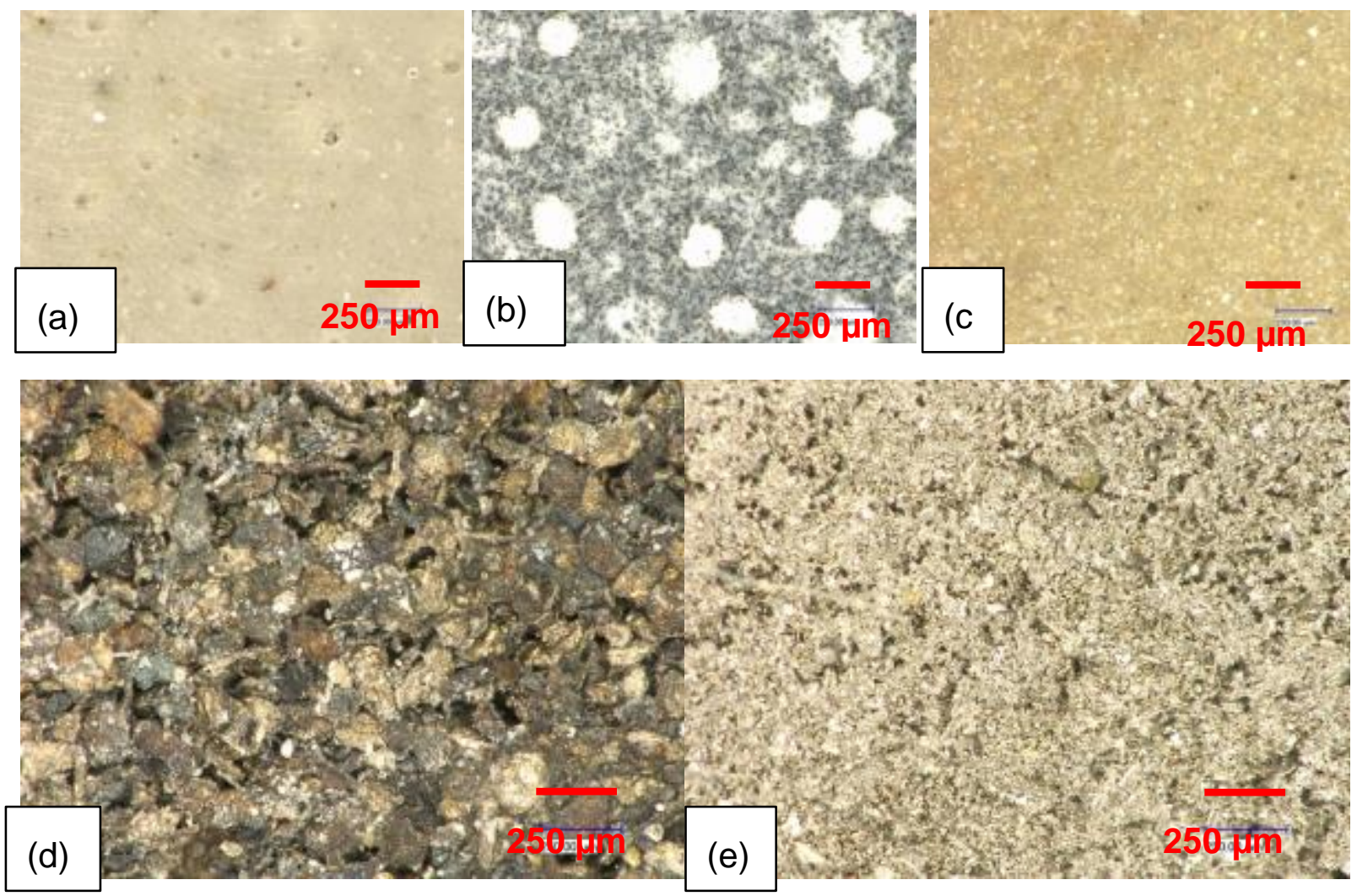

Figure 4.18: Morphology of liquid metal surface of difference products: (a) Loctite aluminum epoxy; (b) Loctite Steel epoxy; (c) BOLDT; (d) Blue Magic; (d) Dorabond.

Ultrasonic hot embossing was carried out with the Rinco welding machine on two stacks of PP layers (each $500 \mu \mathrm{m}$ thick). The parameters are the same as used in Chapter 3: embossing force $250 \mathrm{~N}$ and embossing time $1.5 \mathrm{~s}$. Unfortunately, all the liquid metal tools were damaged after 1 or 2 embossings. The structures were deforming or collapsing, some of them are shown in Figure 4.19. Tools from Loctite aluminum epoxy were partly melted while the structure from Blue Magic and Durabond were collapsed. Even though the endurable temperature of Durabond and Blue magic liquid metal are over $1000^{\circ} \mathrm{C}$, they are not suitable for ultrasonic hot 
embossing tools. The structures from the Blue Magic liquid metal were even seriously broken after embossing.
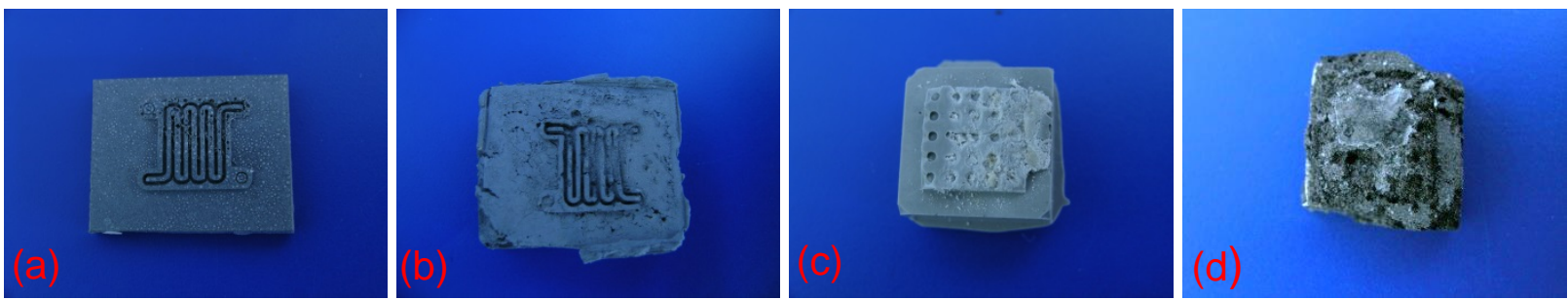

Figure 4.19: Photos of liquid metal tools after ultrasonic hot embossing: (a) Loctite aluminum epoxy; (b) Durabond; (c) BOLDT; (d) Blue Magic.

In order to investigate the reasons of the failure, two measurements: hardness, and stress and strain were carried out. The hardness (Shore D) of these five materials were measured with Hardness Digi tester (Bareiss) and listed in Table 4.4 while PC is listed as a reference. Obviously, the shore $D$ hardnesses of these liquid metals are less than that of PC, but cannot explain why these tools were damaged.

Table 4.4: Hardness measurement of liquid metals

\begin{tabular}{ll}
\hline Liquid metal name & Shore D \\
Loctite aluminum epoxy & 70.5 \\
Loctite steel epoxy & 70.7 \\
BOLDT & 71.4 \\
Blue magic & 70.3 \\
Durabond & 71.16 \\
PC & $81.5[99]$ \\
\hline
\end{tabular}

The flexural stress and strain curve was obtained by a three point bending test with the tensile testing machine (Zwick/Roell Z5.0), shown in Figure 4.20 a. As shown in Figure $4.20 \mathrm{~b}$, all the specimens were prepared as a dog bone shape $(10 \mathrm{~cm}$ in length L, $10 \mathrm{~mm}$ in width b, thicknesses d are: $1.5 \mathrm{~mm}$ for Loctite steel epoxy, $0.8 \mathrm{~mm}$ for Blue Magic and Durabond and $2 \mathrm{~mm}$ for Loctite aluminum epoxy and BOLDT). The reason for different thickness of specimens is due to the different material molding ability when casted into the silicone rubber mold. The tested curves of load and displacement related to the specimens and the corresponding flexural stress and strain calculated curve are shown in Figure 4.21. As the materials were quite brittle and broken easily, the shear deformation could be ignored. Thus the corresponding Young's modulus E and maximum flexural stress $\sigma$ could be simply calculated by [100, 101]:

$$
E=\frac{F L^{3}}{48 \delta I}
$$




$$
\sigma=\frac{3 F L}{2 b^{2}}
$$

Where F, L, $\delta$ and I are the ultimate applied load, span length of specimen, displacement and area momentum of ineria.

The calculated Young's modulus $\mathrm{E}$ and maximum flexural strength $\sigma$ of all liquid metals are listed Table 4.5. The breakings of the liquid metals are different. In Figure 4.21 , it is noticeable that the liquid metals are very brittle, especially the curves of liquid metal from Durabond and Loctite aluminum epoxy have no yield strength points and the ultimate tensile strength of all the specimens are extraordinary less than common metals. Nearly all the specimen were broken after testing as shown in Figure $4.20 \mathrm{c}$. The only comparably ductile liquid metal is from aluminum epoxy metal, which is shown in Figure $4.20 \mathrm{~d}$ as bending after testing. Calculated flexural strength from liquid metals of Blue magic and Dorabond were higher than the other liquid metals.
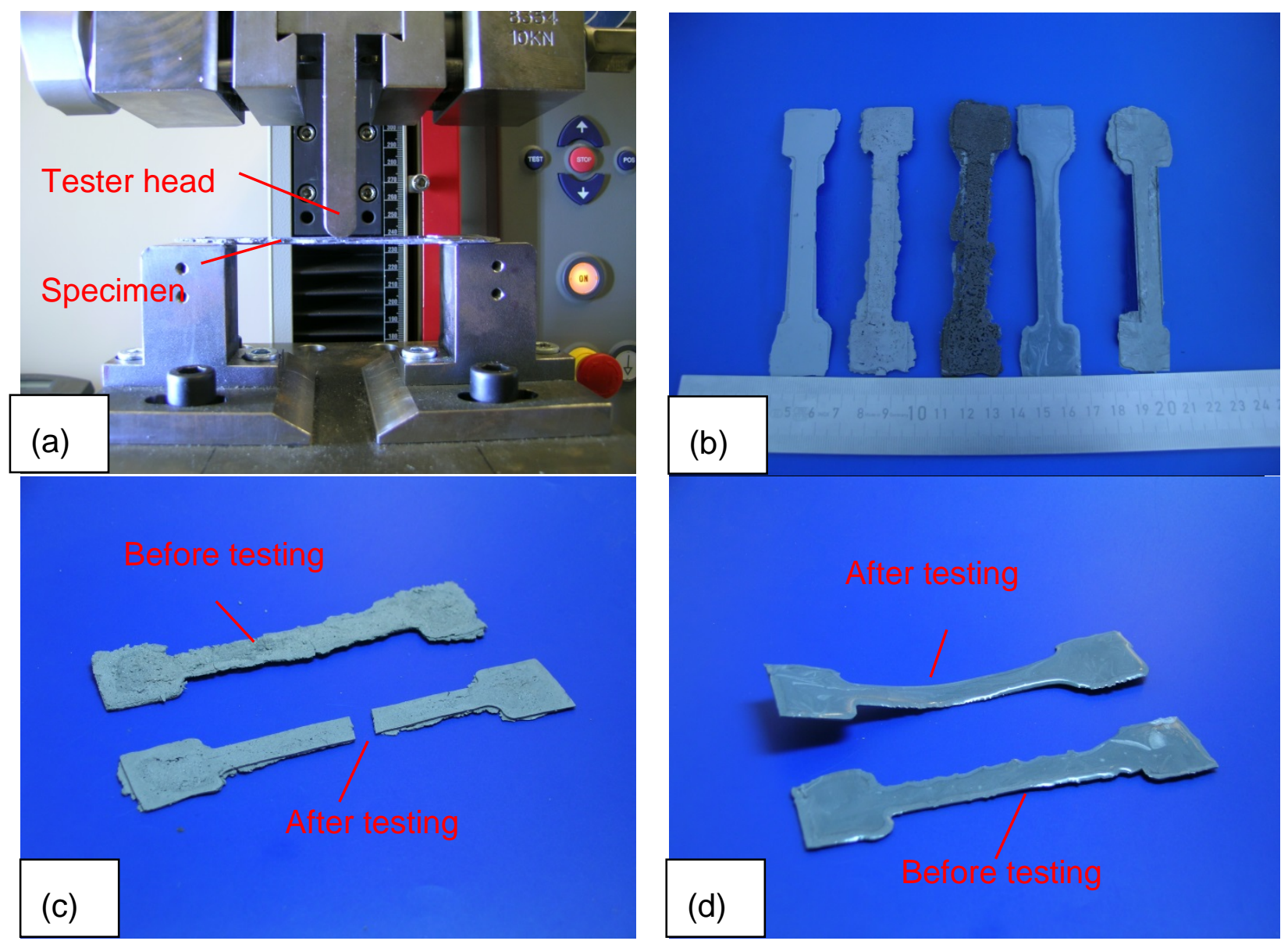

Figure 4.20: (a) three point bending tester and (b) testing specimens from liquid metals, from the left to the right are Loctite steel epoxy, Durabond, Blue magic Loctite aluminum epoxy and BOLDT and the specimen from Durabond (c) and Loctite steel epoxy (d) before and after bending test.

Illustrated in Figure 4.19, the microstructures on the tools collapsed after embossing indicating brittleness of the material. In liquid metals, the coarse metal particles were glued randomly. This results in porous materials full of flaw cavities with inner stress inside. Besides, particles are interconnected to each other only by cured resin glue. 
The particle distribution in the material could be the basic reason for the poor mechanical properties.
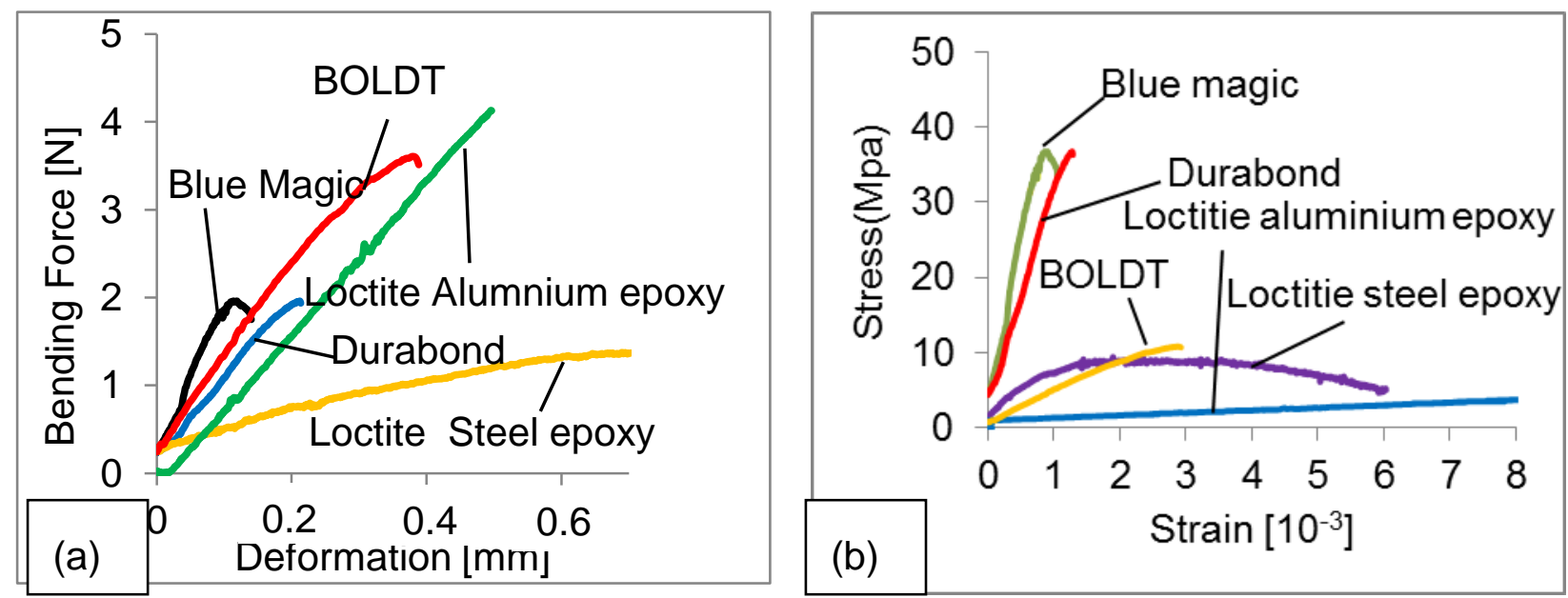

Figure 4.21: (a) measured curve of load and displacement; (b) calculated flexural stress and strain curve of liquid metals.

Rough surfaces have been proven to be harmful for demolding in hot embossing [97]. Worse porous surfaces are detrimental for demolding in ultrasonic hot embossing. As shown in Figure $4.18 \mathrm{e}$ and $\mathrm{d}$, the surface of the two liquid metals are full of intricate voids, into which the molten polymer flows. Figure 4.22 shows a photo of a cut through a tool from Blue Magic liquid metal with embossed PP remaining inside. The PP was embedded in the liquid metal. The PP foils were hard to depart from the tools from liquid metal after ultrasonic hot embossing.

In the product datasheet listed in Table 4.3 the resistance temperature of Loctite liquid metal is only as high as $190^{\circ} \mathrm{C}$. In Chapter 3, the temperature of the metal embossing tool has been measured being over $100^{\circ} \mathrm{C}$. But in the liquid metal tools, the temperature seemed to be even higher than $190^{\circ} \mathrm{C}$ because melting of the tool appeared (cf. Figure 4.19 a). The insufficient temperature durability is probably another reason why liquid metal is not a suitable material for a tool for ultrasonic hot embossing.

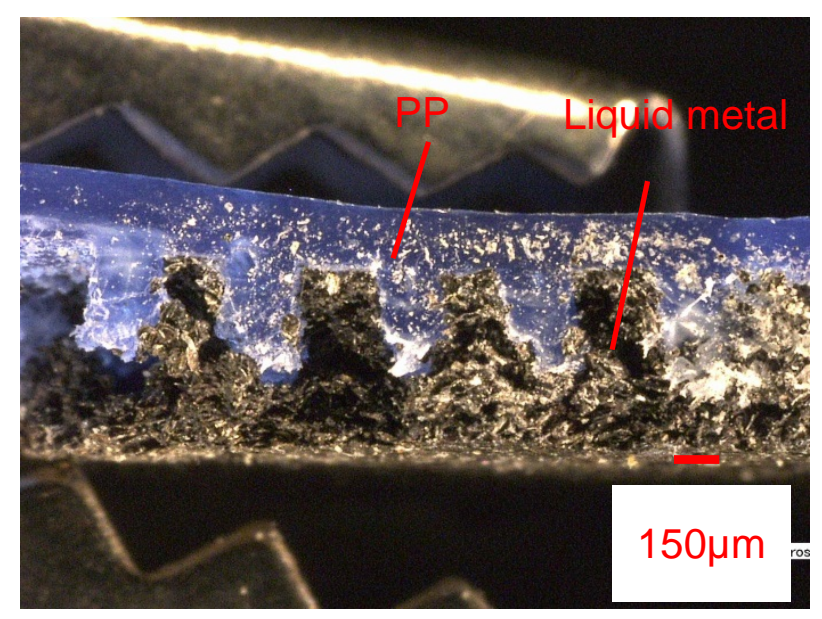

Figure 4. 22: Cross section of the embossed PP with liquid metal. 
Table 4.5: Calculated elastic modulus and flexural strength of all liquid metals.

\begin{tabular}{c|c|c||c|c|c}
\hline Name & $\begin{array}{c}\text { Elastic } \\
\text { modulus E } \\
\text { [GPa] }\end{array}$ & $\begin{array}{c}\text { Flexural } \\
\text { strength } \sigma \\
{[\mathrm{MPa}]}\end{array}$ & $\begin{array}{c}\text { Name } \\
\text { Durabond }\end{array} 28$ & $\begin{array}{c}\text { Elastic } \\
\text { modulus E } \\
{[\mathrm{GPa}]}\end{array}$ & $\begin{array}{c}\text { Flexural } \\
\text { maximum } \\
\text { stress } \sigma \\
{[\mathrm{MPa}]} \\
10.5\end{array}$ \\
BOLDT magic & 31 & 33 & $\begin{array}{c}\text { Loctite } \\
\text { aluminum } \\
\text { epoxy } \\
\text { Loctite steel } \\
\text { epoxy } \\
\text { PC }\end{array}$ & 4.6 & 9.4 \\
\hline
\end{tabular}

\subsection{Conclusions}

The simplest, quickest, and cheapest way to produce a tool for ultrasonic hot embossing is milling into the surface of a plate from aluminum or brass. If microstructures smaller than approximately $100 \mu \mathrm{m}$ are required, electroplating nickel on a template patterned by photo or x-ray lithography is a good solution. The template may also be fabricated by a combination of different production techniques such as photo lithography and milling, drilling, or silicon etching. 


\section{Tools for special applications}

In this chapter, the capabilities of tool fabrication for ultrasonic hot embossing are demonstrated by some special example applications. The surface shape of a Fresnel lens could not be fabricated with the available equipment by milling or lithography, and therefore, the tool was manufactured by electroplating onto an existing polymer lens. The tools for fabricating micro nozzles with a diameter varying in axial direction and for generating conductor paths on a three-dimensionally shaped substrate was generated by micro milling free-form structures into an aluminum plate. Finally, micro structures, just $600 \mathrm{~nm}$ in depth, were ultrasonically hot embossed with a tool electroplated onto a silicon wafer with photolithographic resist structures.

\subsection{Fresnel lens}

Fresnel lenses are employed when a large aperture and short focal length are required, for instance, as a magnifier or for many other optical purposes such as a screen display [102], solar light control in buildings [103] and in a spectrometer [104]. In industrial production, Fresnel lenses have been fabricated by injection molding [105] and here it was for the first time produced by ultrasonic hot embossing.

A lens from a PC plate was employed as the template for nickel electroplating. Its shape included steps of $3 \mu \mathrm{m}$ and $0.5 \mathrm{~mm}$ wide convex areas (cf. Figure 5.1) which cannot be milled with the equipment available at $\mathrm{KE} \mu$. Around $15 \mathrm{~nm}$ titanium and $15 \mathrm{~nm}$ gold were sputtered onto the PC plate lens. As the melting temperature of PC is as high as $220^{\circ} \mathrm{C}$, there was no material molten during sputtering. Later a $350 \mu \mathrm{m}$ thick nickel layer was electroplated within $15 \mathrm{~h}$ generating a tool for ultrasonic hot embossing (cf. Figure $5.1 \mathrm{a}$ ).

This tool was employed for ultrasonic hot embossing of lenses on PC plates, $750 \mu \mathrm{m}$ in thickness. while other transparent polymer plates like PMMA or PET are also possible and have been successfully embossed as well. The nickel tool as well as the embossed lens from PC are shown in Figure $5.1 \mathrm{a}$ and $\mathrm{b}$ and the magnification of some numbers on a pencil are seen in Figure $5.1 \mathrm{c}$ through the produced PC lens. The surface profiles of central facet structures of the original lens, the embossing tool and the replicated lens were measured with a profilometer (Bruker Dektak XT) and are shown in Figure $5.1 \mathrm{~d}$. For convenient comparison, the curve of the Ni tool was reversed. No significant dimension difference was observed at these structures. The embossing process was carried out with the Branson 2000IW+ welding machine with the embossing parameters: embossing force of $1572 \mathrm{~N}$ and embossing time of $0.7 \mathrm{~s}$. When embossing was tried with a polymer plate thicker than $500 \mu \mathrm{m}$, the heat generated by friction between sonotrode, polymer and embossing tool was insufficient to melt the polymer. An auxiliary anvil heating turned out being necessary. Thus the anvil was heat up to $60^{\circ} \mathrm{C}$ as measured by a thermo couple.

Compared to injection molding, which requires an injection pressure of $90 \mathrm{MPa}$ and a total cycle time of $15 \mathrm{~s}$ for heating and cooling [105], only $0.7 \mathrm{~s}$ is needed by ultrasonic hot embossing to produce the Fresnel lens. 

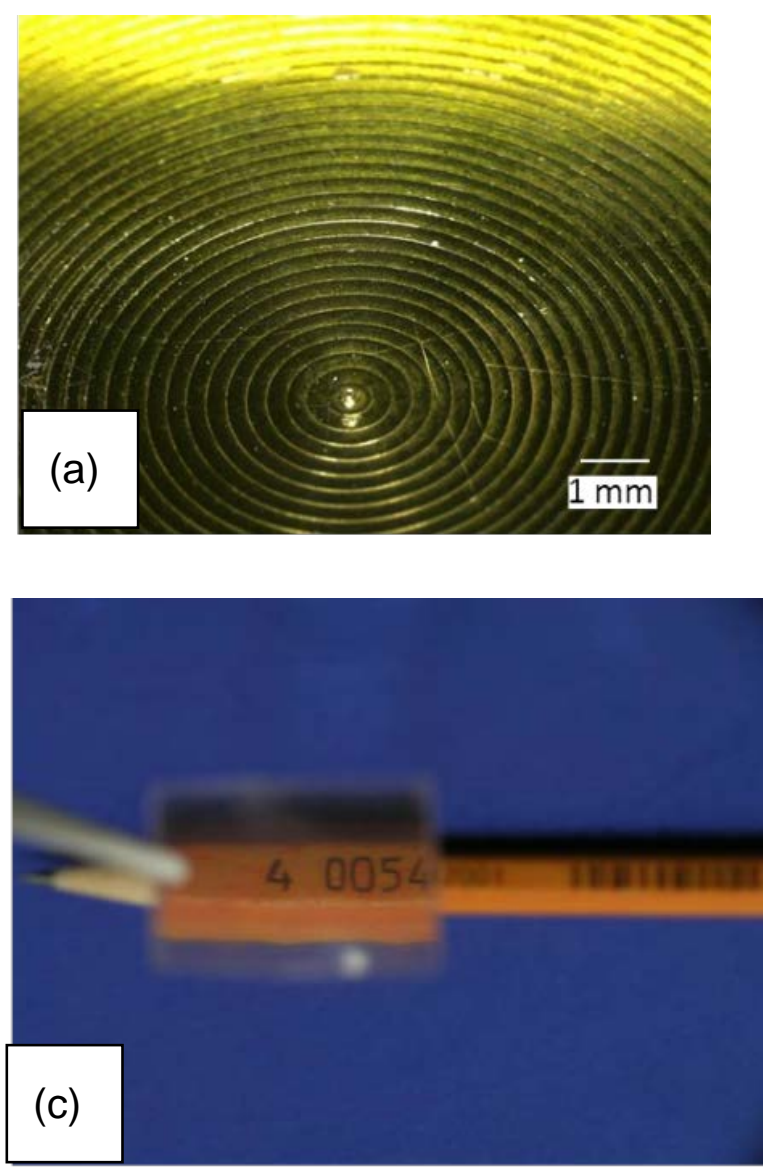
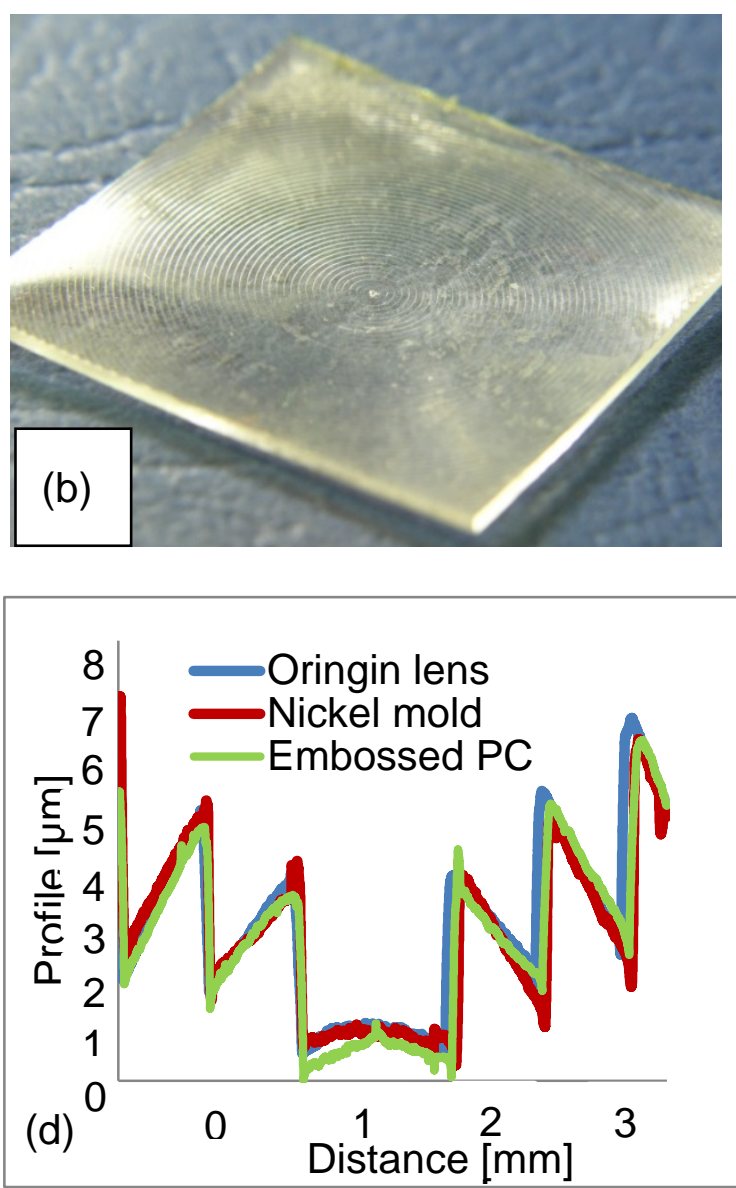

Figure 5.1: (a) Nickel tool for ultrasonic hot embossing of a Fresnel lens; (b) Fresnel lens embossed into a PC plate; (c) magnification of a pencil, and surface profile of the original lens, nickel tool and embossed PC plate (d).

\subsection{Micro nozzles for generating liquid/liquid and gas/liquid dispersions}

Bubbly and slug, Taylor flow, churn and slug-annular flow, and dispersed annular flow [106] are six different flow types in micro channels. The transition of these regimes is a function of flow velocities, phase ratios, fluid properties of the phases, channel geometry and the wettability of the micro channel $[107,108]$. For gas/liquid and liquid/ liquid phase dispersion, micro channel structures $[109,110]$ and modeling approaches [111] are mainly used to realize the dispersion, which acquire energy for the generation of bubbles. Further dispersion decreases the size of the dispersed phase and enlarges the specific surface enhancing the transport process, thus more energy has to be provided for secondary flow structures as vortices [112, 113]. Air agitation and electrical input via a laser are common methods for external energy input. Besides, geometrical changing, e.g., a nozzle is another option, in which the flow pressure is transformed to kinetic energy for phase dispersion. Nozzles from metal have been produced to break up the gas/liquid phase by generating shear and pressure forces in [114]. Polymer nozzles were here firstly produced by ultrasonic hot embossing and later tested on their ability for phase dispersion and re-dispersion. The material replacement from metal to polymer is interesting because polymers have different physical and chemical properties, such as surface energy and surface 
wettability. Besides, nozzles from polymer are faster and cheaper fabricated than from metal. The fabrication process of the nozzle is described in the following.

\subsubsection{Embossing tool fabrication}

The schematic drawing of the nozzle design is shown in Figure 5.2, in which both the nozzle and the in/outlet channels have a circular cross-section. Two kinds of nozzles were designed, $7 \mathrm{~mm} / 4.3 \mathrm{~mm}$ in length and $250 \mu \mathrm{m} / 150 \mu \mathrm{m}$ in diameter, while the dimensions of inlet/outlet channels were $880 \mu \mathrm{m} / 960 \mu \mathrm{m}$ in diameter. To produce the round nozzle, two halves of the reverse pattern of the nozzle were produced on tools and used as a tool for ultrasonic hot embossing. Later the two separate embossed parts were welded on top of each other generating the desired nozzle. An Al plate, $4 \mathrm{~mm}$ in thickness, was milled by the Datron milling machine (M7 HP). The milling time for a single tool was $3 \mathrm{~h} 20$ minutes. The photos of milled tool and the details of the nozzle are shown in Figure 5. Energy directors for ultrasonic welding are also indicated in Figure $5.3 \mathrm{~d}$. The overall dimensions of the embossing tool are $45 \mathrm{~mm} \times$ $27 \mathrm{~mm}$.

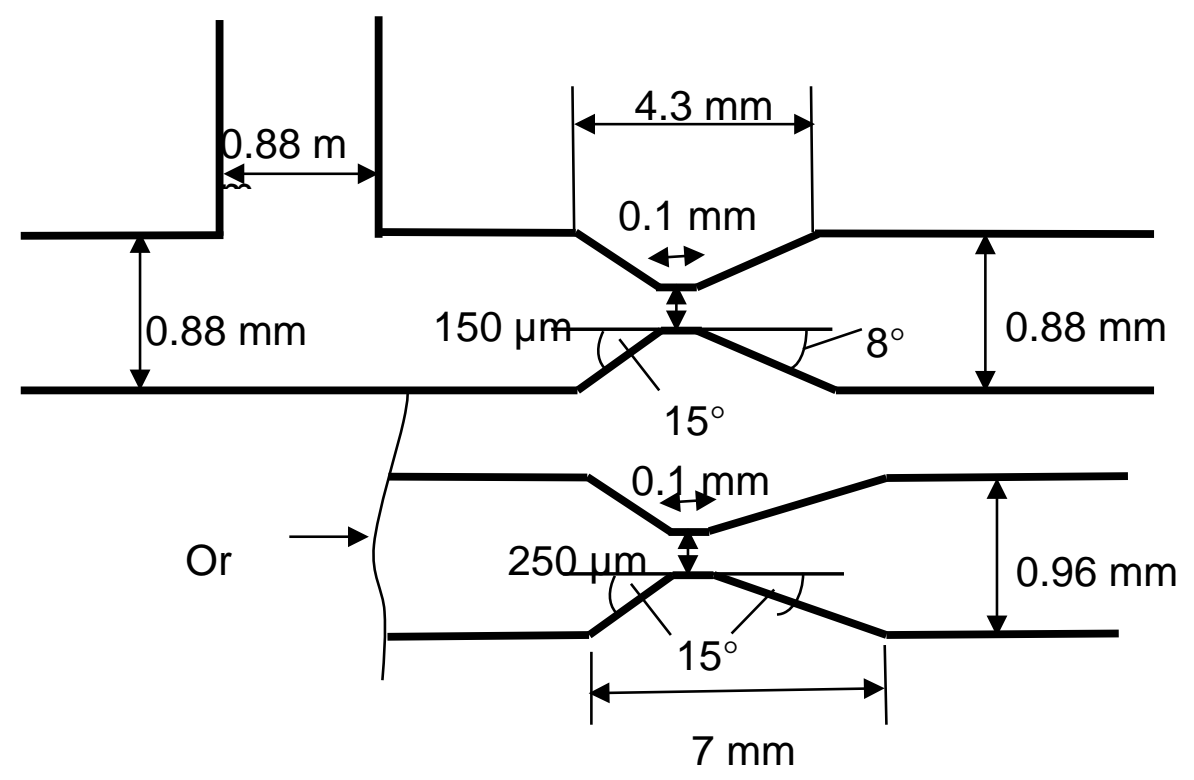

Figure 5.2 : Nozzle design with inlet and outlet. 

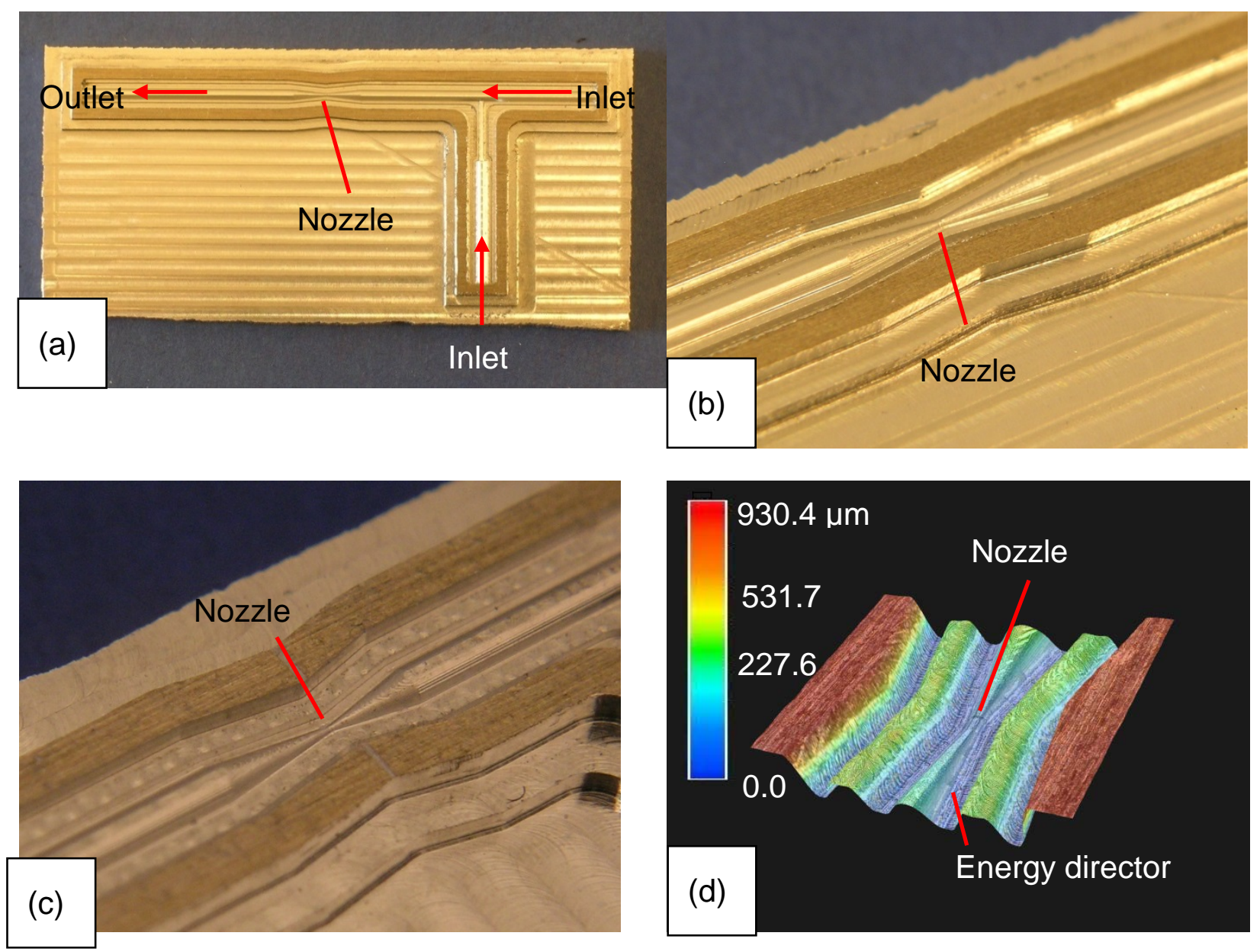

Figure 5.3: (a) tools for embossing nozzles; (b) nozzle of $250 \mu \mathrm{m}$ in diameter; (c) nozzle of $150 \mu \mathrm{m}$ in diameter; (d) 3-dimensional photo of the nozzle.

Another fabrication way is milling combined with nickel electroplating as mentioned in chapter 4.2.2. Employing a milling tool with a round head, milling of a dome-shaped channel is easier than milling of a dome-shaped bar. Therefore, it is another option first to mill the desired shapes of the halves of the nozzle as a grove into an aluminum plate and then to electroplate onto this template. After electroplating, most of the aluminum substrate was milled off. Only a thin aluminum layer(around $150 \mu \mathrm{m}$ in thickness) still remained and etched by heated $\mathrm{KOH}$ (around $100^{\circ} \mathrm{C}$ ) lasting about 1 hour. This way, the reverse of the nozzle halves were obtained as protruding bars on a nickel plate.

The milled Al plate and electroplated Ni tool are shown in Figure $5.4 \mathrm{a}$ and the nozzle on the $\mathrm{Ni}$ tool is seen in Figure $5.4 \mathrm{~b}$. Both the nickel as well as the aluminum tool turned out being suitable for ultrasonic hot embossing and they both showed the desired geometry. Therefore, it is concluded that direct milling of the desired tool structure is quicker and cheaper but, if it is only possible milling the reverse geometry, the combination of milling and electroplating is a good alternative. 

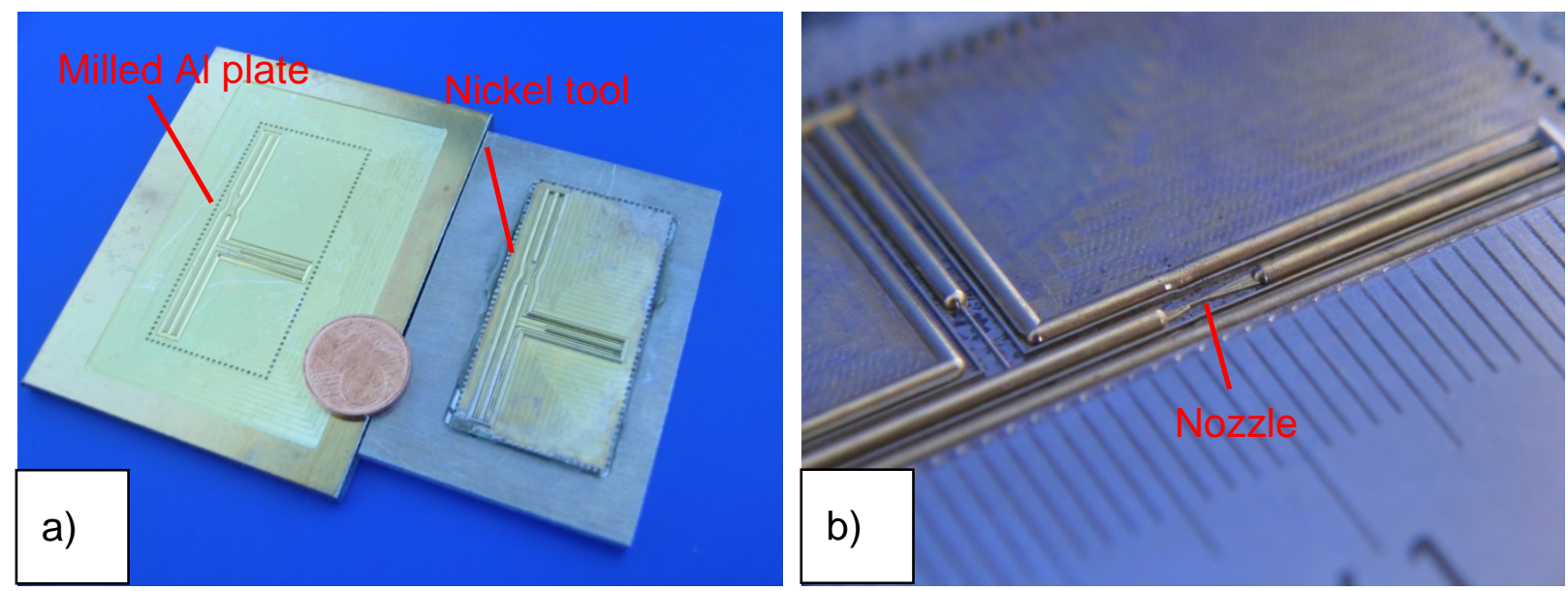

Figure 5.4: (a) Milled Al plate and electroplated Ni tool; (b) detail of the nozzle structure, $150 \mu \mathrm{m}$ in diameter, on the Al plate.

\subsubsection{Production of the nozzle}

The micro channels containing the nozzles were made of up to 9 PVDF foils, each $100 \mu \mathrm{m}$ in thickness, by ultrasonic hot embossing. The Branson 2000IW+ welding machine was used for ultrasonic hot embossing and welding, the process parameters are listed in Table 5.1. The energy for welding is less than for embossing by less embossing force, time and amplitude.

Table 5.1: Parameters used for ultrasonic hot embossing and welding.

\begin{tabular}{lll}
\hline Embossing parameters & Ultrasonic hot embossing & Ultrasonic welding \\
Embossing force & $1258 \mathrm{~N}$ & $629 \mathrm{~N}$ \\
Ultrasonic amplitude & $32 \mu \mathrm{m}$ & $24 \mu \mathrm{m}$ \\
Time of ultrasonic vibrations & $700 \mathrm{~ms}$ & $380 \mathrm{~ms}$ \\
\hline
\end{tabular}

When a micro channel is welded from two halves, small tolerances are required to achieve the desired cross-section. The channel walls on both sides were welded together by energy director alignment. As shown in Figure $5.5 \mathrm{a}$, at the sides of the upper half the energy directors were produced as protruding bars along the channel while at the sides of the lower channel halves a recess was generated aligning the energy director of the upper half. The volumes of the energy director and the recess were designed being equal: the width and depth of the energy director were $250 \mu \mathrm{m}$ and $400 \mu \mathrm{m}$, respectively, while width and depth of the recess were $400 \mu \mathrm{m}$ and $250 \mu \mathrm{m}$, respectively. The purpose of this design is on the one hand to align the two embossed parts. On the other hand, the narrower energy director is easier to weld inside the recess and the melted polymer can fill up the recess without leaking into the channel.

Figure $5.5 \mathrm{~b}$ shows a cut perpendicular through the welded channel. The welding seam of energy director and recess are visible. The channel with a nearly circular cross-section was successfully welded from two halves. Deviations were observed when too less or too much energy was applied during ultrasonic welding. Over 
welding induces a deformation of the channel or even the nozzle was occluded, while with not enough energy, a significant gap was left between the contacting surfaces of the two channel walls even though the channel was sealed, enlarging the channel dimensions. With proper welding parameters, well welded nozzles were obtained. Figure 5.6 shows cuts in axial and perpendicular direction through the nozzle.
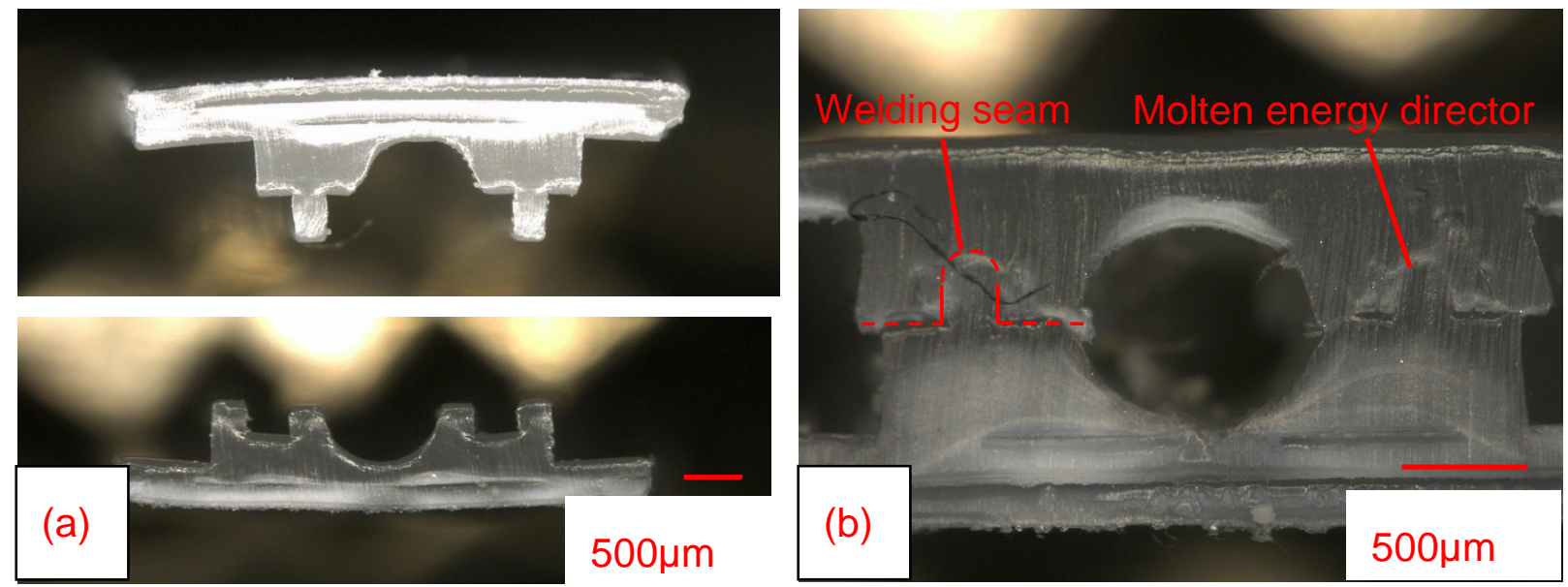

Figure 5.5: (a) separated energy director and the corresponding cap; (b) radially cut section of welded nozzle.

Leakage was tested at both $20^{\circ} \mathrm{C}$ and $90^{\circ} \mathrm{C}$. Pressed gas was pumped into one opening while the other two openings were closed. The whole specimen was laid inside a water bath to observe the gas coming up due to leakage. All the tested specimens were proven being tight up to a pressure difference of more than $600 \mathrm{kPa}$. The observed mean pressures which could be applied before leakage were $2.9 \mathrm{MPa}$ and $2.5 \mathrm{MPa}$ at $20^{\circ} \mathrm{C}$ and $90^{\circ} \mathrm{C}$, respectively. Leakage occurred mostly either at the connections to the outside or at $90^{\circ}$ curves in the channel.
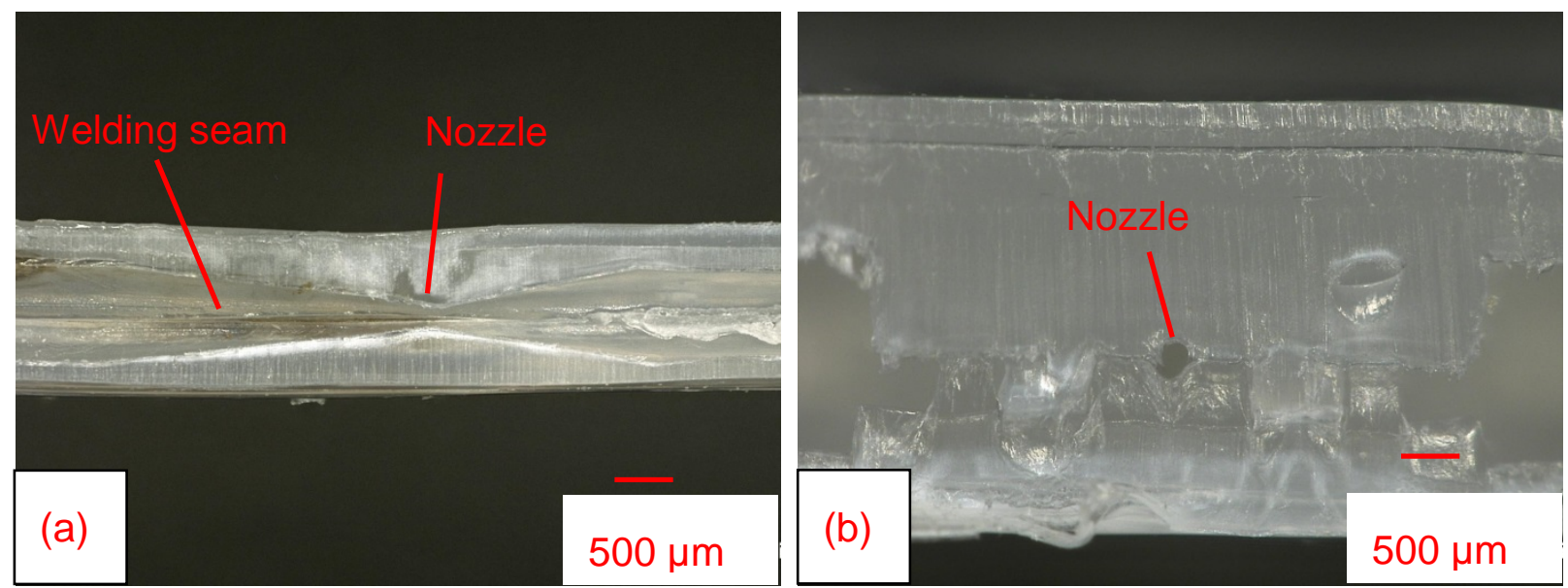

Figure 5.6: Axial (a) and perpendicular (b) cut through nozzles, $250 \mu \mathrm{m}$ in diameter.

\subsubsection{Testing of the micro nozzle}

The phase dispersing testing was accomplished in the laboratory of Equipment Design of Dortmund University and the experimental set up is shown in Figure 5.7 [38]. Two inlets of the polymer structures were separately connected to two syringe 
pumps (HiTec Zang GmbH, Germany). One of the pumps was used for supplying water while the other was exchanged by a rotameter (Aalborg Instruments \& Controls, Inc., USA) for gas/liquid systems. Used substances were deionized water and toluene (Merck KGaA, Germany). The structure was placed under a transmitted-light microscope (Advance ICD (10x)-(160x), Bresser Gmbh, Germany), which was connected to a high speed camera (Xtra Motion NR4, imaging solutions $\mathrm{GmbH}$, Germany) for recording. Frequencies of up to $8500 \mathrm{~Hz}$ and an exposure time of $15 \mu \mathrm{s}$ were used.

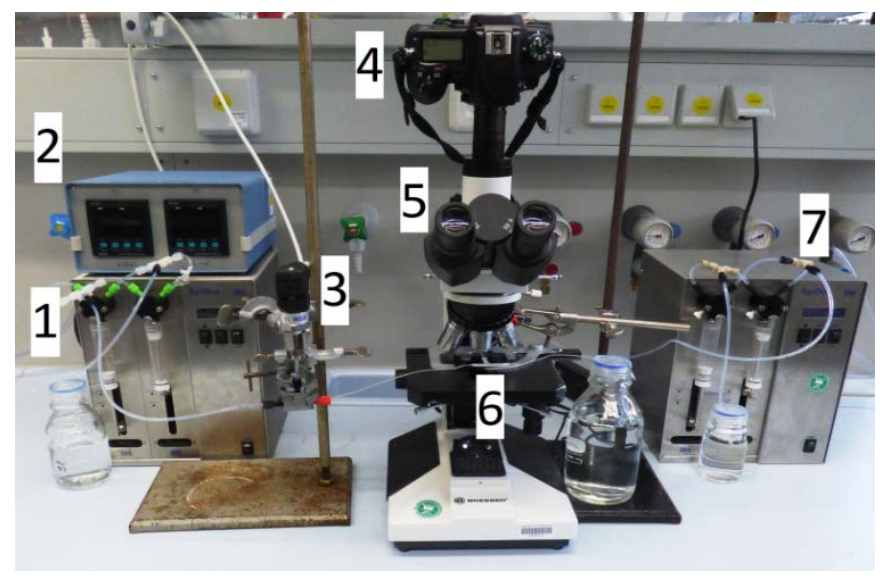

Figure 5.7: Experimental set-up, 1: Syringe pumps for continuous phase, 2: Pressure display, 3: Pressure sensor at the continuous inlet, 4: Digital camera, 5: Microscope, 6: PVDF nozzle structure, 7: Syringe pump of the dispersed phase. Published with permission of Laboratory of Equipment Design of TU Dortmund University.

Turbulent flow was realized at high flow velocity. When this flow passes through the narrow nozzle, the phase dispersion is severe. Large droplets were broken up into swirling bubbles at the outlet of the nozzle $(250 \mu \mathrm{m})$, shown in Figure 5.8. After $2 \mathrm{~ms}$, a large amount of bubbles was generated.

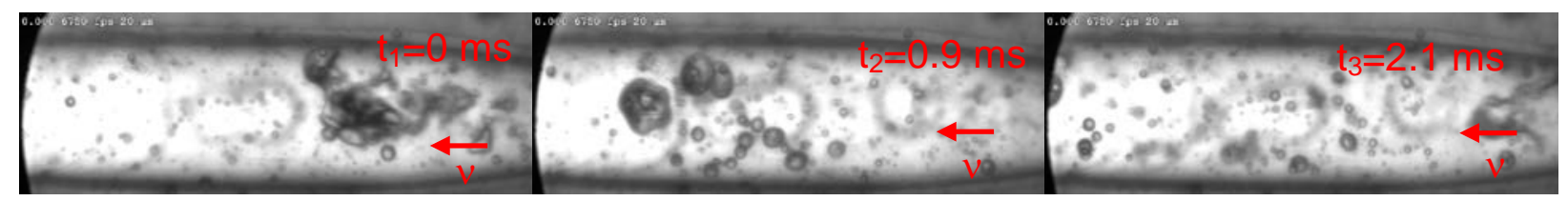

Figure 5.8: Droplets broke up at $0 \mathrm{~ms}, 0.5 \mathrm{~ms}$ and $2.1 \mathrm{~ms}$ for a volume flow rate of 50 $\mathrm{mL} / \mathrm{min}$ and $R e=5870$. Published with permission of Laboratory of Equipment Design of Dortmund University.

\subsection{Spiral coils}

Ultrasonic hot embossing has been used to produce Molded Interconnect Devices (MID) $[45,115]$. These are conductor paths connecting electronic circuits on a circuit board. The fabrication was accomplished by a polymer substrate covered with a copper layer which was partly displaced into the isolating polymer by ultrasonic hot embossing.

It was investigated now, whether also MID on a curved substrate can be generated by ultrasonic hot embossing. As an example, a conductor path in the shape of a spiral coil has been manufactured. 


\subsubsection{Embossing tool fabrication}

The tool for embossing spiral coils was milled on a $4 \mathrm{~mm}$ thick Al plate by the Datron milling machine (M7 HP). The conductor path was designed as a horizontal path, $150 \mu \mathrm{m}$ in width, on a cone-shaped polymer substrate. At the rim of the path there was milled a cutting edge on the tool, about $150 \mu \mathrm{m}$ and $500 \mu \mathrm{m}$ in height and width, respectively. The convex cone was $2 \mathrm{~mm}$ high with a taper angle of $7.8^{\circ}$. The path with the cutting edge at its rim was distributed along a projected spiral curve, shown in Figure 5.9. The polar coordinates of the spiral curve are:

$$
\begin{aligned}
& r(t)=2+t(0.05 \times 250) \\
& \theta=0.05+t(6 \times 360) \\
& z=0
\end{aligned}
$$

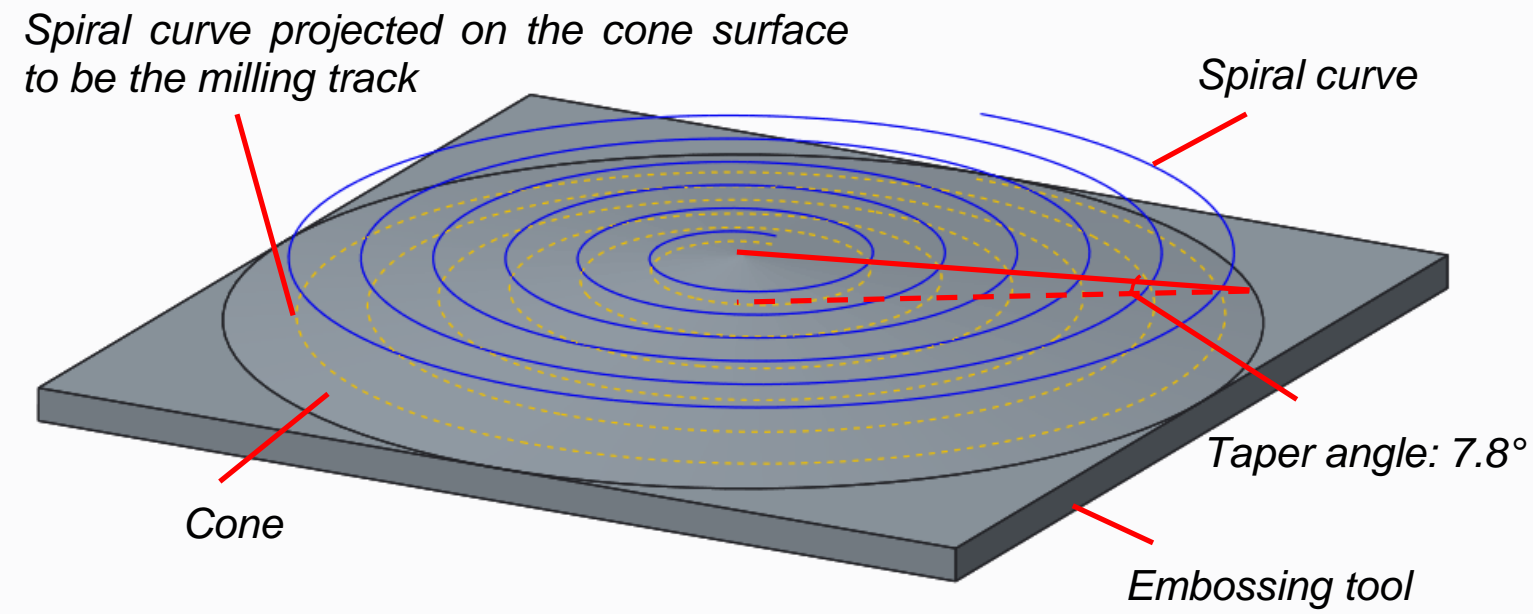

Figure 5.9: Spiral curve distributed on the cone.

A photo of the embossing tool is shown in Figure $5.10 \mathrm{a}$. The polymer employed for embossing was PET, $270 \mu \mathrm{m}$ in thickness. Instead of metal sputtering for making the polymer electric conductive, a cooper foils ( $20 \mu \mathrm{m}$ in thickness) was glue onto the PET by a double side adhesive tape (50 $\mu \mathrm{m}$ in thickness). As the upper surface of the tool is not flat, the embossing energy would had been most concentrated at the highest part -the center - while the other areas would had not been embossed at all. To solve this problem, a concave milled PEEK plate ( $4 \mathrm{~mm}$ thick) was applied between PET foils and sonotrode during embossing as shown in Figure $5.10 \mathrm{~b}$. The dimension of the concave recess on the PEEK plate is the reverse of the convex cone on the embossing tool. The PEEK plate forced the PET foils to adapt to the shape of the tool but was not welded together with the PET since no chemical bound happened.

There are two dimension limits for designing the tool. One is the minimum width of the cutting edge at the rim. The working principle of the edge is to cut the copper foil. The narrower the edge, the better cutting quality is achieved. The aspect ratio of the structure in Figure $5.10 \mathrm{a}$ is $500 / 150=3.33$. Edges with higher aspect ratios were milled as well. But when embossing with a narrower edge, some parts of the edge deformed after several embossings because of the inferior strength for such an ex- 
treme structure. The $150 \mu \mathrm{m}$ wide edge was applied for embossing for more than 20 times without any deformation and the cutting quality was also satisfying.
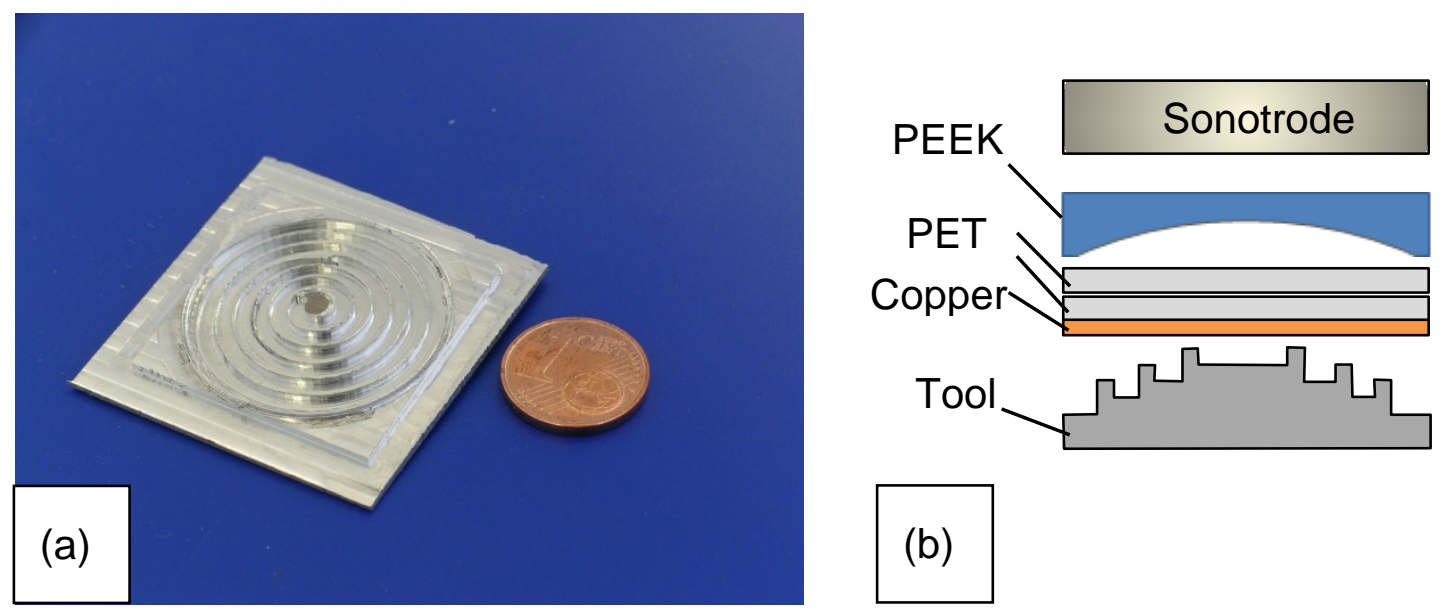

Figure 5.10: (a) embossing tool; (b) arrangement of ultrasonic hot embossing on a curved surface

The other limit is the maximum height of the cone on the tool. The height of the convex cone in Figure $5.10 \mathrm{a}$ is $2 \mathrm{~mm}$ with a taper angle of $7.8^{\circ}$. Another tool with a height of the convex cone of $5 \mathrm{~mm}$ with a taper angle of $18.5^{\circ}$ was also produced and could not yet be employed successfully for ultrasonic hot embossing. Ultrasonic hot embossing with the higher tool failed because the PET used needed to be bent more to adapt to the shape of the steeper cone. More energy is required to accomplish the embossing. If too much energy was applied, the reverse PEEK plate was broken into pieces and the structures were still not embossed. Thus the maximum structure which has been successfully applied is $2 \mathrm{~mm}$ high.

Two layers of PET were embossed by the Branson 2000IW+ welding machine with embossing force: $943 \mathrm{~N}$, embossing time: $270 \mathrm{~ms}$, amplitude: $22.5 \mu \mathrm{m}$ and cooling time for solidification: $4 \mathrm{~s}$. The cut through the middle of the embossed 3D spiral coil and its details are shown in Figure 5.11, in which the concave conductive path was formed with the taper angle of approximately $7.8^{\circ}$.
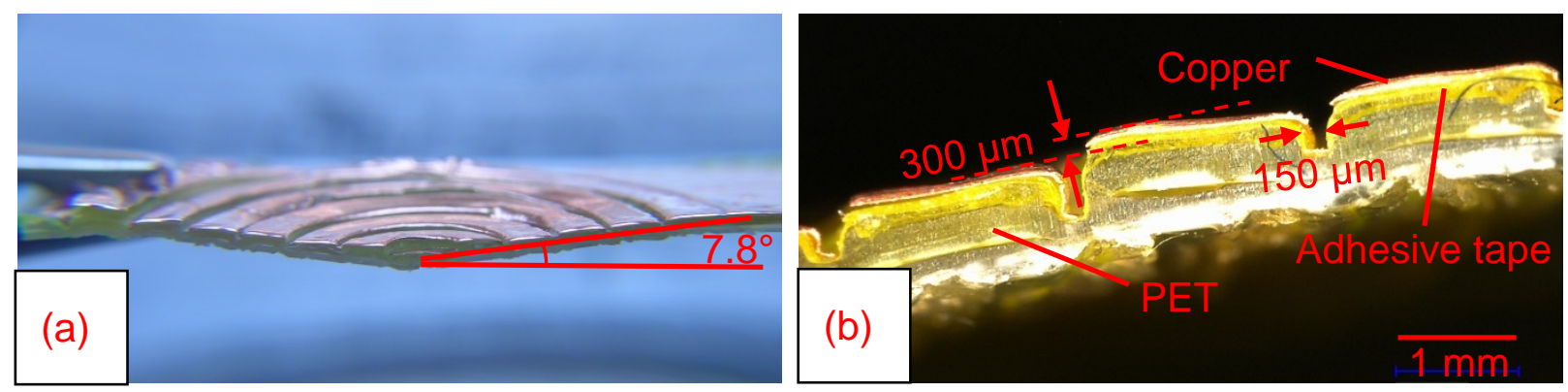

Figure 5.11: Cut through the conductor path of the spiral coil: (a) total view; (b) magnification.

\subsubsection{Evaluation of spiral coil}

The resistance and inductance of the spiral coil produced by ultrasonic hot embossing was measured to be $0.2 \Omega$ and $100 \mathrm{nH}$. An SMD capacitor with $100 \mathrm{nF}$ was 
soldered to the center and the end of the coil to build an oscillator (cf. Figure $5.12 \mathrm{a}$ ). The resonance frequency of this oscillator was calculated by:

$$
f=\frac{1}{2 \pi \sqrt{L C}}
$$

Where $\mathrm{C}=100 \mathrm{nF}$ and $\mathrm{L}=100 \mathrm{nH}$.

Thus, the resonance frequency $\mathrm{f}$ is $1.6 \mathrm{MHz}$ and the measured value was $1.65 \mathrm{MHz}$. Another air coil with $1.4 \mathrm{mH}$ was isolated from the spiral coil by a $3 \mathrm{~mm}$ thick polymer plate. The air coil provided electromagnetic induction to the spiral coil with alternating frequency sweeping from $0 \mathrm{kHz}$ to $2 \mathrm{MHz}$. The arrangement of the two coils and the schematic drawing of the whole testing electronics is shown in Figure $5.12 \mathrm{~b}$ and c. The resonance frequency of the resonance circuit was measured to be around 1.7 $\mathrm{MHz}$ and shown by the oscilloscope (Tektronix 7DS 1002B), cf. Figure $5.12 \mathrm{~d}$. The ordinate value is the voltage to indicate the amplitude of resonance wave with $1 \mathrm{mV} /$ division while the abscissa value is frequency with $0.1 \mathrm{MHz} /$ division.
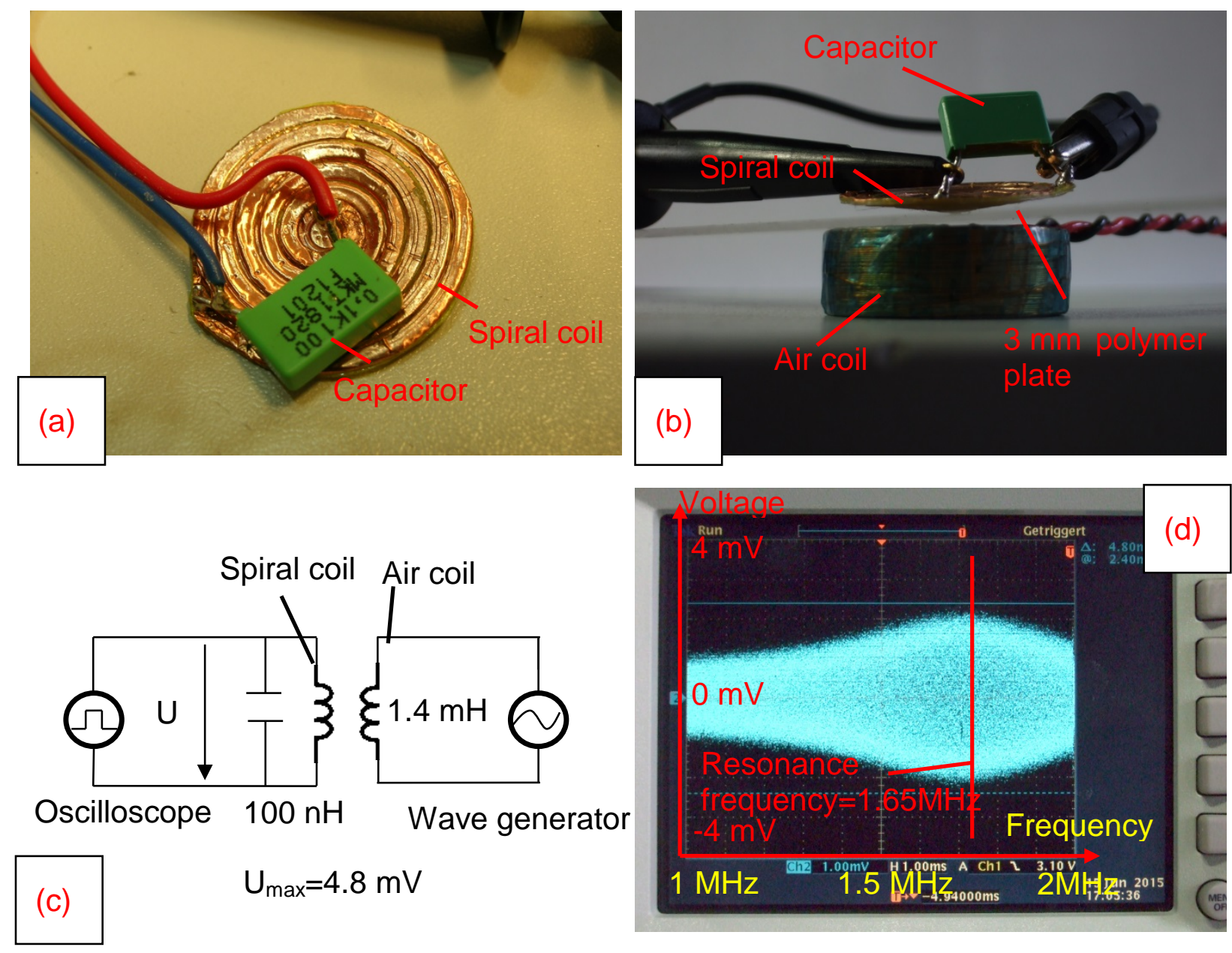

Figure 5.12: (a) Spiral coil soldered with capacitor; (b) arrangement of air coil and spiral coil; (c) schematic drawing of electronic testing process (d) screen display on an oscilloscope showing the function of voltage and frequency. 


\subsection{Hydrophobic surfaces}

In recent years, hydrophobic surfaces, which have static contact angles of more than $90^{\circ}$ have attracted much attention for fundamental research. Especially super hydrophobic surfaces with a contact angle of more than $150^{\circ}$ were greatly noticed $[17,116]$. Originated from the lotus effect, super hydrophobic surfaces were found out to be water repelling and self-cleaning $[117,118]$. Therefore, lots of practical applications have been derived, such as super hydrophobic coatings on antennas to prevent snow or rain adhesion [119], or umbrellas with water repellant coatings [120] etc.

\subsubsection{Hydrophobic surface fabrication}

Most of the surface modification methods are based on adjusting material chemical compositions. Besides, surface morphology like roughness and distributed micro Inano structures also modify material wettability. At KE $\mu$ four polymers: PA, PVDF, PE, and PPHM (PP with high Young's modulus) were micro patterned by ultrasonic hot embossing and the wettability of these four surfaces was investigated. Two types of embossing tools were applied: a LIGA (Shortname of Lithographie, Galvanik und Abformung in German) tool from nickel with the inverse of a honeycomb structure (10 $\mu \mathrm{m}$ and $50 \mu \mathrm{m}$ for rim width and length) [71] and an Al tool with arrays of periodic holes $(50 \mu \mathrm{m}, 50 \mu \mathrm{m}$ and $100 \mu \mathrm{m}$ in diameter, depth and period), some optical and SEM photos of which are shown in Figure 5.13.

All the polymer layers employed for ultrasonic hot embossing of superhydrophobic micro structures were $100 \mu \mathrm{m}$ in thickness and always four layers were applied using the Branson 2000IW+ welding machine. The embossing parameters for the LIGA and the Al tool are listed in Table 5.2. The height of embossed structures: hexagon pillars and round pillars were measured and listed in Table 5.3. Worth to mention that all the polymers except PA had been fully embossed when the Al tool was employed and the parameters listed in Table 5.3 were used. This is recognized by the fact that the heights of the embossed structures are nearly the same as the depth of the holes in the tool. But the polymers were not completely embossed by the LIGA tool. Best results have been obtained with PVDF filling only half of the height of the LIGA tool, while other polymers were filling only about $30 \%$ of the depth of the embossing tool. In ultrasonic hot embossing applying more embossing energy would improve polymer melting and better filling of the tool can be achieved, which were also investigated by $[36,121]$. 

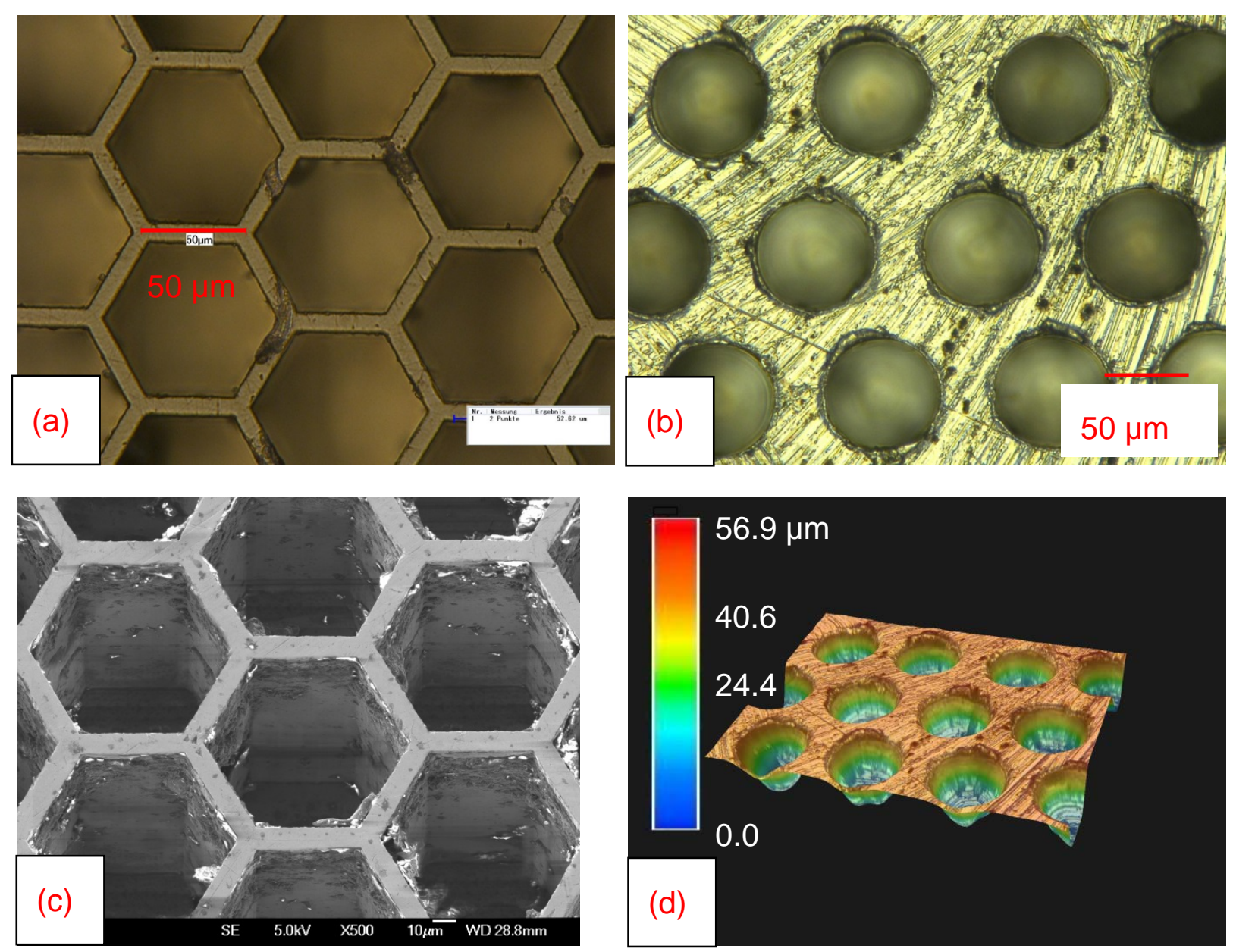

Figure 5.13: Photos of embossing tools: (a) LIGA nickel tool; (b) Al tool; (c) SEM photo of LIGA tool; (d) 3-dimensional measurement of AL tool. ( $a, b, d$ ) were taken by a Keyence microscope.

Polymers with high melting temperature and stiffness are harder to emboss. Taking PA and PVDF embossed with the LIGA tool for instance, the melting temperature of $\mathrm{PA}$ and PVDF are $260^{\circ} \mathrm{C}$ and $174^{\circ} \mathrm{C}$, respectively. The embossed structure height on PA is less than on PVDF even though more embossing time had been applied on PA. In addition, Table 5.2: Parameters used for ultrasonic hot embossing on LIGA and Al tool.

\begin{tabular}{lll}
$\begin{array}{lll}\text { Embossing } \\
\text { parameters }\end{array}$ & LIGA tool & Al tool \\
Embossing force & $1258 \mathrm{~N}$ & $1258 \mathrm{~N}$ \\
Ultrasonic amplitude & $24 \mu \mathrm{m}$ & \multicolumn{2}{c}{$16 \mu \mathrm{m}$} \\
& & \\
Time of ultrasonic & PA: & $250 \mathrm{~ms}$ \\
vibrations & PPHM/PVDF: $150 \mathrm{~ms}$ & $200 \mathrm{~ms}$ \\
& PE: & $185 \mathrm{~ms}$
\end{tabular}
the melting temperature of PVDF and PPHM are nearly the same while the height of embossed structures from PVDF is still higher than from PPHM, showing the suitability of PVDF for ultrasonic hot embossing. 
The embossed structures from PVDF on both tools are shown in Figure 5.14, showing that cylinder pillars instead of hexagon columns were embossed by the LIGA tool because the micro structures on the tool had not been filled completely, cf. Figure $5.14 \mathrm{a}, \mathrm{b}$. But the cylinder columns were successfully embossed into PVDF by the Al tool, cf. Figure $5.14 \mathrm{c}$, d.

Table 5.3: Average depth of structures embossed on LIGA and AI tool, respectively.

\begin{tabular}{cccccr}
\hline Tool & Polymer & $\begin{array}{c}\text { Average } \\
\text { depth }[\mu \mathrm{m}]\end{array}$ & Tool & Polymer & $\begin{array}{c}\text { Average } \\
\text { depth }[\mu \mathrm{m}]\end{array}$ \\
LIGA tool & PA & 38 & Al tool & PA & 29.3 \\
average & PVDF & 94.8 & average & PVDF & 56.4 \\
structure & PPHM & 59.8 & structure depth: & PPHM & 51.4 \\
depth:190 $\mu \mathrm{m}$ & PE & 54.3 & $56.5 \mu \mathrm{m}$ & PE & 42.3 \\
\hline
\end{tabular}
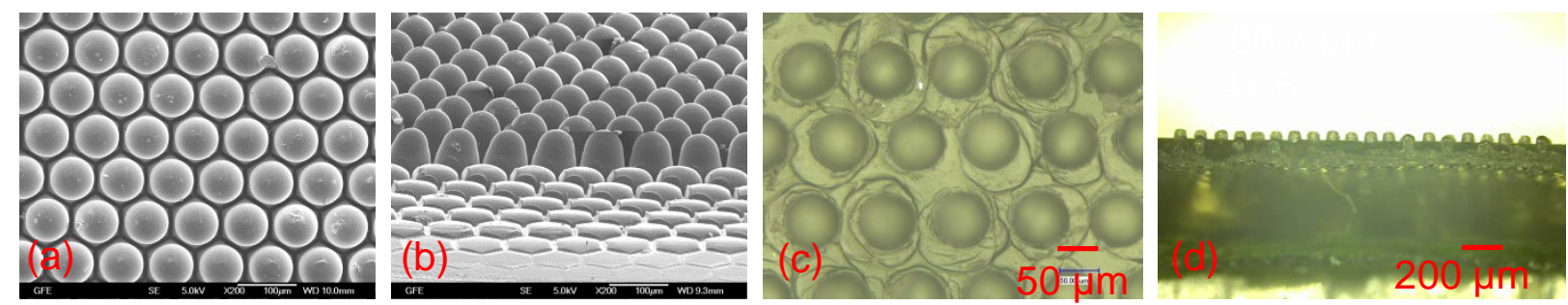

Figure 5.14: Embossed PVDF structures from LIGA tool with top view (a); side view (b) and Al tool with top view (c); side view (d). (c, d) were taken by the Keyence microscope.

\subsubsection{Surface wettablity evaluation}

The wettability of the polymers was evaluated by measuring contact angles $\theta$ on flat and embossed surfaces. The Keyence microscope was used for the measurement and the average values from five specimens were calculated. A deionized water droplet with a radius of approximately $1 \mathrm{~mm}(5 \mu \mathrm{L}$ volume) was dropped onto the surface. The droplet shapes on the flat and embossed polymer surfaces are shown in Figure 5.15 and the definition of the contact angle is illustrated as well. The contact angles of various polymer surfaces are compared in Figure 5.16. 
Flat surface
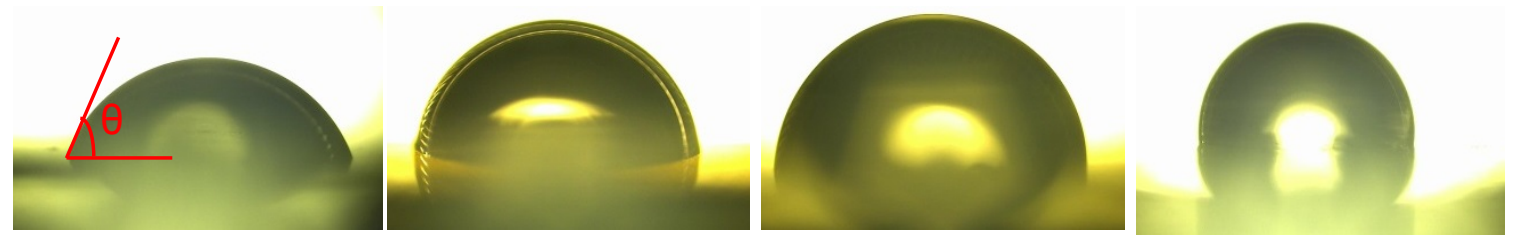

LIGA tool
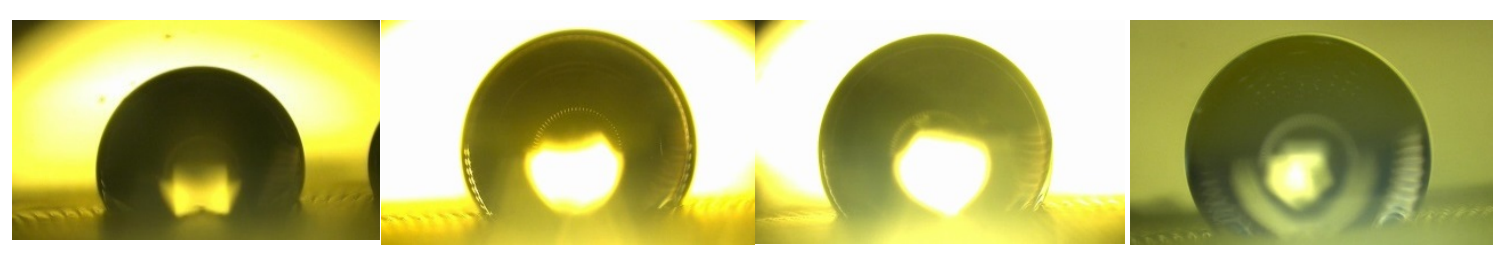

Al tool
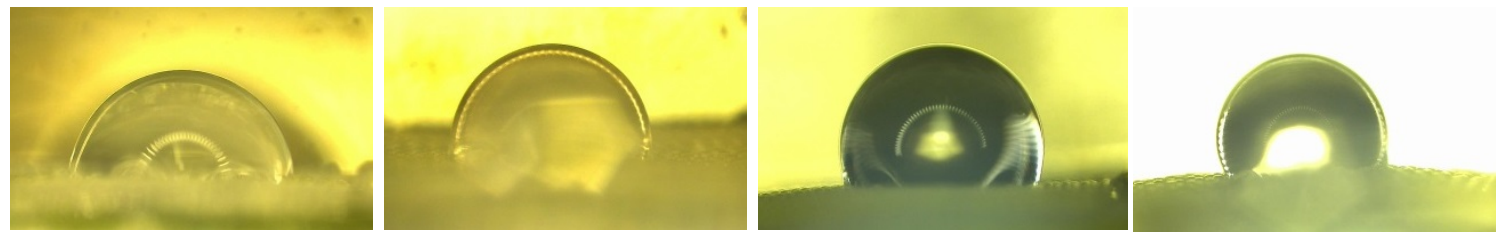

Figure 5.15: Droplet shape on embossed surfaces generated by LIGA tool and AI tool.

From Figure 5.15 and Figure 5.16 it is seen that polymer surface wettability depends not only on material properties but also on the surface pattern. Surface energy of liquid, air and material influence the liquid contact angle to a flat surface [122]. However, surface roughness and patterns can also affect the surface wettability. In the measurement, flat PA, PVDF and PE surfaces were hydrophilic but became hydrophobic after embossing with the LIGA tool. This transfer was most noticeable for PA and

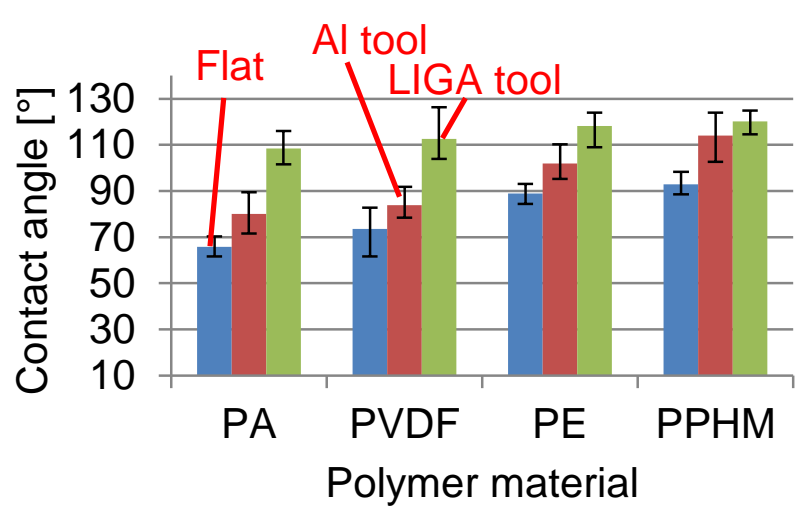

Figure 5.16: Contact angle comparison of flat and embossed polymer surface.

PVDF. The hydrophobicity of

PPHM was also improved after embossing with the LIGA tool. However, the pattern embossed from the Al tool has a comparably limited effect on improving surface hydrophobicity as only the PE and PPHM surface showed hydrophobicity after embossing with the Al tool.

The different performance of LIGA and Al tools on hydrophobicity of the embossed polymers is due to the structure design. To analyze the influence of surface roughness on the contact angle, Wenzel model [123] and Cassie-Baxter [124] model are most used for theoretical evaluation. The schematic drawing of two contacting regimes are shown in Figure 5.17. The structure dimensions are designated as: $\mathrm{m}, \mathrm{n}$, and c for the columns diameter, pit interval and height, respectively. In the Wenzel state a droplet has filled the voids between the surface structures, while in CassieBaxter state, the droplet is suspending above the surface structure with air trapped inside of the voids. 
The equilibrium (contact angle $\theta_{\mathrm{w}}$ ) of the Wenzel contact state is [123]:

$$
\cos \theta_{\mathrm{w}}=\mathrm{r} \cos \theta_{0}
$$

where $\theta_{0}$ is the contact angle on a flat surface, $\mathrm{r}$ is defined as the surface roughness factor, which is calculated by [36]:

$$
\mathrm{r}=1+\frac{2 \mathrm{c}}{\mathrm{m}+\mathrm{n}}
$$

In Cassie-Baxter contact state, the contact angle $\theta_{c}$ is calculated by [124]:

$$
\cos \theta_{\mathrm{c}}=\mathrm{h}\left(1+\cos \theta_{0}\right)-1
$$

Where $\mathrm{h}$ is called the surface fraction under the water drop, which is contacting the liquid. The $\mathrm{h}$ is expressed by [36]:

$$
\mathrm{h}=\frac{\mathrm{m}}{\mathrm{m}+\mathrm{n}}
$$

According to the above formulas, when in the Wenzel state the surface roughness factor is increased, the contact angle is decreased. While in Cassie-Baxter state, increasing the void between structures, e.g., increasing n and decreasing $\mathrm{m}$, results in a smaller surface fraction and the contact angle is increased. Supposed that the embossed structure from LIGA and Al tools were pillar arrays with $\mathrm{m}=$ $50 \mu \mathrm{m}, \mathrm{n}=10 \mu \mathrm{m}$ (LIGA tool)/86.6 $\mu \mathrm{m}$ (Al tool)

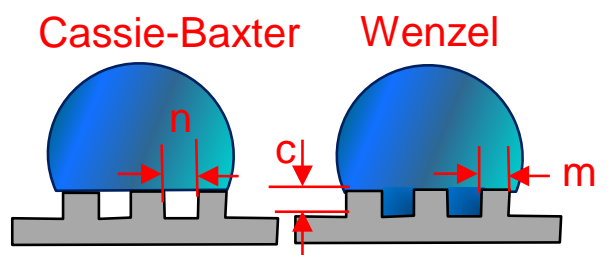

Figure 5.17: Contact regime of droplet, left: Cassie-Baxter state; right: Wenzel state. and $\mathrm{c}$ has been tested (cf. Table 5.3). The r, h, $\theta_{\mathrm{w}}$ and $\theta_{\mathrm{c}}$ and the measured $\theta_{\mathrm{M}}$ were calculated and compared in Table 5.4.

Table 5.4: Calculated surface roughness factor ( $r$ ), surface fraction (h), contact angle $\theta_{\mathrm{W}}$ and $\theta_{\mathrm{C}}$, measured $\theta_{\mathrm{M}}$ and $\theta_{0}$.

\begin{tabular}{llllllll}
\hline $\begin{array}{l}\text { Embossing } \\
\text { tool }\end{array}$ & Polymer & & & & & & \\
LIGA tool & PA & 1.76 & 0.896 & 74.73 & 43.82 & 108.47 & 65.80 \\
& PVDF & 2.896 & 0.896 & 81.45 & 35.26 & 112.51 & 73.62 \\
& PE & 2.196 & 0.896 & 95.02 & 87.69 & 118.27 & 88.95 \\
& PPHM & 2.086 & 0.896 & 98.54 & 95.95 & 120.24 & 92.85 \\
\hline Al tool & PA & 1.586 & 0.5 & 107.16 & 49.45 & 80.08 & 65.80 \\
& PVDF & 2.128 & 0.5 & 111.04 & 53.13 & 83.77 & 73.62 \\
& PE & 2.028 & 0.5 & 119.39 & 87.86 & 101.83 & 88.95 \\
\hline
\end{tabular}




\begin{tabular}{lllllll}
\hline PPHM & 1.846 & 0.5 & 121.66 & 95.27 & 114.00 & 92.85 \\
\hline
\end{tabular}

According to the measurements, all of the surface contact angles were increased after ultrasonic hot embossing. But the Wenzel state calculation for a surface embossed with the LIGA tool shows a reverse trend: contact angles decreased after embossing, except for PPHM. Besides, the deviation between Cassie-Baxter calculation and real measurement is also smaller than from the Wenzel calculation. Thus the contacting state of the surface patterned with the LIGA tool is believed to be in Cassie-Baxter regime, for which the calculated contact angle was increased after embossing. The reason for the deviation between calculated Cassie-Baxter state and measured values could be due to on the one hand measurement uncertainties and on the other hand the fact that for the calculation the embossed structures were supposed to be cylinder columns with $10 \mu \mathrm{m}$ interval, what is achieved only if the micro structures are fully embossed. In fact, the diameter of the columns is less than $87 \mu \mathrm{m}$ and the pit interval is larger than $10 \mu \mathrm{m}$. Thus the real h should be less than 0.9 and the calculated contact angle $\theta_{c}$ should be larger as well. For the surface embossed with the Al tool, the calculated $\theta_{\mathrm{w}}$ is also less than $\theta_{0}$, which is in contradiction to the measurements. By calculation, the $\theta_{M}$ is nearly the middle value between $\theta_{\mathrm{c}}$ and $\theta_{\mathrm{w}}$, the contact state is thereby probably mixed in both states. As the distance between two pillars is $50 \mu \mathrm{m}$, the droplet may tend to drop down severely and contacted partly the bottom of the pillars, resulting in partly wetting on the surface. Thus the measured contact angle $\theta_{M}$ is less than $\theta_{c}$.

Based on the measurement results, the surfaces embossed with the LIGA tool is more hydrophobic than the surfaces embossed with the Al tool. Adjusting surface structures to realize either hydrophobicity or hydrophilicity, much more of theoretical and experimental research needs being carried out $[125,126]$, which is out of the range of discussion here.

In many applications, ultrasonic hot embossing has been proven to be a fast and effective way to pattern polymer surfaces for realizing different functions [17, 39], including hydrophobicity. The key problem is not only the design of the patterns but also the possibility to fabricate the ultrasonic hot embossing tool. As long as the mold can be produced, ultrasonic hot embossing is an option to produce functional surfaces. The methods of many fabrication ways have been discussed on Chapter 4.

\subsection{Nanostructures}

The fabrication of very wide or shallow micro structures is difficult by ultrasonic hot embossing, because the polymer layer next to the tool is in contact to both the protruding micro structure and the rest of the surface. Therefore, the ultrasonic energy is not concentrated on the protruding structures and polymer melting is hard to achieve. In the scientific literature the smallest structures produced by ultrasonic hot embossing are square pillars, $1 \times 1 \mu \mathrm{m}^{2}$ in lateral dimensions and $600 \mathrm{~nm}$ in depth, embossed together with microstructures of $20 \times 20 \mu \mathrm{m}^{2}$ as the base [17]. Here, it was tried to generate nanostructures directly on the polymer surface by ultrasonic hot embossing.

\subsubsection{Embossing tool fabrication}

The design for the nanostructures is a biological chip with various reaction chambers and the inlet/outlet channels. Photolithography $(\lambda=365 \mathrm{~nm})$ was used to fabricate the 
nanostructures in SU8 photoresist on a 4 inch silicon wafer. The thickness of the photoresist was $600 \mathrm{~nm}$. Figure 5.18 shows three patterns for biological purposes on the silicon wafer. The widths of the structure range from $1 \mu \mathrm{m}$ to $50 \mu \mathrm{m}$ while the gaps between structures were even less than $1 \mu \mathrm{m}$.

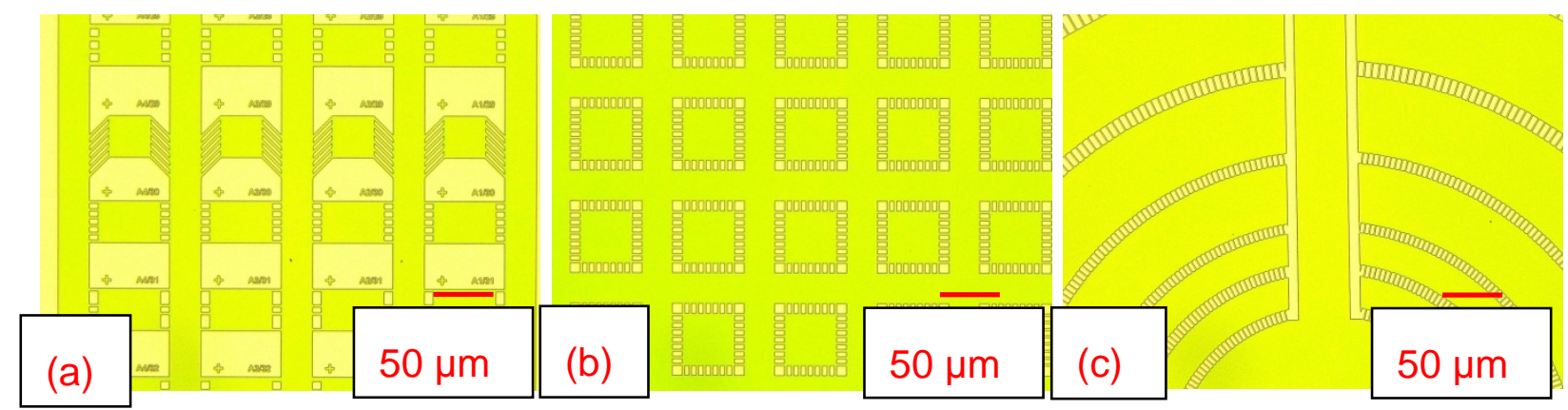

Figure 5.18: Three patterns of nanostructures from SU8 on a silicon wafer, taken by the Keyence Microscope.

Nickel electroplating was carried out for duplicating the nanostructures to produce the embossing tool because a silicon wafer is not suitable for ultrasonic hot embossing and would break during the process. The process details of nickel electroplating has been mentioned in 4.2.2. The silicon wafer was cut into 4 pieces for easy clamping in the electroplating bath. $15 \mathrm{~nm} \mathrm{Ti}$ and $15 \mathrm{~nm}$ gold were sputtered onto the silicon surface before electroplating.

The critical point of nanostructure electroplating is the current density management. Large current density results in a deposited layer peeling off the substrate. In the first attempt, $2 \mathrm{~A} / \mathrm{dm}^{2}$ was used when electroplating started. After several hours, some cracks appeared on the layers and later parts of it were warped and peeled off the silicon wafer seriously, cf. Figure $5.19 \mathrm{a}$, due to the tensile inner stress generated inside of the deposited material. Even though $2 \mathrm{~A} / \mathrm{dm}^{2}$ is already a small current density for normal nickel electroplating, the nano-patterned photoresist is still very sensitive to the tiny inner stress of the deposited layer. Furthermore, high current density results in larger nickel crystallites generating a rough upper surface of the electroplated metal and larger residual stress in the deposited films. By electroplating at lower current density, these problems were solved. As an improvement, at the beginning a very small current density of $0.05 \mathrm{~A} / \mathrm{dm}^{2}$ was applied and gradually increased to $1 \mathrm{~A} / \mathrm{dm}^{2}$ after $15 \mathrm{~h}$. After about $35 \mathrm{~h}$ electroplating, a $350 \mu \mathrm{m}$ thick nickel plate was successfully achieved. Next, heated $\mathrm{KOH}$ (around $100^{\circ} \mathrm{C}$ ) solution was applied to dissolve the silicon wafer and finally the ultrasonic hot embossing tool was obtained.

Four embossing tools are shown in Figure $5.19 \mathrm{~b}$. The electroplated nanostructures on the tool obtained from the resist structures shown in Figure 5.18 are shown in Figure 5.20. The quality of the electroplated nanostructures on the nickel tool is good as the obtained electroplated surface profile is quite smooth . 


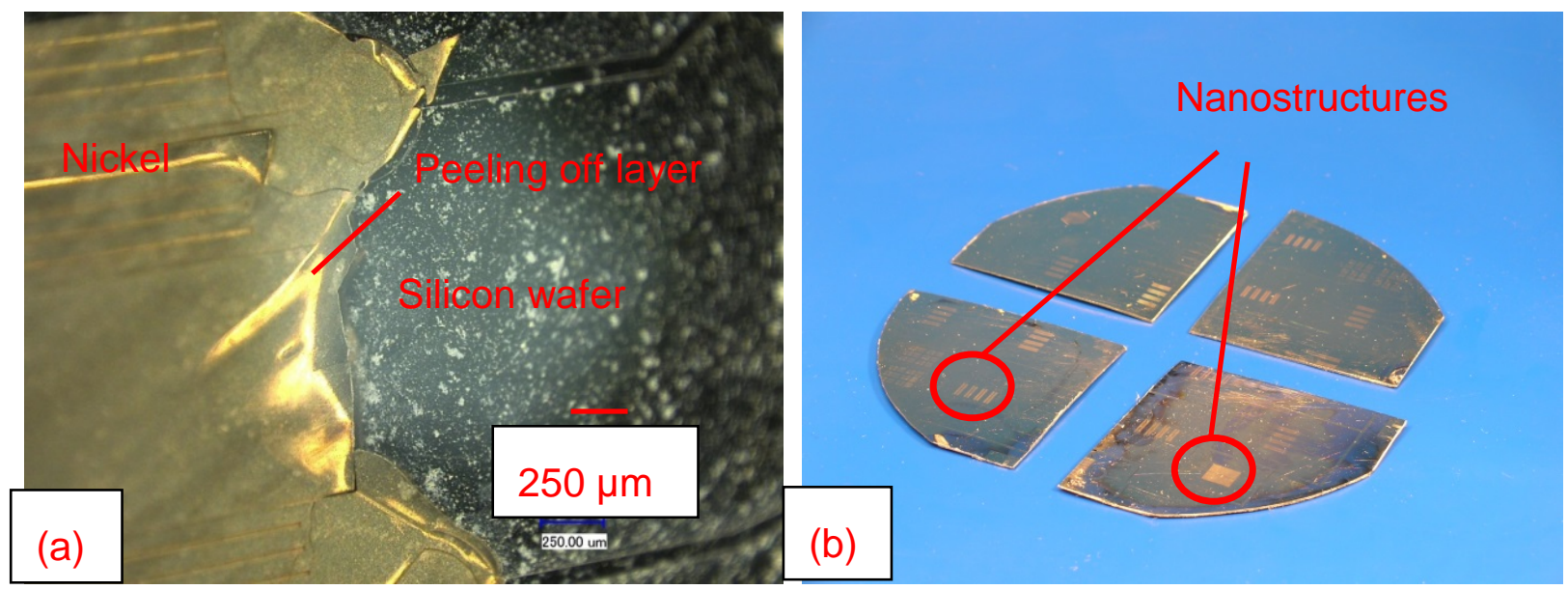

Figure 5.19: Nickel layer peeled off from silicon wafer; (b) Four pieces of nickel tools electroplated from silicon wafers.

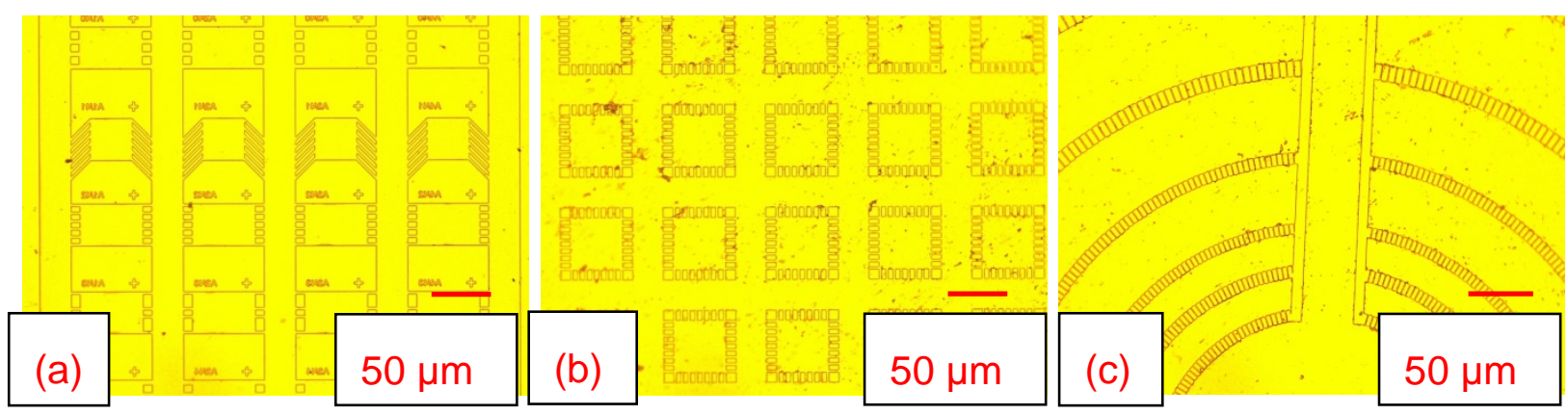

Figure 5.20: Electroplated nanostructures on the tools shown in Fig. 5.18 b corresponding to the resist structures on the silicon wafer shown in Fig. 5.17.

\subsubsection{Embossing of nanostructures}

In ultrasonic hot embossing, ultrasound is transmitted from the sonotrode to the polymer and the anvil (cf. Figure 3.1), initiating high frequency vibrations inside and between the polymer foils and the embossing tool. Friction due to the vibrations is generated where protruding micro structures are in contact to the polymer and where, this way, the ultrasonic energy is focused. The requirements of micro structures on the tool to generate enough heat have been mentioned in [16]: protruding structures are desired for melting polymer and filling in cavities on the tool.

In our prepared embossing tool, the maximum height of the micro structure is not more than $1 \mu \mathrm{m}$ and no particular protruding structures were designed on a flat tool surface. Several polymer foils and plates (750 $\mu \mathrm{m}$ in thickness) such as PC, HDPE and PVDF, had already been tried for ultrasonic hot embossing directly with these nanostructure tools, but none of the structures was successfully embossed and the polymer surfaces showed no modification. The reason is that the ultrasonic energy was distributed to the entire surface of the polymer and not concentrated to certain positions.

Therefore, auxillary heating of the ultrasonic embossing tool was required and it was realized by inserting an electrical heater into the anvil to heat up both the anvil and embossing tool. The temperature of the heater was set up to $80^{\circ} \mathrm{C}$. At higher temperatures possibly better results could had been achieved, but the anvil would become too hot for manual handling of the samples. With the heating of anvil and em- 
bossing tool, the polymer temperature was increased and the polymer was easier metled. Thus, the embossing of nanostructures was realized.

Besides the heating of the anvil, in a first step, micro structures were generated on the polymer by ultrasonic hot embossing. These micro structures are called prestructures. In a second embossing step, the pre-structures are molten first generating the required liquid polymer to fill the nanostructures on the tool. The pre-structures are actually much larger than the nanostructures and they are easy to be embossed.

To investigate the effect of pre-structures, a tool with pre-structures was designed with an array of protruding peaks (diameter and height are $200 \mu \mathrm{m}$ and $150 \mu \mathrm{m}$, respectively.) and milled into an $\mathrm{Al}$ plate. Photos of the embossing tool for prestructures are shown in Figure 5.21, in which the holes are distributed next to each other with boundary wall thicknesses of less than $50 \mu \mathrm{m}$.
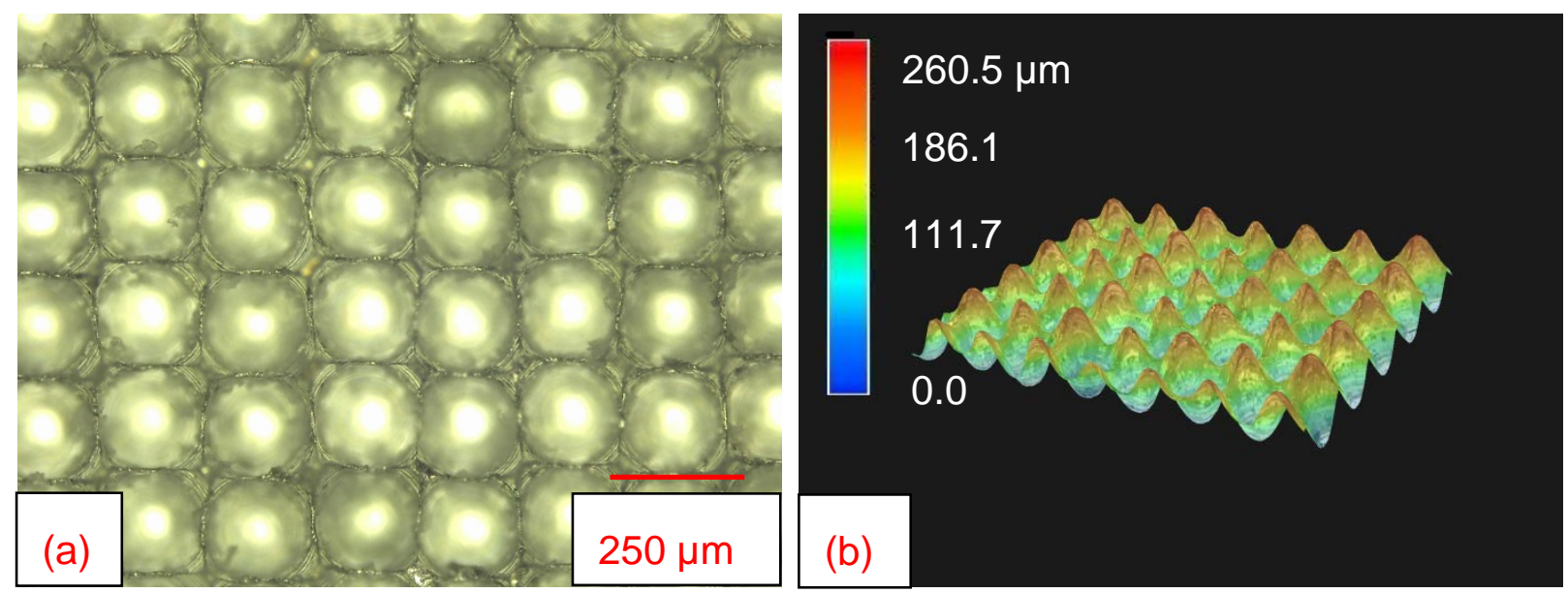

Figure 5.21: Embossing tool for pre-structures as seen from the top (a) and as a side view (b), taken by the Keyence microscope.

PMMA and PC plates, $750 \mu \mathrm{m}$ in thickness, were employed. The reason for choosing a polymer plate instead of foils is that the plate is stiffer than foils. The surface flatness of the plate keeps consistent or has just negligible bending after embossing. And when polymer foils were embossed with pre-structures, they were deformed more and twisting or warping because the layers were melting together. Then the surface was not flat anymore impeding the following ultrasonic hot embossing of nanostructures.

Pre-structures embossing was realized by the Branson 2000IW+ welding machine with the embossing parameters listed in Table 5.5. By the mentioned embossing parameters and the heated anvil, pre-structures on PC and PMMA plates were not yet fully embossed (cf. Figure 5.22). Only partly protruding structures were embossed on the surface. Completely embossed pre-structures are in fact not necessary as long as the protruding micro structures produce enough heat to melt the polymer. 
Table 5.5: Embossing parameters for pre-structures and nanostructure.

\begin{tabular}{lll}
\hline & Pre-structures & Nanostructures \\
Ultrasonic force $[\mathrm{N}]$ & 1258 & 1258 \\
Vibrating time $[\mathrm{s}]$ & 1.2 & 1 \\
Amplitude $[\mu \mathrm{m}]$ & 32 & 32 \\
\hline
\end{tabular}

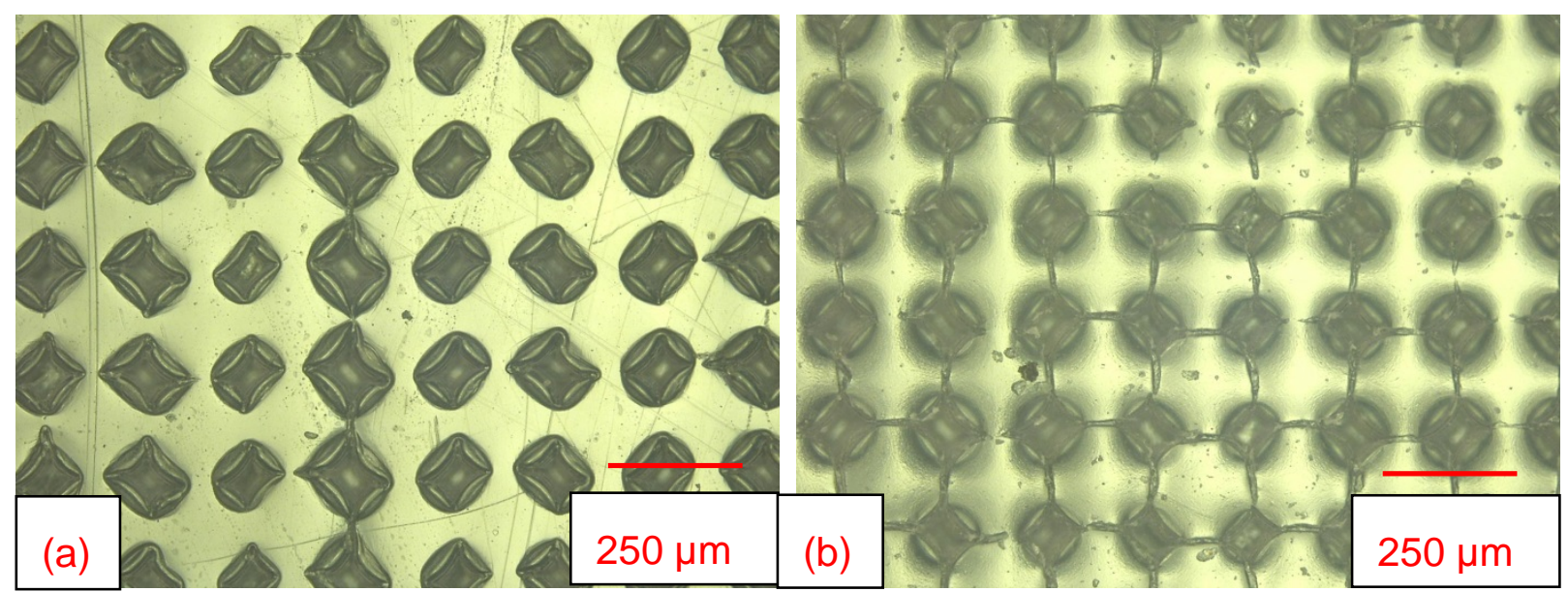

Figure 5.22: Pre-structures embossed on a PC plate (a) and PMMA plate (b), taken by the Keyence microscope.

The ultrasonic hot embossing of nanostructures was done by the same machine and the parameters are also listed in Table 5.5. As the embossing is quite sensitive to the surface flatness, the tool needs to be well aligned parallel to the sonotrode. The embossed nanostructures on both PC and PMMA plates are shown in Figure 5.23 and the embossing results from PC and PMMA plates are similar. It is also observed that not all the structures have been embossed completely. Only the structures in Figure $5.23 \mathrm{~b}$ corresponding to Figure $5.20 \mathrm{~b}$ were successfully embossed. In Figure $5.23 \mathrm{a}$, $c, d$ and f some structures are missing compared with the mold in Figure 5.20. The reason is probably due to the incompletely filling of the mold cavities by the molten polymer. Another problem is that the pre-structures were not totally melted away and were still left after embossing as shown in Figure 5.24 a on the PMMA plate. These remaining pre-structures affect the nanostructures precision and should be avoided. Increasing the embossing energy could be an improvement. 

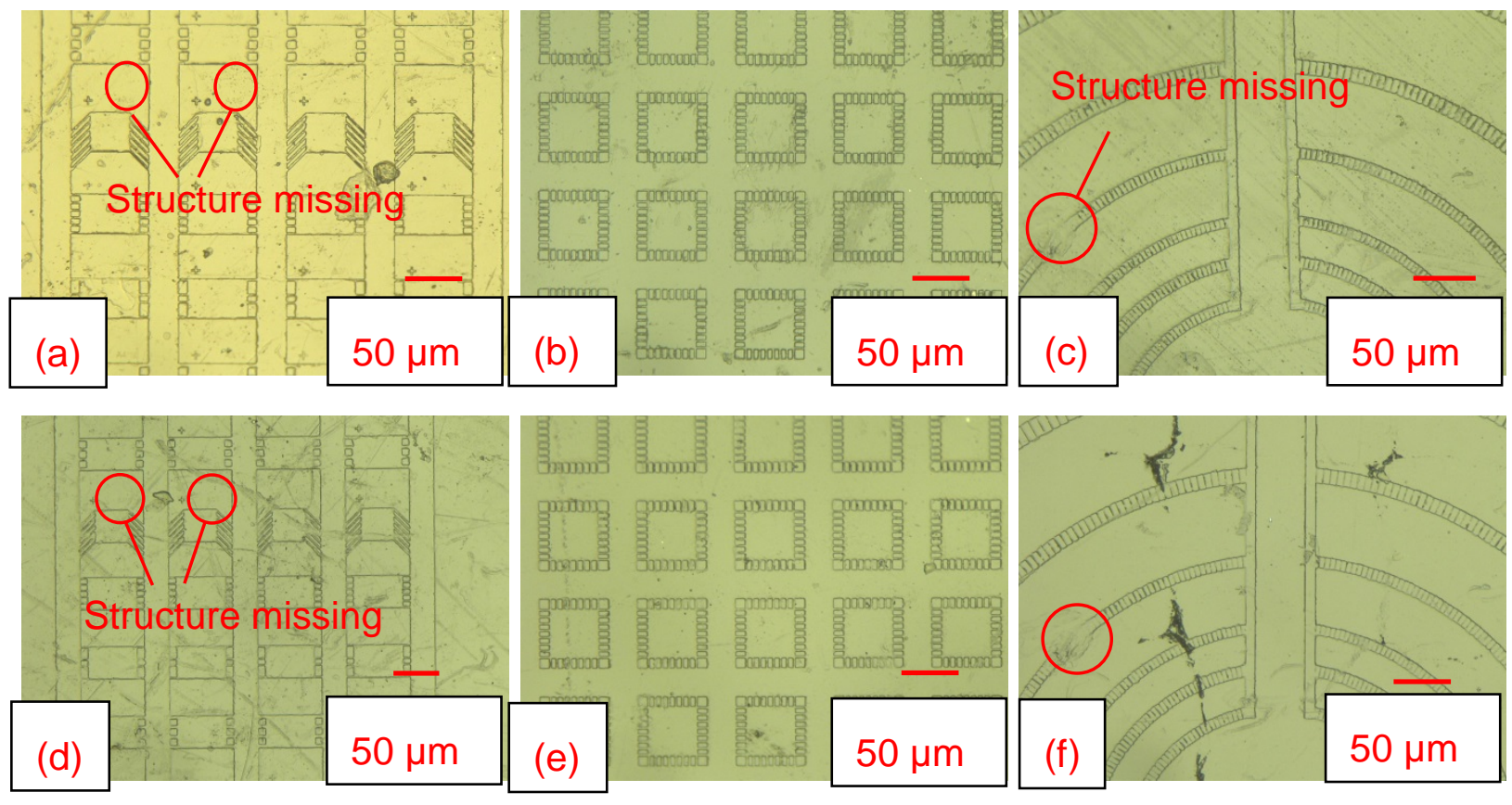

Figure 5.23: Embossed nanostructure on $P C(a, b, c)$ and PMMA (d, e, f) plates, corresponding to silicon wafer template, taken by Keyence microscope.

The height of corresponding structures of photoresist, nickel mold and embossed PC plate were measured by the profilometer (Bruker Dektak XT) and are shown in Figure $5.24 \mathrm{~b}$, in which the curve of the nickel mold was reversed. The heights of the structures from all, silicon wafer, nickel tool and embossed PC plate are nearly the same.
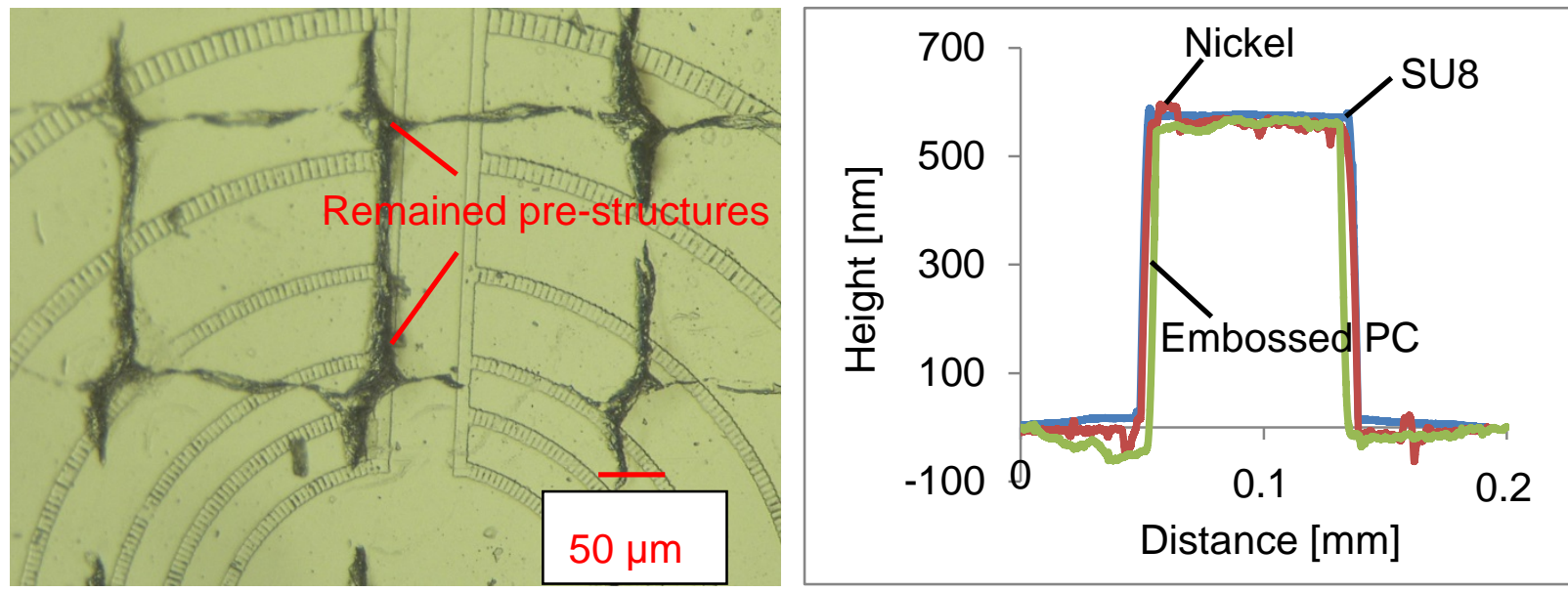

Figure 5.24: (a) Remained pre-structures after ultrasonic hot embossing of PC; (b) profile of the structure on the photoresist SU8, nickel mold and embossed PC plate.

Obviously pre-structuring of a polymer sample is advantageous, but the embossing is still an additive step to the process. To simplify the procedure, it would be ideal avoiding this additional step. However, in all experiments, pre-structures turned out being necessary. As mentioned above, ultrasonic hot embossing with polymer foils without pre-structures failed except for PLA, which could be embossed directly with the nickel tool without pre-structures. This embossing result is shown in Figure 5.25.

PLA, short for poly (lactic acid), is one type of aliphatic thermoplastic polyester and degraded from renewable resources [31]. PLA foils have also been tested to be 
easily processed by molding [127]. The glass transition temperature $T_{g}$ and melting temperature $T_{m}$ of $\mathrm{PLA}$ are $55^{\circ} \mathrm{C}$ and $175^{\circ} \mathrm{C}$ [31], which is quite lower than the other polymers listed in Table 2.1. In Figure 5.25, the embossed results from PLA were not as good as from PC or PMMA as some nanosturctures were not embossed onto it. How to improve the embossing quality on PLA is still a challenge. In addition, the low $\mathrm{T}_{\mathrm{g}}$ of PLA is also a limit and may easily result in deformations in structures when the polymer's temperature is higher than $55^{\circ} \mathrm{C}$. Nevertheless, it is worth to confirm that PLA is still an easily embossed polymer since no pre-structures are required.

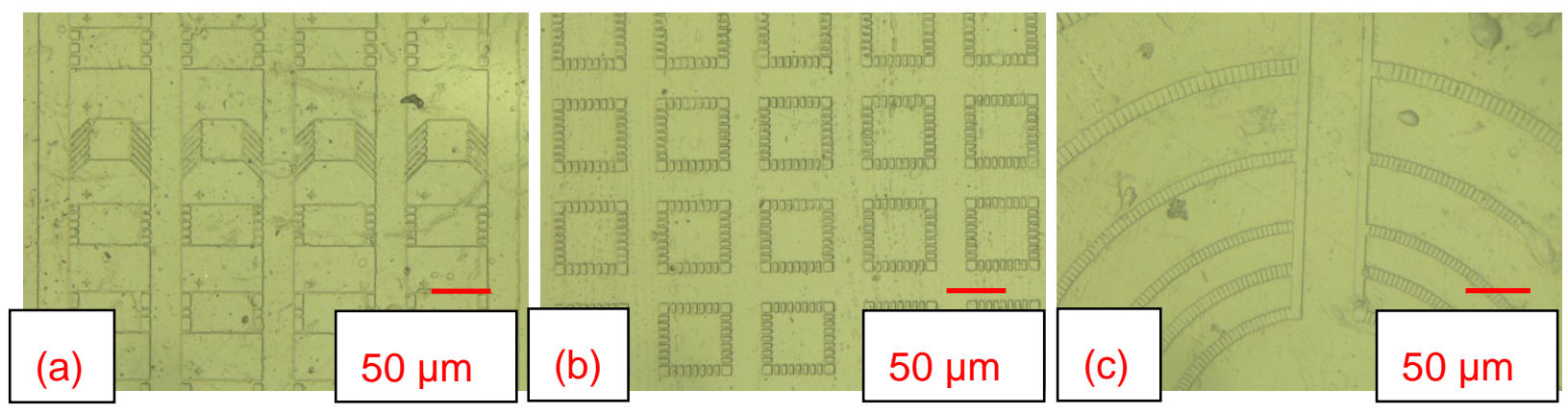

Figure 5.25: Corresponding nanostructures embossed on PLA from the nickel mold shown in Fig. 5.19, taken by the Keyence microscope.

After ultrasonic hot embossing of the nanostructure onto a polymer plate, a polymer lid above the embossed structures could be welded by a laser to build a closed system of nano channels suitable for example for a biological analysis.

In 4.2.2, microstructures with a depth of $25 \mu \mathrm{m}$ were also successfully embossed with the help of pre-structures. Shown in Figure 5.26, pre-structures were embossed as cone arrays with a radius of $160 \mu \mathrm{m}$ and a height of $220 \mu \mathrm{m}$ onto HDPE foils and later the embossing with a nickel tool followed. The $25 \mu \mathrm{m}$ high microstructures were finally embossed and the result is shown in Figure 4.10.

In conclusion, from the above five examples, ultrasonic hot embossing is a fast, low-cost fabrication method of polymer based microsystems. Its manufacturing quality can accomplish

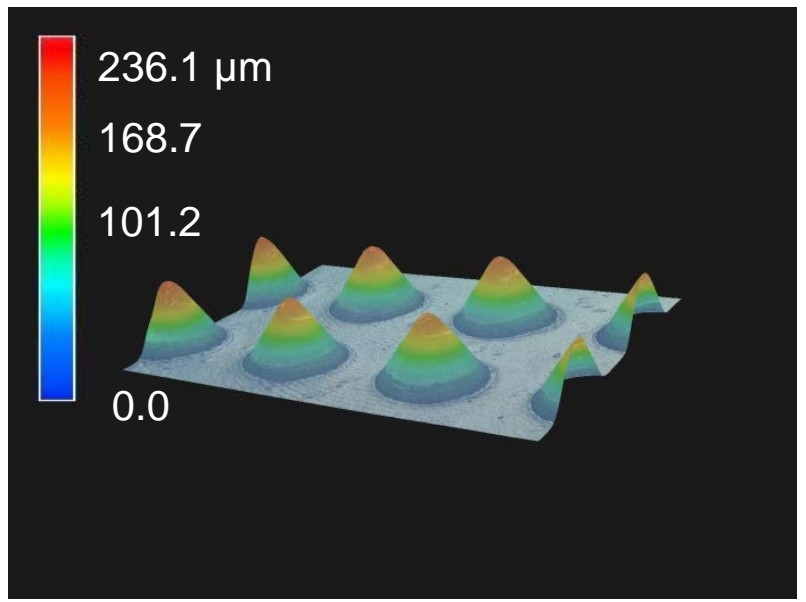

Figure 5.26: Pre-structures for embossing the structures from Figure 4.10. most tasks in fluidic microsystems. For ultrasonic hot embossing of nanostructures, further improvements are desirable for structure transferring precision. 


\section{Conclusions}

The tool affects the embossing result, which has been investigated by measuring the temperature in the embossing tool, measuring the dimensions of embossed structures and calculating the energy distribution in tool and embossed polymer. Besides, milling, electroplating, lithography and silicon etching were applied to produce embossing tools, by which the following new micro-devices or functional surfaces were ultrasonically hot embossed or welded: Fresnel lens, micro nozzle, spiral coils, nanostructures and hydrophobic surfaces.

In the ultrasonic hot embossing process, ultrasound transfers from a sonotrode, through a polymer stack and embossing tool, and finally arrives at the anvil. Meanwhile, the ultrasound wave is also reflected between the polymer foils, embossing tool and anvil, co-inducing the polymer vibration to generate a large amount of heat at material contact interfaces. Thus, the polymer stack, embossing tool and anvil are heated up. The more reflections occur at the interfaces, the more vibration is induced generating more heat. In order to melt polymer, a weak ultrasound reflection between sonotrode and polymer but a stronger reflection of ultrasound between polymer and embossing tool are beneficial for maximum energy utilizing.

Applying an embossing tool material with larger acoustic impedance than and a sonotrode material with a similar acoustic impedance as the embossed polymer reflects more ultrasound at the polymer-tool interface and the ultrasound reflection at sonotrode-polymer interface is less. This has been proven by comparing tools from the four metals: Al, Ni, St235JR and St1.2343. To utilize more ultrasonic energy, Al is a more suitable material for the sonotrode due to its smaller acoustic impedance and $\mathrm{Ni}$ and the two steels are suitable for the embossing tool. On the other hand, $\mathrm{Al}$ is excellent for milling and the disadvantage of $\mathrm{Al}$ as a tool material can be compensated by increasing the embossing energy.

Experiments with embossing tools from polymers (PC and PEEK) also confirmed the above mentioned results. The embossing result from a tool from PEEK is more precise than the one from PC. Because the acoustic impedance difference between PEEK and embossed HDPE is larger, more ultrasound reflection was induced, generating more heat. Heat capacity and thermal conductivity of the embossing tool materials influence the temperature of the embossing tool during ultrasonic hot embossing. At the same embossing energy, the embossing tool material with the larger thermal conductivity achieves the faster cooling rate on the embossing tool. The summit temperature of the embossing tool depends on the multiply value of specific heat capacity and density. Thermal isolation between tool and anvil also affects the heat dissipation to the anvil and increases the embossing tool temperature. Increasing the tool temperature is beneficial for polymer melting as less embossing energy is required from the ultrasonic welding machine.

Thus, a suitable tool material for ultrasonic hot embossing should fulfill the following specifications:

1) high enough melting temperature (more than at least $100^{\circ} \mathrm{C}$ ) to avoid melting or deformation;

2) small heat capacity;

3) large heat conductivity;

4) large acoustic impedance. 
The acoustic impedance of the anvil has less effect on the embossing result than the effect from the embossing tool. A rough calculation shows that little energy arrives at the interface of embossing tool and anvil.

Milling, electroplating, lithography and silicon etching and their combinations have been used to fabricate ultrasonic hot embossing tools and each of them has its particular advantages and disadvantages.

Milling of an aluminum plate is a very convenient way to produce tools for ultrasonic hot embossing. Aluminum is a cheap and common metal with enough strength for ultrasonic hot embossing and is still soft enough for milling. Structures with dimensions from hundreds of micrometers up to several centimeters were easily fabricated by CNC milling. The ultrasonic embossing tools for micro nozzle and spiral coil were produced by milling into an aluminum plate. The advantage of milling is a fast and low cost process, especially for the surface structures required for ultrasonic hot embossing. The limit of milling is that not all the materials are suitable to be machined. Polymer and soft metal (e.g. aluminum), are often used. Another limit is that milling structures smaller than $50 \mu \mathrm{m}$ is a great challenge to both milling tool and machine.

Besides milling, metal electroplating, especially nickel, is another option. The template for electroplating was prepared by lithography and silicon etching. By lithography, microstructures smaller than $50 \mu \mathrm{m}$ and even nanostructures were patterned on flat silicon wafers. Even more complex structures can be fabricated on silicon wafers by etching after lithography. However, silicon wafers either after lithography or etching are not suitable as a tool for ultrasonic hot embossing because of their brittleness. Thus, nickel electroplating was applied to obtain a hard and stiff embossing tool. In addition, there are no strict limits for the template material, which could be a silicon wafer, an aluminum plate, or even polymer plates. As long as the original pattern has been prepared and were electrical conductive, electroplating copies the shape of the micro structures. The embossing tool for a Fresnel lens is an application electroplated from an original polymer lens. Electroplating is suitable for producing structures smaller than $50 \mu \mathrm{m}$. The embossing tool with nanostructures was also produced by electroplating on a silicon wafer, which had been patterned by lithography. The shortcoming of nickel electroplating is that it takes a long-time (several hours up to days).

Photolithography, milling and electroplating were joined together to fabricate multilevel structures. This idea integrated both the advantages of lithography in producing small dimension structures and milling on polymer plates for different levels. Nickel electroplating was used at last to obtain the embossing tool.

Producing an embossing tool with a large area $\left(>100 \mathrm{~cm}^{2}\right)$ of micro structures by milling may last more than a day and the milling tool will break during that time. As a consequence, a step may occur in the micro structures where the milling tool was exchanged. As an alternative, a tool with small overall dimensions was produced first and then employed for embossing into PC repeatedly next to each other on a large area. Finally electroplating was applied to get a large tool for embossing.

The experiments showed that liquid metals, which are mainly used for repairing broken metal parts in machines, are not suitable for fabricating tools for ultrasonic hot embossing, because of their poor hardness and strength.

Ultrasonic hot embossing of a Fresnel lens showed that a tool can be fabricated by electroplating onto a micro structure and the original micro structure can be reproduced by employing this tool. The time for embossing the Fresnel lens into a PC 
plate was just $0.7 \mathrm{~s}$, which is much less than the production time by injection molding (15 s) [105].

The fabrication of a micro nozzle showed that three-dimensional hollow micro structures can be fabricated by ultrasonic hot embossing of two halves joined by ultrasonic welding. Besides this, the fabrication of the required tools showed that three-dimensional tools for ultrasonic hot embossing can be generated by direct milling of aluminum.

The production of a spiral coil demonstrated that also three-dimensional conductor paths can be generated by ultrasonic hot embossing onto a curved substrate.

Hydrophobic polymer surfaces were prepared by ultrasonic hot embossing. PA, PVDF, PE and PPHM were embossed with LIGA tools. The surface embossed from the LIGA tool showed more hydrophobicity than the one embossed from the aluminum tool indicating that for this application tools fabricated by LIGA are superior.

Nanostructures from a biochip with structure heights of $600 \mathrm{~nm}$ were also successfully electroplated forming a tool and this tool was employed for ultrasonic hot embossing into PC, PMMA plates and PLA foils. For embossing into PC and PMMA plates, pre-structures needed being embossed firstly before the nanostructures were embossed. But this step was not required for embossing PLA. The embossing quality of PC and PMMA is better than the one of PLA, but extra pre-structures are required. Furthermore, the glass transition temperature of PLA is just $55^{\circ} \mathrm{C}$, which could deform when temperature is above this value. The final embossed nanostructures could probably be closed with a lid by laser but it appears being impossible closing such shallow structures $(600 \mathrm{~nm})$ by ultrasonic welding. 


\section{References}

[1] M. Heckele, W. K. Schomburg. "Review on micro molding of thermoplastic polymers". Journal of Micromechanics and Microengineering, 14(3), (2004):R1-R14.

[2] U. M. Attia, S. Marson, J. R. Alcock. "Micro-injection moulding of polymer microfluidic devices". Microfluidics and Nanofluidics, 7(1), (2009):1-28.

[3] W. Bernauer, M. Torge, T. Hanemann, W. Pfleging. "Rapid fabrication and replication of metal, ceramic and plastic mould inserts for application in microsystem technologies". Proceedings of the Institution of Mechanical Engineers, Part C: Journal of Mechanical Engineering Science, 217(1), (2003):53-63.

[4] V. Poitter, T. Hanemann, R. Ruprecht, J. Hausselt. "Injection molding and related techniques for fabrication of microstructures". Microsystem Technologies, 3(3), (1997):129-133.

[5] A. de Mello. "Plastic fantastic?". Lab Chip, 2(2), (2002):31N-36N.

[6] J. Giboz, T. Copponnex, P. Mélé. "Microinjection molding of thermoplastic polymers: a review". Journal of Micromechanics and Microengineering, 17(6), (2007):R96-R109.

[7] M. Sahli, C. Millot, C. Roques-Carmes, C. Khan Malek, T. Barriere, J. C. Gelin. "Quality assessment of polymer replication by hot embossing and microinjection moulding processes using scanning mechanical microscopy". Journal of Materials Processing Technology, 209(18-19), (2009):5851-5861.

[8] M. Heilig, S. Giselbrecht, A. Guber, M. Worgull. "Microthermoforming of nanostructured polymer films: a new bonding method for the integration of nanostructures in 3-dimensional cavities". Microsystem Technologies-microand Nanosystems-information Storage and Processing Systems, 16(7), (2010):1221-1231.

[9] R. Truckenmüller, Z. Rummler, T. Schaller, W. Schomburg. "Low-cost thermoforming of micro fluidic analysis chips". Journal of Micromechanics and Microengineering, 12(4), (2002):375-379.

[10] P. Abgrall, A. M. Gué. "Lab-on-chip technologies: making a microfluidic network and coupling it into a complete microsystem-a review". Journal of Micromechanics and Microengineering, 17(5), (2007):R15-R49.

[11] Bartolini R, K. D. Hannan W, L. M. "Embossed hologram motion pictures for television playback.". Applied Optics, 9(10), (1970):2283-2290.

[12] M. Worgull. "Hot embossing : theory and technology of microreplication". William Andrew; (2009).

[13] M. T. Gale. "Replication techniques for diffractive optical elements". Microelectronic Engineering, 34(3-4), (1997):321-339.

[14] R.-D. Chien. "Hot embossing of microfluidic platform". International Communications in Heat and Mass Transfer, 33(5), (2006):645-653.

[15] H. Mekaru, O. Nakamura, O. Maruyama, R. Maeda, T. Hattori. "Development of precision transfer technology of atmospheric hot embossing by ultrasonic vibration". Microsystem Technologies, 13(3-4), (2006):385-391.

[16] W. K. Schomburg, K. Burlage, C. Gerhardy. "Ultrasonic Hot Embossing". Micromachines, 2(4), (2011):157-166.

[17] C. H. Lee, P. G. Jung, S. M. Lee, S. H. Park, B. S. Shin, J. H. Kim, K. Y. Hwang, K. M. Kim, J. S. Ko. "Replication of polyethylene nano-micro hierarchical structures using ultrasonic forming". Journal of Micromechanics and Microengineering, 20(3), (2010):035018. 
[18] H. Schift, C. David, M. Gabreil, J. Gobrect, L. J. heyderman, W. Kaiser, S. Köppel, L. Scandella. "Nanoreplication in polymers unsing hot embossing and injection molding". Microelectronic Engineering, 53, (2000):171-174.

[19] J. Sackmann, K. Burlage, C. Gerhardy, B. Memering, S. Liao, W. K. Schomburg. "Review on ultrasonic fabrication of polymer micro devices". Ultrasonics, 56(0), (2015):189-200.

[20] H. V. Fairbanks. "Applying ultrasonics to the moulding of plastic powders". Ultrasonics, 12(1), (1974):22-24.

[21] S.-J. Liu, I. T. Chang, S.-W. Hung. "Factors affecting the joint strength of ultrasonically welded polypropylene composites". Polymer Composites, 22(1), (2001):132-141.

[22] A. Benatar, T. G. Gutowski. "Ultrasonic welding of PEEK graphite APC-2 composites". Polymer Engineering \& Science, 29(23), (1989):1705-1721.

[23] W. Martienssen, H. Warlimont. "Springer handbook of condensed matter and materials data". 2005 XVIII Edition ed. Berlin: Springer; (2005).

[24] C. Siviour, S. Walley, W. Proud, J. Field. "Mechanical behaviour of polymers at high rates of strain". In: Journal de Physique IV (Proceedings); 2006: EDP sciences. 949-955.

[25] R. C. Weast, C. Chemical Rubber. "CRC handbook of chemistry and physics : a ready-reference book of chemical and physical data". Cleveland: CRC Press; (1974).

[26] H. Müunstedt. "Relationship between rheological properties and structure of poly (vinyl chloride)". Journal of Macromolecular Science, Part B: Physics, 14(2), (1977):195-212.

[27] X. Lu, R. A. Weiss. "Development of miscible blends of polyamide- 6 and manganese sulfonated polystyrene using specific interactions". Macromolecules, 24(15), (1991):4381-4385.

[28] H. Domininghaus. "Kunststoffe: Eigenschaften und Anwendungen". SpringerVerlag; (2007).

[29] D. J. Blundell, B. N. Osborn. "The morphology of poly(aryl-ether-ether-ketone)". Polymer, 24(8), (1983):953-958.

[30] M. Al-Hussein, G. Strobl. "The melting line, the crystallization line, and the equilibrium melting temperature of isotactic polystyrene". Macromolecules, 35(5), (2002):1672-1676.

[31] D. Garlotta. "A literature review of poly (lactic acid)". Journal of Polymers and the Environment, 9(2), (2001):63-84.

[32] C. Q. Zhang, J. D. Robson, O. Ciuca, P. B. Prangnell. "Microstructural characterization and mechanical properties of high power ultrasonic spot welded aluminum alloy AA6111-TiAl6V4 dissimilar joints". Materials Characterization, 97(0), (2014):83-91.

[33] S.-I. Matsuoka, H. Imai. "Direct welding of different metals used ultrasonic vibration". Journal of Materials Processing Technology, 209(2), (2009):954960.

[34] Y. N. Zhou. "Microjoining and nanojoining". Elsevier; (2008).

[35] H. Mekaru, M. Takahashi. "Ultrasonic Nanoimprint on Poly(ethylene terephthalate) at Room Temperature". Japanese Journal of Applied Physics, 47(6), (2008):5178-5184.

[36] Y. H. Cho, Y. S. Seo, I. Y. Moon, B. H. Kim, K. Park. "Facile fabrication of superhydrophobic poly(methyl methacrylate) substrates using ultrasonic imprinting". Journal of Micromechanics and Microengineering, 23(5), (2013):055019. 
[37] S. J. Liu, Y. T. Dung. "Hot embossing precise structure onto plastic plates by ultrasonic vibration". Polymer Engineering \& Science, 45(7), (2005):915-925.

[38] H. W. Yu. "Polymer microreplication using ultrasonic vibration energy". Journal of Micro/Nanolithography, MEMS, and MOEMS, 8(2), (2009):021113.

[39] S.-J. Liu, Y.-C. Huang, S.-Y. Yang, K.-H. Hsieh. "Rapid fabrication of surfacerelief plastic diffusers by ultrasonic embossing". Optics \& Laser Technology, 42(5), (2010):794-798.

[40] B. Altmann, R. Ahrens, A. Welle, H. Dinglreiter, M. Schneider, A. Schober. "Microstructuring of multiwell plates for three-dimensional cell culture applications by ultrasonic embossing". Biomedical microdevices, 14(2), (2012):291-301.

[41] P. Khuntontong, T. Blaser, W. K. Schomburg. "Ultrasonic hot emboosing of polymers exemplified by a micro thermal flow sensor". Proc. Smart Systems Integration 2008, Barcelona, Spain, 9th - 10th April (2008) 327 - 334, ISBN 978-3-8007-3081-0.

[42] K. Burlage, C. Gerhardy, W. K. Schomburg. "PVDF micro heat exchanger manufactured by ultrasonic hot embossing and welding". In: Proc. 21st MicroMechanics Europe Workshop, MME 2010; 2010; Enschede, Niederlande.

[43] A. Barth, S. Krabbe, C. Gerhardy, W. K. Schomburg. "Herstellung eines preiswerten, bistabilen Mikroventils mit niedriger Ansteuerspannung". In: Proceedings Mikrosystemtechnik Kongress 2013; 2013; Aachen. 59-61.

[44] B. Memering, C. Gerhardy, D. Loibl, W. K. Schomburg. "Filamentary Micro Sensors with Predetermined Breaking Points". Procedia Engineering, 47(0), (2012):100-103.

[45] J. Li, C. Gerhardy, W. K. Schomburg. "Polymer circuit boards fabricated by ultrasonic hot embossing". Journal of Micromechanics and Microengineering, 23(7), (2013):075028.

[46] B. Memering. "Rolle-zu-Rolle Fertigung von Mikrostrukturen durch Ultraschallheißprägen.". RWTH-Aachen, (2014).

[47] M. Sinha, D. Buckley. "Acoustic Properties of Polymers". In: Mark J, editor. Physical Properties of Polymers Handbook. Springer New York; (2007). 10211031.

[48] S. S. Young, P. Keun. "Direct patterning of micro-features on a polymer substrate using ultrasonic vibration". Microsystem Technologies, 18(12), (2012):2053-2061.

[49] J. F. Shackelford, W. Alexander. "CRC materials science and engineering handbook". CRC press; (2010).

[50] R. Powell, C. Y. Ho, P. E. Liley. "Thermal conductivity of selected materials". DTIC Document; (1966).

[51] P. American Institute of, B. H. Billings, D. E. Gray. "American Institute of Physics handbook". New York: McGraw-Hill; (1972).

[52] M. Iordachescu, J. Ruiz Hervías, D. Iordachescu, A. Valiente Cancho, L. Caballero Molano. Thermal influence of welding process on strength overmatching of thin dissimilar sheets joints. In: CIFIE 2010, Iberian Conference on Fracture and Structural integrity. Oporto, Portugal: Universidade do Porto; 2010.

[53] U. Maradia, K. Wegener, J. Stirnimann, R. Knaak, M. Boccadoro. "Investigation of the Scaling Effects in Meso-Micro EDM". In: ASME 2013 International Mechanical Engineering Congress and Exposition; 2013: American Society of Mechanical Engineers. 1-10. 
[54] A. R. Selfridge. "Approximate material Properties in Isotropic Materials". IEEE Transaction on sonic and ultrasonic, SU-32(3), (1985):381-394.

[55] R. A. Orwoll, P. J. Flory. "Equation-of-state parameters for normal alkanes. Correlation with chain length". Journal of the American Chemical Society, 89(26), (1967):6814-6822.

[56] T. Nishino, H. Ohkubo, K. Nakamae. "Temperature dependence of the elastic modulus of crystalline regions of polyethylene with different microstructures explanation with the kinked-chain model". Journal of Macromolecular Science, Part B, 31(2), (1992):191-214.

[57] H. A. Khonakdar, J. Morshedian, U. Wagenknecht, S. H. Jafari. "An investigation of chemical crosslinking effect on properties of high-density polyethylene". Polymer, 44(15), (2003):4301-4309.

[58] Z. Qu, Y. Ono. "A Dual-Mode Ultrasonic Probe for Viscoelastic Material Characterization". In: Proc. 34st Canadian Medical and Biological Engineering Conference; 2011; Toronto, Ontario. 1-4.

[59] K. Raum, K. V. Jenderka, A. Klemenz, J. Brandt. "Multilayer Analysis Quantitative Scanning Acoustic Microscopy for Tissue Characterization at a Microscopic Scale". IEEE Transactioncs on Ultrasonic and Frequency Control, 50(5), (2003):507-516.

[60] D. Kemmish. "Update on the Technology and Applications of Polyaryletherketones". ISmithers; (2010).

[61] S. Z. D. Cheng, M. Y. Cao, B. Wunderlich. "Glass Transition and melting Behavior of Poly(oxy-1,4-phenylene oxy-1,4 phenylene carbon 1-1,4phenylene)". Macromolecules, 19, (1986):1868-1876.

[62] J. Wen. "Heat Capacities of Polymers". In: Mark J, editor. Physical Properties of Polymers Handbook. Springer New York; (2007). 145-154.

[63] P. Davies, Y. D. Rajapakse. "Durability of composites in a marine environment". Springer; (2014).

[64] V. Kumar, J. Weller. "Production of microcellular polycarbonate using carbon dioxide for bubble nucleation". Journal of Manufacturing Science and Engineering, 116(4), (1994):413-420.

[65] M. B. Esch, S. Kapur, G. Irizarry, V. Genova. "Influence of master fabrication techniques on the characteristics of embossed microfluidic channels". Lab Chip, 3(2), (2003):121-127.

[66] L. J. Guo. "Recent progress in nanoimprint technology and its applications". Journal of Physics D: Applied Physics, 37(11), (2004):R123-R141.

[67] M. Worgull. "Hot embossing - Theory and Technology of microreplication". Wijliam Andrew Applied Science Publishers; (2009).

[68] J. Böhm, A. Schubert, T. Otto, T. Burkhardt. "Micro-metalforming with silicon dies". Microsystem Technologies, 7, (2001):191-195.

[69] G. S. Fiorini, G. D. Jeffries, D. S. Lim, C. L. Kuyper, D. T. Chiu. "Fabrication of thermoset polyester microfluidic devices and embossing masters using rapid prototyped polydimethylsiloxane molds". Lab Chip, 3(3), (2003):158-163.

[70] M. L. Hupert, W. J. Guy, S. D. Llopis, H. Shadpour, S. Rani, D. E. Nikitopoulos, S. A. Soper. "Evaluation of micromilled metal mold masters for the replication of microchip electrophoresis devices". Microfluidics and Nanofluidics, 3(1), (2007):1-11.

[71] S. Harsch, W. Ehrfeld, A. Maner. "Untersuchungen zur Herstellung von Mikrostrukturen großer Strukturhöre durch Galvanoforming in Nikelsulfamatelektrolyten". Kernforschungszentrum Karlsruhe, (1988). 
[72] F. Liu, K. B. Tan, P. Malar, S. K. Bikkarolla, J. A. van Kan. "Fabrication of nickel molds using proton beam writing for micro/nano fluidic devices". Microelectronic Engineering, 102, (2013):36-39.

[73] T. Mappes, M. Worgull, M. Heckele, J. Mohr. "Submicron polymer structures with X-ray lithography and hot embossing". Microsystem Technologies, 14(911), (2008):1721-1725.

[74] H. Becker, U. Heim, O. Rötting. "The fabircation of polymer high aspect ratio stuctures with hot embossing for microfluidic applications". In: SPIE Conference on Microfluidic Devices and System; 1999; Santa Clara California.

[75] H. Mekaru, H. Goto, M. Takahashi. "Development of ultrasonic micro hot embossing technology". Microelectronic Engineering, 84(5-8), (2007):12821287.

[76] E. Kukharenka, M. M. Farooqui, L. Grigore, M. Kraft, N. Hollinshead. "Electroplating moulds using dry film thick negative photoresist". Journal of Micromechanics and Microengineering, 13, (2003):567-574.

[77] J. M. Park, N. H. Kim, B.-K. Lee, K.-H. Lee, T. H. Kwon. "Nickel stamp fabrication and hot embossing for mass-production of micro/nano combined structures using anodic aluminum oxide". Microsystem Technologies, 14(9-11), (2008):1689-1694.

[78] D. Baudrand. "Nickel sulfate plating, its mystique and practicality". Metal Finishing, (1996):15-18.

[79] Y. Tsuru, M. Nomura, F. R. Foulkes. "Effects of boric acid on hydrogen evolution and internal stress in films deposited from a nickel sulfamate bath". Journal of Applied Electrochemistry, 32, (2002):629-634.

[80] W. Prapaitrakul, A. Shwikhat, A. D. King Jr. "The influence of pH on gas solubilities in aqueous solutions of sodium octanoate at $25^{\circ} \mathrm{C}$ ". Journal of Colloid and Interface Science, 115(2), (1987):443-449.

[81] T. E. Buchheit, D. A.LaVAN, J. R.Michael, T. R. Christenson, S. D.Leith. "Microstructural and Mechanical Properties Investigation of Electrodeposited and Annealed LIGA Nickel Structures". Metallurgical and Material Transactions A, 33A, (2002):539-554.

[82] T. Shibata, Y. Takahashi, T. Kawashima, T. Kubota, M. Mita, T. Mineta, E. Makino. "Micromachining of electroformed nickel mold using thick photoresist microstructure for imprint technology". Microsystem Technologies, 14(9-11), (2008):1359-1365.

[83] R. Muhammad, S.-H. Cho, J.-H. Lee, J.-G. Park. "Fluorocarbon film-assisted fabrication of a CoNi mold with high aspect ratio for nanoimprint lithography". Microelectronic Engineering, 104, (2013):58-63.

[84] X. Lin, X. Dou, X. Wang, R. T. Chen, I. Fllow. "Nickel Electroplating for nanostructure Mold Fabrication". Journal of nanoscience and nanotechnology, 11(8), (2011):7006-7010.

[85] C. Kluge, J. Adam, N. Barie, P. J. Jakobs, M. Guttmann, M. Gerken. "Multiperiodic nanostructures for photon control". Optics Express, 22 Suppl 5, (2014):A1363-A1371.

[86] M. Schlesinger, M. Paunovic. "Morder Electroplating, fifth edition nickel electroplating". In.: Join Wiley \& Sons, Inc; (2010).

[87] A.Ruzzu, B.Matthis. "Swelling of PMMA-structures in aqueous solutions and room temperature Ni-electrofoming". Microsystem Technologies, 8, (2002):116-119. 
[88] H. Becker, U. Heim. "Hot embossing as a method for the fabrication of polymer high aspect ratio structures". Sensors and Actuators A: Physical, 83, (2000):130-135.

[89] E. W. Becker, W. Ehrfeld, P. Hagmann, A. Maner, D. Münchmeyer. "Fabrication of microstructures with high aspect ratios and great structural heights by synchrotron radiation lithography, galvanoforming, and plastic moulding (LIGA process)". Microelectronic Engineering, 4, (1986):35-56.

[90] P. Bley, M. Menz, W. Bacher, K. Feit, W. K. Schomburg, W. Stark. "Application of the LIGA process in fabrication of three-dimensional mechanical microstructures.". In: Intern.Microprocess Conference; 1991. 384389.

[91] L. Uriarte, A. Herrero, P. T. Tang, A. Ivanov, H. Oosterling, L. Staemmler, D. Allen. "Comparison between microfabrication technologies for metal tooling". Proceedings of the Institution of Mechanical Engineers, Part C: Journal of Mechanical Engineering Science, 220(11), (2006):1665-1676.

[92] J. Narasimhan, I. Papautsky. "Polymer embossing tools for rapid prototyping of plastic microfluidic devices". Journal of Micromechanics and Microengineering, 14(1), (2004):96-103.

[93] P. H. Pham, D. V. Dao, S. Amaya, R. Kitada, S. Sugiyama. "Fabrication and characterization of Smooth SI Mold For Hot Embossing Process". IEEJ Transactions on Sensors and Micromachines, 127(3), (2007):187-191.

[94] G. Tosello, G. Bissacco, P. T. Tang, H. N. Hansen, P. C. Nielsen. "High aspect ratio micro tool manufacturing for polymer replication using $\mu$ EDM of silicon, selective etching and electroforming". Microsystem Technologies, 14(9-11), (2008):1757-1764.

[95] R. Förster, A. Schoth, W. Menz. "Micro-ECM for production of microsystems with a high aspect ratio". Microsystem Technologies, 11(4-5), (2005):246-249.

[96] M. R. H. Knowles, G. Rutterford, D. Karnakis, A. Ferguson. "Micro-machining of metals, ceramics and polymers using nanosecond lasers". The International Journal of Advanced Manufacturing Technology, 33(1-2), (2007):95-102.

[97] S. Malahat, P. G. Iovenitti, I. Sbarski. "Influence of tool fabrication process on characteristics of hot embossed polymer microfluidic chips for electrospray". Microsystem Technologies, 16(12), (2010):2075-2085.

[98] C. A. May. "Epoxy Resins: Chemistry and Technology, Second Edition". Taylor \& Francis; (1987).

[99] F. Carrion, J. Sanes, M.-D. Bermúdez. "Influence of ZnO nanoparticle filler on the properties and wear resistance of polycarbonate". Wear, 262(11), (2007):1504-1510.

[100] C. C. Chamis, L. R. Center. "Analysis of the Three-point-bend Test for Materials with Unequal Tension and Compression Properties". National Aeronautics and Space Administration; (1974).

[101] I. PETRESCU, C. MOHORA, C. ISPAS. "The Determination of Young Modulus for CFRP Using Three Point Bending Tests at Different Span Lengths". UPB Sci. Bull., Series D, 75(1), (2013):121-128.

[102] A. Davis, R. C. Bush, J. C. Harvey, M. F. Foley. "P-95: Fresnel Lenses in Rear Projection Displays". SID Symposium Digest of Technical Papers, 32(1), (2001):934-937.

[103] Y. Tripanagnostopoulos, C. Siabekou, J. K. Tonui. "The Fresnel lens concept for solar control of buildings". Solar Energy, 81(5), (2007):661-675.

[104] N. Kitaura, S. Ogata, Y. Mori. "Spectrometer employing a micro-Fresnel lens". Optical Engineering, 34(2), (1995):584-588. 
[105] G. Tosello, H. N. Hansen, S. Gasparin, J. A. Albajez, J. I. Esmoris. "Surface wear of TiN coated nickel tool during the injection moulding of polymer micro Fresnel lenses". CIRP Annals - Manufacturing Technology, 61(1), (2012):535538.

[106] J. Yue, L. Luo, Y. Gonthier, G. Chen, Q. Yuan. "An experimental investigation of gas-liquid two-phase flow in single microchannel contactors". Chemical Engineering Science, 63(16), (2008):4189-4202.

[107] N. Shao, A. Gavriilidis, P. Angeli. "Flow regimes for adiabatic gas-liquid flow in microchannels". Chemical Engineering Science, 64(11), (2009):2749-2761.

[108] R. Seemann, M. Brinkmann, T. Pfohl, S. Herminghaus. "Droplet based microfluidics". Reports on progress in physics, 75(1), (2012):016601.

[109] G. Christopher, S. Anna. "Microfluidic methods for generating continuous droplet streams". Journal of Physics D: Applied Physics, 40(19), (2007):R319R336.

[110] R. Parmar, S. K. Majumder. "Microbubble generation and microbubble-aided transport process intensification-A state-of-the-art report". Chemical Engineering and Processing: Process Intensification, 64, (2013):79-97.

[111] P. Garstecki. "Formation of droplets and bubbles in microfluidic systems". In: Microfluidics Based Microsystems. Springer; (2010). 163-181.

[112] N. Kockmann, D. M. Roberge. "Scale-up concept for modular microstructured reactors based on mixing, heat transfer, and reactor safety". Chemical Engineering and Processing: Process Intensification, 50(10), (2011):10171026.

[113] N. Kockmann. "Pressure Loss and Transfer Rates in Microstructured Devices with Chemical Reactions". Chemical Engineering \& Technology, 31(8), (2008):1188-1195.

[114] A. Tollkoetter, N. Kockmann. "A Modular Microfluidic System for High Flow Rate Re-Dispersion of Gas-Liquid". In: ASME 2014 12th International Conference on Nanochannels, Microchannels, and Minichannels collocated with the ASME 2014 4th Joint US-European Fluids Engineering Division Summer Meeting; 2014: American Society of Mechanical Engineers. 1-9.

[115] W. K. Schomburg, J. Li, S. Liao, C. Gerhardy, J. Sackmann. "MID Fabricated by Ultrasonic Processing". In: Advanced Materials Research; 2014: Trans Tech Publ. 83-88.

[116] Y. Lee, S. H. Park, K. B. Kim, J. K. Lee. "Fabrication of Hierarchical Structures on a Polymer Surface to Mimic Natural Superhydrophobic Surfaces". Advanced materials, 19(17), (2007):2330-2335.

[117] Y.-T. Cheng, D. E. Rodak. "Is the lotus leaf superhydrophobic?". Applied Physics Letters, 86(14), (2005):144101.

[118] B. Bhushan, Y. C. Jung, K. Koch. "Micro-, nano- and hierarchical structures for superhydrophobicity, self-cleaning and low adhesion". Philosophical Transactions of the Royal Society of London A: Mathematical, Physical and Engineering Sciences, 367(1894), (2009):1631-1672.

[119] A. Nakajima, K. Hashimoto, T. Watanabe. "Recent Studies on SuperHydrophobic Films". Monatshefte für Chemie / Chemical Monthly, 132(1), (2001):31-41.

[120] P. Gould. "Smart, clean surfaces". Materials Today, 6(11), (2003):44-48.

[121] P. Khuntontong. "Fabrication of polymer micro devices by ultrasonic hot embossing". RWTH-Aachen, (2008).

[122] T. Young. "An Essay on the Cohesion of Fluids". Philosophical Transactions of the Royal Society of London, 95, (1805):65-87. 
[123] R. N.Wenzel. "Resistance of solid surfaces to wetting by water". Industrial \& Engineering Chemistry, (1936):988-994.

[124] A. B. D. Cassie, S. Baxter. "Wettability of porous surfaces". Transactions of the Faraday Society, 40, (1944):546.

[125] D. Öner, T. J.McCarthy. "Ultrahydrophobic surface. Effects of topography length scale on wettability". Langmuir, 16, (2000):7777-7782.

[126] C. W. Extrand. "Criteria for ultralyophobic surfaces". Langmuir, 20(12), (2004):5013-5018.

[127] M. H. Hartmann. "High Molecular Weight Polylactic Acid Polymers". In: Kaplan D, editor. Biopolymers from Renewable Resources. Springer Berlin Heidelberg; (1998). 367-411. 